Universidad de Lima

Facultad de Comunicación

Carrera de Comunicación

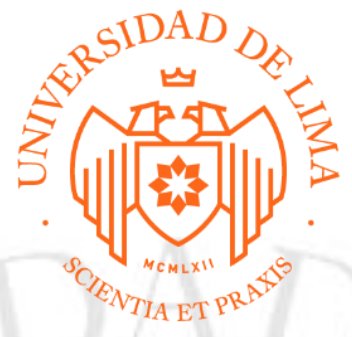

\title{
DIRECCIÓN DE UNA CAMPAÑA POLÍTICA \\ CASO: NORMA ALENCASTRE MIRANDA \\ CANDIDATA A LA ALCALDÍA PROVINCIAL \\ DEL SANTA, ANCASH - 2018
}

Trabajo de Suficiencia Profesional para optar el Título Profesional de Licenciado en

Comunicación

Jhony Percy Pulido Pereda

Código 892571

Asesor

Carlos Rivadeneyra Olcese

Lima - Perú

Junio de 2019 


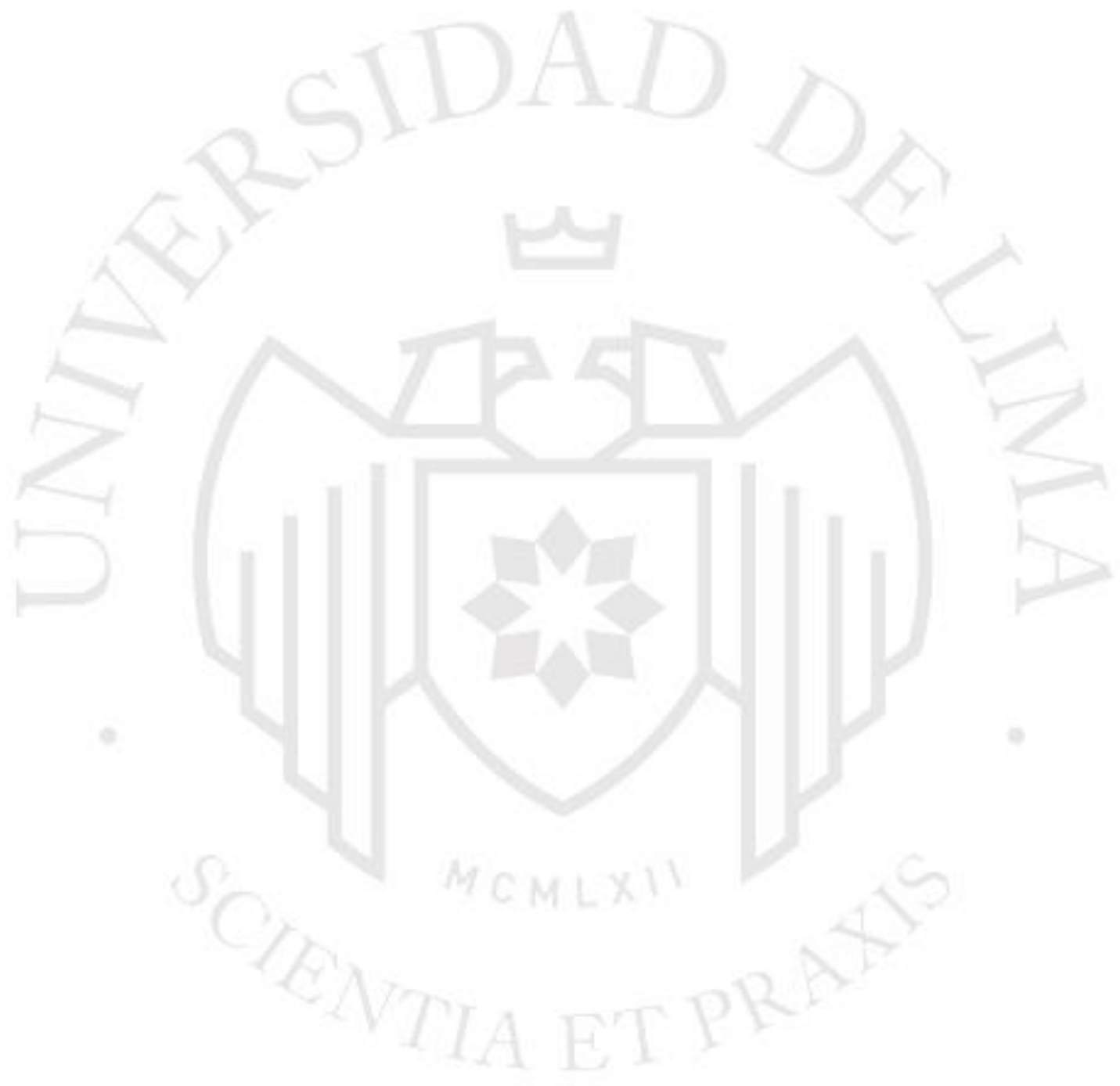




\section{DIRECCIÓN DE UNA CAMPAÑA POLÍTICA CASO: NORMA ALENCASTRE MIRANDA CANDIDATA A LA ALCALDÍA PROVINCIAL DEL SANTA, ANCASH - 2018}




\section{Índice}

$\begin{array}{lr}\text { Resumen } & 10\end{array}$

$\begin{array}{ll}\text { Introducción } & 11\end{array}$

$\begin{array}{lr}\text { 1. Antecedentes } & 12\end{array}$

$\begin{array}{lll}1.1 & \text { La comunicación política } & 12\end{array}$

$\begin{array}{lll}\text { 1.1.1 La investigación del voto } & 13\end{array}$

$\begin{array}{lll}\text { 1.1.2 Los canales de transmisión } & 13\end{array}$

$\begin{array}{lll}\text { 1.1.3 Rol de los partidos en la preparación de los comicios } & 14\end{array}$

$\begin{array}{lll}1.2 & \text { Estudio de mercado } & 15\end{array}$

$\begin{array}{lll}1.2 .1 & \text { Focus group } & 15\end{array}$

$\begin{array}{lll}1.2 .2 & \text { Encuestas } & 15\end{array}$

$\begin{array}{lll}1.3 & \text { Diagnóstico situacional } & 16\end{array}$

2. Realización 21

2.1 Plan de comunicación integrada 21

2.2 Etapa preelectoral $\quad 22$

2.3 Diseño y gestión de la campaña política $\quad 22$

2.4 Público objetivo $\quad 25$

2.5 Objetivos 26

2.6. Estrategia de comunicación integrada 26

$\begin{array}{lll}2.6 .1 & \text { Publicaciones impresas y digitales } & 28\end{array}$

2.6.2 Merchandising 35

2.6.3 Publicidad exterior $\quad 35$

2.6.4 Audiovisuales 39

2.6.5 Eventos y participación en la comunidad 41

2.6.6 Cronograma de actividades 43

3. Sustentación 44

3.1 El marketing político y la democracia 44

3.2 Estrategia de comunicación en campaña 47

3.3 Modelo de contingencia estratégica 48

3.4 Los medios en campaña 49

4. Logros y resultados 51 
$\begin{array}{lll}4.1 & \text { A nivel cuantitativo } & 51\end{array}$

$\begin{array}{lll}4.2 & \text { A nivel cualitativo } & 57\end{array}$

4.2.1 Respecto a capacidades desarrolladas en media training 57

4.2.2 Respecto al plan programático 57

4.2.3 Respecto a valores explotados y percibidos en la candidata 58

4.2.4 Respecto al ánimo que logro despertar la candidata 58

5. Lecciones aprendidas 59

Referencias

$\begin{array}{ll}\text { Anexos } & 67\end{array}$ 


\section{Índice de ilustraciones}

Ilustración 01: Estrategia de comunicación $\quad 27$

Ilustración 02: Volante vida de candidata 29

Ilustración 03: Volante sector salud $\quad 29$

Ilustración 04: Volante sector educación $\quad 29$

Ilustración 05: Volante sector trabajo 30

Ilustración 06: Volante sector seguridad $\quad 30$

Ilustración 07: Volante de propuestas 30

Ilustración 08: Volante candidato a regidor $\mathrm{N}^{\circ} 1$

Ilustración 09: Volante candidato a regidor $\mathrm{N}^{\circ} 3 \quad 31$

Ilustración 10: Volante candidato a regidor $\mathrm{N}^{\circ} 4 \quad 31$

Ilustración 11: Volante candidato a regidor $\mathrm{N}^{\circ} 9$

Ilustración 12: Volante celebración de fiestas patrias

Ilustración 13: Calendario de pared 32

Ilustración 14: Calendario de bolsillo $\quad 32$

\begin{tabular}{l|l|l} 
Ilustración 15: Afiche mensaje central & 33
\end{tabular}

Ilustración 16: Afiche recta final $\quad 33$

Ilustración 17: Publicaciones Facebook 33

Ilustración 18: Portadas Facebook $\quad 34$

Ilustración 19: Spots, videos, live - Facebook 34

Ilustración 20: Polos, vinchas, llaveros

Ilustración 21: Banderines, mandiles, pulseras 31$\}$

Ilustración 22: Torre unipolar - Mensaje central 36

Ilustración 23: Panel - Mensaje segmento agro: valles Santa y Nepeña 36

Ilustración 24: Panel - Mensaje recta final $\quad 36$

Ilustración 25: Torre unipolar / panel - Equipo candidatos región, provincia 37

Ilustración 26: Torre unipolar / panel - Equipo candidatos región, provincia, distrito Nuevo Chimbote 37

Ilustración 27: Panel - Equipo candidatos región, provincia, distrito Coishco 37

Ilustración 28: Panel - Equipo candidatos región, provincia, distrito Santa 38

Ilustración 29: Norma móvil, mascota Somos Perú 38

Ilustración 30: Equipo anfitrionaje 38 
Ilustración 31: Inauguración de bases políticas $\quad 41$

Ilustración 32: Campañas médicas 41

Ilustración 33: Caminatas 41

Ilustración 34: Caravanas $\quad 42$

Ilustración 35: Cierre de campaña 42 


\section{Índice de tablas}

Tabla 1: Bases de apoyo aperturadas $\quad 51$

Tabla 2: Mítines de campaña realizadas $\quad 52$

Tabla 3: Concurrencia en mítines 53

Tabla 4: Número de banners en avenidas de Chimbote y Nuevo Chimbote $\quad 54$

Tabla 5: Número de afiches y volantes en millares distribuidos 55

Tabla 6: Alianzas estratégicas y de apoyo en la localidad 56 


\section{Índice de gráficos}

Gráfico 1: Bases de apoyo aperturadas 52

Gráfico 2: Mítines de campaña realizadas 53

Gráfico 3: Concurrencia en mítines 54

Gráfico 4: Número de banners en avenidas de Chimbote y Nuevo Chimbote 55

Gráfico 5: Número de afiches y volantes en millares distribuidos 


\section{RESUMEN}

El presente informe aborda las diferentes etapas de una campaña política municipal, las herramientas y los procesos que se realizan siguiendo un enfoque comunicacional estratégico e integral. La campaña electoral municipal de la candidata Norma Alencastre Miranda, se desarrolló con el partido político Somos Perú, dentro de un escenario bastante particular, donde más de 20 organizaciones políticas compitieron aspirando conseguir la máxima representación, la Alcaldía de la Municipalidad Provincial del Santa en la región Ancash.

Esta campaña política, involucró a líderes políticos, organizaciones partidarias, simpatizantes, medios de comunicación y ciudadanos en general. En este informe, se describe el rol que tuvieron cada uno de los actores mencionados y su injerencia en el proceso electoral. Se detalla el procedimiento desarrollado, el tratamiento y las estrategias empleadas a lo largo de la campaña electoral en el marco de las Elecciones Municipales y Regionales 2018.

Palabras clave: campaña política, elecciones, marketing político, municipal.

\section{ABSTRACT}

This report addresses the different stages of a municipal political campaign, the tools and processes that are carried out following a strategic and comprehensive communication approach. The municipal electoral campaign of the candidate Norma Alencastre Miranda, was developed with the political party Somos Perú, within a quite particular scenario, where more than 20 political organizations competed aspiring to achieve maximum representation, the Mayor of the Provincial Municipality of Santa in the Ancash region.

This political campaign involved political leaders, party organizations, supporters, media and citizens in general. In this report, we describe the role that each of the aforementioned actors played and their interference in the electoral process. The procedure developed, the treatment and the strategies used throughout the electoral campaign in the framework of the 2018 Municipal and Regional Elections are detailed.

Keywords: political campaign, elections, political, marketing. 


\section{INTRODUCCIÓN}

Dirigir una campaña electoral, implica entre otras cosas, plena consciencia de enfrentar inicialmente un verdadero panorama de caos, literalmente hablando. Un caos de gente, de opiniones, de acciones, de ideas, de reacciones, de proyectos, de palabras, etc. Ante este panorama de caos inicial, es imprescindible la elaboración de una estrategia, que es el plan general que orienta todas las acciones durante un periodo de tiempo, es una guía para la acción, pero una guía flexible, que ordena, que organiza, que optimiza recursos y simplifica el camino. La estrategia, es aquella que permitirá una cooperación masiva flexible y necesaria para lograr nuestro objetivo; es decir, una gran cantidad de personas trabajando coordinadamente, cada quien, desde su ámbito y lugar, luchando por un mismo objetivo: ganar las elecciones. Es así, como podemos describir una campaña electoral, como una gran obra colectiva, donde la estrategia constituye el plan maestro.

No existe un consenso de cómo se debe desarrollar la planificación de una campaña política para que esta sea efectiva, sin embargo, el objetivo de este proyecto profesional es mostrar de manera coherente las diversas herramientas y procesos de comunicación que intervienen en el campo de batalla electoral, en la mente de los electores, que desde siempre ha constituido el principal escenario donde se despliega la comunicación política.

La representación pública, es el objetivo a lograr en una campaña electoral; la ejecución de acciones coordinadas, planificadas y orientadas a persuadir mayorías electorales, constituyen la esencia de las estrategias de comunicación. Son creativas, inteligentes y cada vez más diferentes, debido a la aparición de nuevas tecnologías, que realizan los partidos, candidatos y equipos de campaña para conectar con sus mensajes a la ciudadanía, haciendo uso de diversos medios, para lograr finalmente, el respaldo y el voto de los electores.

En el presente proyecto profesional se describe y analiza la estrategia de comunicación desarrollada para la candidata a la alcaldía de la Provincia del Santa Región Ancash, Norma Alencastre Miranda, quien participó en las Elecciones Municipales y Regionales 2018, representando al partido político Somos Perú. 


\section{ANTECEDENTES}

\subsection{La comunicación política}

La comunicación política, en la práctica, está conformada por la producción y la transmisión de la política, sin que una se desligue de la otra; ambas actividades, están estrechamente conectadas y su ejecución no se realiza de manera independiente. Por lo tanto, cualquier forma de transmisión política, puede ser considerada comunicación política, abarcando las siguientes áreas: información política, participación política y comunicación política - ésta última considerada como el trabajo de campaña política.

Con frecuencia, el tratamiento de la comunicación política, se centra en el punto de las campañas electorales; donde la información, la comunicación, el manejo de los temas coyunturales y de actualidad, así como de sus actores o protagonistas y sus relaciones, son necesarios. Los políticos, sus discursos, sus mensajes y los medios de comunicación que reflejan los hechos acontecidos, opinando críticamente sobre ellos e informando sobre las diferentes corrientes de opinión existentes, cumplen un rol determinante. Sin embargo, no debemos olvidar a la participación política, como otro elemento central de la comunicación política; ésta no puede ser concebida como acciones unilaterales desde la esfera política hacia la ciudadanía, sino más bien, como un proceso dinámico e interactivo entre gobernantes y gobernados. La participación política, no se reduce al ejercicio del voto, realizado en épocas electorales cada cuatro o cinco años, sino está representada por toda forma de expresión política, si es que la opinión pública la percibe como tal.

La comunicación política, se planifica persiguiendo objetivos inmediatos, de plazos cortos y buscando la persuasión. Su contenido dependerá de las personas involucradas y de las organizaciones políticas que intervengan en las elecciones, según los tiempos y el lugar. Es necesario resaltar, que no solo se recurre a ella en momentos de comicios electorales, sino también en períodos más largos como gestiones de gobierno u oposición. 
Para analizar y estudiar los procesos de comunicación política encontramos tres vías:

\subsubsection{La investigación del voto}

Referida a conocer las acciones que pueden influir en el comportamiento y la decisión de los electores; este conocimiento se articula posteriormente en las estrategias de campaña. Existen afirmaciones que sostienen que la campaña política por sí misma, tiene una influencia relativa en comparación a otros factores, lo cual se explica con la idea de que los resultados de la elección, están determinados por elementos de la socialización en los que es muy difícil influir, tales como acontecimientos inesperados, escándalos políticos o desastres naturales, por ejemplo. Existen dos posiciones al respecto; la primera, en la que los políticos y partidos sostienen que las campañas son decisivas e influyen categóricamente en los resultados electorales, por lo cual se invierten muchos recursos. La segunda, defendida por los politólogos, quienes consideran que la incidencia en la intención de voto, es mínima.

\subsubsection{Los canales tradicionales de transmisión}

En los años 20’ la radio, era el medio estrella y preferido por los sistemas totalitarios de la época, como el nazismo, modelo basado en el conductismo, donde se pensaba que era posible influenciar directamente en los ciudadanos a través de la propaganda, bajo el esquema de estímulo-respuesta-efecto.

Luego de la Segunda Guerra Mundial, en los 60' los modelos creados remarcaban el efecto limitado de los medios masivos, los que pasaron a segundo plano y se usaban como refuerzo a las movilizaciones ciudadanas que eran las preferidas de la época.

Desde 1980, con el modelo Agenda-Setting, se sostiene que los medios masivos de comunicación fijaban la importancia de los temas, aunque no la forma de pensar de la audiencia. 
En la actualidad, el Prime time-politics (horario político estelar), es un modelo que combina la campaña política con el trabajo de los medios de comunicación, es decir, se generan o producen acontecimientos diseñados para ser transmitidos en los medios.

\subsubsection{Rol de los partidos en la preparación de los comicios}

Referida al estudio de la forma como los partidos y organizaciones políticas organizan la campaña electoral, el financiamiento y la dependencia entre partidos y candidatos. De acuerdo a la historia encontramos diferentes etapas en la planificación de campañas:

La Campaña Pre Moderna, ubicada entre 1920 a 1945, etapa en la que el contacto personal, el cara a cara era lo más importante y era reforzado con la propaganda por radio. Cada mitin tenía como objetivo lograr la persuasión en los electores a través del contacto personal con el candidato, los abrazos y saludos tenían que ser efectivos por sí mismos, y no en relación a la retransmisión mediática.

La Campaña Moderna, la encontramos entre 1945 a 1990, donde la comunicación masiva adquiere protagonismo, principalmente la televisión, en la que los políticos son expuestos y se busca que sus mensajes lleguen al electorado en el menor tiempo; Catch All es el nombre de la estrategia como se conocía a esta nueva forma de enfrentar una campaña. En la recta final de esta etapa moderna, se produce un decrecimiento de la participación en los comicios electorales, las movilizaciones pasan al olvido y las campañas se concentran en persuadir al electorado. Se genera un alejamiento y deslealtad de los ciudadanos a los partidos y organizaciones políticas, asesores y equipos de campaña son quienes toman el control de la planificación.

A partir de 1990, la Campaña Posmoderna tiene lugar, donde adquieren protagonismo la comunicación estratégica, el marketing directo, el estudio de los públicos y asesores especializados. Existe una mayor concentración en la persuasión hacia el sector de los indecisos, fidelización de militantes y recuperación de la lealtad partidaria son decisivas. 


\subsection{Estudio de mercado}

\subsubsection{Focus group}

El objetivo fue conocer la percepción de los actores políticos y sociales directos respecto al contexto socioeconómico y político de la provincia del Santa. Fueron convocados representantes de colegios profesionales, cámara de comercio provincial, asociación civil organizada, periodistas y regidores municipales.

Existió un común denominador respecto a la falta de confiablidad de la población en sus autoridades y por lo tanto en los candidatos del proceso electoral del 2018; la falta de cumplimiento de las promesas de campaña por las actuales autoridades, generó un efecto rebote en quienes participan en el presente escrutinio. A ello se suma la falta de transparencia en la gestión realizada y la corrupción institucionalizada por las coimas, que representaban el 10\% del valor de la obra o servicio en la mayoría de casos, comúnmente conocidos como los diezmos del sector público. En el caso de la Municipalidad Provincial del Santa, alcaldes prófugos - Victoria Espinoza y Julio Cortés - empañaron más el contexto socioeconómico y político en la ciudad.

En cuanto a los principales problemas que enfrenta la provincia, fueron la corrupción y el desempleo los que destacaron por unanimidad; las grandes mayorías son las más afectadas reflejándose en la pobreza y en menos oportunidades de desarrollo con miles de jóvenes sin trabajo y sin saber quehacer.

El panorama electoral es desalentador, de gran desconfianza hacia los candidatos y la clase política en general; sin embargo, gobernar con transparencia, dinamizar la economía provincial y generar trabajo deben convertirse en la prioridad de la nueva gestión.

\subsubsection{Encuestas}

Se realizó un estudio cuantitativo de opinión pública bajo la técnica de encuestas cara a cara, un muestreo probabilístico en un universo de hombres y mujeres mayores de 
18 años, con una muestra de 516 encuestas en Chimbote y Nuevo Chimbote; el margen de error fue de $+/-4.3 \%$ y la confiabilidad del $95 \%$.

Los resultados reflejaron:

- Desaprobación absoluta de la gestión de la alcaldesa provincial Victoria Espinoza con un $72.1 \%$

- El 9.9\% de la población, aprueba el papel desempeñado por los movimientos políticos regionales, mientras que el $74 \%$ no. Sumado a ello, el $20.7 \%$ votaría por un partido político, mientras que un $26 \%$ lo haría por un movimiento regional, pero un $42.2 \%$ no lo haría por ninguno; y respecto a la situación caótica de la política en la región, 56\% responsabiliza a los movimientos regionales.

- En cuanto al nivel de reconocimiento de la candidata Norma de la farmacia Bazán, el 68.4\% sí la conoce; dentro de ellos, el segmento de 46 a 55 años es el que más la conoce, sin embargo, en los segmentos de 18 a 25 años, 26 a 35 años, 36 a 45 años y 56 a más posee un alto índice de reconocimiento.

- En la intención de voto para la Provincia del Santa, Norma de la farmacia Bazán obtuvo $26.6 \%$, mientras que la segunda posición era de $10.7 \%$, otros con $6.9 \%$ y $55.8 \%$ no saben aún a quien respaldarán con su voto.

\subsection{Diagnóstico situacional}

A través del Decreto Supremo N004-2018-PCM, publicado el 10 de enero de 2018 en El Diario Oficial El Peruano, el presidente de la Republica convocó a las elecciones Regionales y Municipales, a realizarse el domingo 7 de octubre del 2018. Las elecciones Regionales y Municipales se realizan cada cuatro años para elegir las autoridades de los gobiernos regionales, consejeros regionales, alcaldes y regidores de los concejos municipales, provinciales y distritales en toda la República. 
En Ancash, encontramos a la Provincia del Santa conformada por 9 distritos, por lo que, en esta jurisdicción se elegirán un alcalde provincial, 8 alcaldes distritales y también a sus regidores municipales respectivos.

La candidata Norma Alencastre Miranda, llegó a ser regidora provincial en el año 2014 con la agrupación política Alianza para el Progreso, a la cual renunció en el 2017 para afiliarse en su actual organización política. La señora, decidió participar en los comicios electorales para la alcaldía de la Municipalidad Provincial del Santa en el año 2018, dicha contienda la asumió desde el Partido Político Democrático Somos Perú.

Existieron 21 organizaciones políticas las que presentaron ante el JEE-S (Jurado Electoral Especial del Santa) sus candidatos para la Provincia del Santa. Dentro de ellos algunos investigados y con proceso por presuntos actos de corrupción y otros sentenciados. También existieron varios candidatos ligados al movimiento Cuenta Conmigo, que fue liderado por el hoy sentenciado exgobernador regional César Álvarez. Cuatro aspirantes a la alcaldía provincial se desempeñaron como burgomaestres o regidores.

Otro candidato fue Julio Cortes, militante del movimiento regional Río Santa Caudaloso y actual regidor, quien además afronta dos procesos judiciales por los casos "semáforos inteligentes” y "Nehalem”; la fiscalía solicita pena de cárcel por considerarlo culpable por actos de corrupción. El actual alcalde del distrito de Nuevo Chimbote, Valentín Fernández, también pretendía llegar al sillón provincial, aunque siendo presidente y fundador del movimiento regional Vale Ancash, participó en estas elecciones con Alianza por el Progreso; es necesario precisar, que el burgomaestre es investigado por la fiscalía por lavado de activos. José Servat Chocano, dirigente transportista de carga pesada fue candidato provincial por Podemos Perú, pero también ha sido incluido en la investigación de la donación de un millón de soles al hoy sentenciado exgobernador regional Waldo Ríos, los delitos son cohecho y lavado de activos. El movimiento regional Ancash a la Obra, llevó como candidato a su secretario general, Roberto Briceño, quien en el 2014 postuló a la provincia y quedó en segunda posición por Alianza por el Progreso, en el cual permaneció afiliado hasta el año 2016. Finalmente, son 15 candidatos provinciales que, según el ROP, no registran en las agrupaciones por la cual fueron inscritos. 
El primer trimestre del año 2018, se inició con el trabajo operativo de campo. La candidatura de Norma Alencastre Miranda, tenía que lograr una máxima exposición, es por ello que el despliegue del equipo de campaña trató de alcanzar una gran cobertura en los 9 distritos de la provincia del Santa. La candidata lideró la lista provincial, sin embargo, no tuvo autonomía para elegir a sus candidatos distritales, razón por la que el trabajo de coordinación política y de actividades estratégicas de campaña, no fueron las ideales.

Paralelamente, se inició con el proceso de evaluación y selección del equipo técnico que conformaría la plancha de regidores; proceso necesario, ya que los regidores deberían cumplir el perfil adecuado para conformar la lista que acompañaría a Norma. Se tuvo en cuenta que cada uno de ellos tenga una hoja de vida limpia y sin denuncias, con solvencia moral, profesional y que principalmente sea un líder del segmento que representaba.

El 08 de marzo, Día Internacional de la Mujer, fue una fecha importante en la campaña. La candidata, representa a la mujer que surgió desde abajo y en base a trabajo disciplinado, coraje y honradez logró salir adelante. Por tal motivo, se realizó una marcha multitudinaria que fue convocada por Norma de la farmacia Bazán. Esta marcha constituye la primera actividad de campaña de carácter masivo en la ciudad de Chimbote. Los resultados sobrepasaron las expectativas, marcharon aproximadamente 1,600 personas acompañando a la candidata; se hicieron presente los 8 distritos aledaños. Esta marcha fue una muestra de la fuerza y aceptación que a la fecha lograba Norma Alencastre Miranda en la provincia.

El ambiente pre electoral, mostraba un panorama en el cual resaltaban algunos candidatos; entre ellos, el Arq. Roberto Briceño (Ancash a la Obra), Valentín Fernández (Alianza para el Progreso), Víctor Capristán (El Maicito), Norma Alencastre (Somos Perú) y Líder Saavedra (Democracia Directa). Todos ellos y los 16 candidatos restantes, eran pre candidatos, pues tenían que realizar sus elecciones al interior de sus organizaciones políticas y luego de ganar, inscribirlas en el JEE-S para la admisión de su inscripción como fórmula provincial para las elecciones municipales. 
En el Partido Político Somos Perú, las elecciones internas para la región Ancash, Provincia del Santa y distritos, se realizaron el 6 de mayo 2018. Fue una actividad que se desarrolló sin inconvenientes, a la cual acudieron a emitir su voto cientos de simpatizantes. Sin embargo, la coordinación regional que era quien lideraba el proceso eleccionario, tuvo algunas dificultades con el PADRON DE SIMPATIZANTES AFILIADOS, pues al local partidario llegaban una gran cantidad de simpatizantes con la finalidad de emitir su voto, pero su nombre no figuraba en dicha lista. Superados los inconvenientes, la lista ganadora para la provincia fue la única presentada y liderada por Norma Alencastre y sus trece candidatos a regidores.

Luego de presentar la Lista provincial al JEE-S, el 19 junio 2018, con resolución $\mathrm{N}^{\circ}$ 073-2018-JEE-SNTA/JNE, fue declarada inadmisible, debido a incoherencias en la elección interna. Según la resolución se explica que no existió una relación lógica entre el número de sufragantes y los votos emitidos consignados en el acta elaborada por Somos Perú, luego de la elección interna realizada en Chimbote el 6 de mayo 2018.

El 17 de Julio 2018, con emisión de la resolución N00493-2018- JEE-SNTA/JNE y publicada el 24 de julio 2018, el pleno del Jurado Especial en uso de sus atribuciones, resuelve dar por SUBSANADA la observación realizada en la resolución $\mathrm{N}^{\circ}$ 073-2018JEE-SNTA/JNE. Por tanto, se ADMITE Y PUBLICA la lista de candidatos del Partido Político Somos Perú para la Municipalidad Provincial del Santa, para participar en las Elecciones Municipales 2018. Sin embargo, paralelamente se presentaron dos (02) tachas; 1 tacha contra la lista de candidatos y 1 tacha contra la candidata a Alcalde Provincial Norma Alencastre Miranda, los cuales originaron los expedientes ERM.2018022492 y ERM.2018022789 respectivamente.

Con Resolución $\mathrm{N}^{\circ}$ 01015-2018-JEE-SNTA/JNE, de fecha 22 de agosto de 2018, se declaró infundada la tacha formulada contra la lista de candidatos, resolución que se declaró consentida, conforme se tiene en la Resolución N01071-2018-JEE-SNTA/JNE y, de lo resuelto en el expediente ERM.2018022789, se tiene que mediante Resolución N01014-2018-JEE-SNTA/JNE, de fecha 17 de agosto 2018, se declaró infundada la tacha formulada contra la candidata a Alcalde Provincial, Norma Alencastre Miranda por la organización política Somos Perú; resolución que se declaró consentida, conforme se 
tiene en la Resolución N 01070-2018-JEE-SNTA/JNE y que permitió a la candidata y su plancha estar $100 \%$ en carrera hacia la municipalidad provincial.

Este fue cronológicamente el ambiente pre electoral que la candidata encontró. Fue un trabajo arduo, que demandó gran esfuerzo para lograr la inscripción final de la lista provincial. Norma Alencastre Miranda, nunca desmayó ante estos hechos, muy por el contrario; el trabajo en campo nunca se detuvo y el despliegue del equipo de campaña se doblegó. 


\section{REALIZACIÓN}

2.1. Plan de comunicación integrada

La estrategia y las acciones tácticas que presentaremos, son producto de los resultados del estudio del electorado, del análisis del panorama político y de innumerables visitas a diferentes distritos, asentamientos humanos y pueblos jóvenes de la provincia, realizados como punto de partida en la campaña para la Municipalidad Provincial del Santa.

De acuerdo a Luis Costa (1994):

Anteriormente, la forma en que los políticos tradicionales trataban de conseguir votos, era mediante el conocimiento personalizado del electorado y el uso de la elocuencia; conocer los gustos y preferencias de los electores era de suma importancia para la elaboración de los discursos, un verbo elocuente sobre una ciudadanía conocida era sinónimo de votos asegurados. Sin embargo, en la actualidad la forma de realizar una campaña electoral, representa una evolución de las técnicas de conocimiento del electorado y de las técnicas de comunicación; cientos de miles o millones de electores, exigen para su estudio, técnicas cuantitativas y cualitativas. La comunicación, hace uso de formas más eficaces y persuasivas; lo que hace que una campaña política se planifique siguiendo una estrategia, la misma que se diseña de acuerdo a las características del electorado y los objetivos del candidato, haciendo uso de diversos medios de comunicación y nuevas tecnologías (p. 4).

Se diseñó un plan de comunicación integrada abordando como estrategia la combinación de diferentes herramientas de comunicación. A continuación, se presenta los elementos que formaron parte de la estrategia integrada de comunicación desde la etapa pre electoral, como la gestión de la campaña política, el público objetivo, los objetivos principales y la combinación de herramientas de comunicación para informar, comunicar y entregar valor a los diferentes segmentos electorales. 


\subsection{Etapa pre electoral}

Iniciamos este punto, sosteniendo que considerar que la contienda electoral comienza una vez que el presidente de la República convoca oficialmente a elecciones, es un grave error; las campañas se inician desde mucho antes. En esta etapa, lo que predomina no son las propuestas, sino más bien la exposición que los principales medios de comunicación masivos, hayan otorgado al candidato, generándole un posicionamiento determinado. En la etapa preelectoral, la realidad es presentada de una forma determinada, lo cual sugiere implícitamente, la generación de una posición e identificación de las personas respecto a los candidatos; esto es realizado a través de los discursos o narrativa que manejan los medios de comunicación.

La gestión municipal provincial del movimiento político regional Río Santa Caudaloso 2014 - 2018, liderado por Victoria Espinoza, llegaba debilitada a su cuarto año de gobierno, con una ex alcaldesa prófuga y con procesos por presuntos actos de corrupción, de igual forma el primer regidor quien asumió la alcaldía; también existieron algunos candidatos ligados al movimiento Cuenta Conmigo, el mismo que fue liderado por el hoy preso exgobernador regional César Álvarez. Hacemos mención de este aspecto, ya que la Provincia del Santa es parte de la región Ancash, lugar que en la actualidad ocupa los primeros lugares en el ranking de corrupción en el país y donde eventualmente, los medios podrían presentar la realidad de una forma determinada.

En este contexto, comenzamos a gestionar la presente campaña desde diciembre del 2017, con un cronograma de actividades navideñas en diferentes barrios y distritos de la Provincia del Santa.

\subsection{Diseño y gestión de la campaña política}

Debido a que la candidata Norma Alencastre Miranda, desde hace más de 40 años dirige una cadena de farmacias muy bien posicionada en la ciudad de Chimbote, estratégicamente utilizamos el branding de su farmacia como una especie de alianza entre ésta y la candidata, para obtener una mejor recordación. Farmacia Bazán, no sólo proyecta confiabilidad, sino también identidad debido a su trayectoria en el tiempo y la 
provincia. Por lo tanto, generamos la marca de nuestra candidata, sería presentada como "NORMA de la farmacia BAZAN".

De esta forma, buscamos posicionarnos rápidamente en la mente del electorado, agregándole valor a la candidata y promoviendo una conexión emotiva, apuntando a diferenciarnos entre la oferta electoral provincial.

Teniendo en cuenta que, el escenario electoral en la Provincia del Santa se había definido como aquel donde existe una desconfianza total en la clase política - autoridades actuales y candidatos - generado por la falta de transparencia y corrupción de las diferentes gestiones anteriores, la campaña de "NORMA de la farmacia BAZAN", se planteó como objetivo posicionar a una mujer honesta que gobernará de manera transparente y preocupada por el bienestar de las mayorías más desprotegidas. El electorado estaba desmotivado y sin esperanza de la clase política tradicional, sin embargo, presentamos en esta contienda a una mujer de grandes cualidades personales, agradecida de la provincia, especialmente de Chimbote, que le dio una familia hermosa y la oportunidad de trabajar, con honradez y vocación de servicio, de lo cual el pueblo es testigo desde hace 4 décadas; en definitiva, una candidata diferente, identificada con el pueblo más que con la clase política tradicional.

Se centralizó la conducción de la campaña en un comité de campaña, el mismo que el primer trimestre del año 2018, inició con el trabajo operativo, realizando lo siguiente:

- Conformación de un equipo operativo estratégico

- Evaluación y selección de equipo de coordinadores zonales

- Segmentación y mapeo de la Provincia del Santa y sus 9 distritos

- Programa de reuniones con dirigentes de pueblos

- Formación de bases en zonas segmentadas

Paralelamente, se inició con la selección y evaluación del equipo técnico o plancha de regidores, ciudadanos con experiencia en la administración pública y privada, especialmente con reconocido prestigio moral y elevada responsabilidad, quienes además 
de poseer un hoja de vida limpia, representarán a diferentes sectores de la provincia, tales como educación, salud, agro, comercio, juventudes, mujer, colegios profesionales, transporte, entre otros: de tal manera, que el pueblo sintiera una plena identificación y representación de su sector y sus necesidades más urgentes.

Diariamente y de acuerdo a un cronograma establecido, se comenzó con las capacitaciones dirigidas a coordinadores zonales, así como la conformación de bases en las diferentes zonas de los distritos de la provincia; se inició este trabajo organizado, que no solamente sirvió como estructura política, sino también nos permitió conocer in situ, las necesidades, dificultades y oportunidades reales del pueblo, la problemática de fondo que la candidata interiorizó en sus visitas y que finalmente se trasladó con coherencia en la formulación de propuestas de solución que fueron plasmadas en el plan de gobierno.

Estos hechos y las acciones propias de la dinámica de la competencia electoral, fueron coordinados entre sí y subordinados a la conducción estratégica del comité de campaña, además de haber sido registrados fotográfica y audiovisualmente obedeciendo al plan de comunicación integrada, con las que, a través de las diferentes herramientas de comunicación generadas, se informó y comunicó al electorado.

El diseño del concepto de la campaña, destaca como valor principal la preocupación por el bienestar de los que menos tienen; "Primero los pobres" fue el mensaje central de campaña. Pues se buscó hacer política desde el pueblo mismo, desde las bases; en las que escuchamos las necesidades del ciudadano de a pie y buscamos las soluciones a sus problemas cotidianos. Con este concepto, se buscó atender aquellos sectores sociales populares olvidados, postergados por aquellas autoridades que solamente se habían ocupado de beneficiar a una minoría privilegiada. A su vez, se creó un mensaje de persuasión para darle fuerza a la campaña en su recta final "Este 7 de octubre se acaba la corrupción ... Primero los pobres". La candidatura de Norma de la farmacia Bazán, buscó lograr una máxima exposición, es por ello que el despliegue del equipo de campaña trató de alcanzar una gran cobertura en los 9 distritos de la provincia del Santa. 
La fuerza conceptual de la estrategia creativa, estuvo orientada en crear conciencia en el electorado de que existe una esperanza para que aquellas personas que nunca fueron escuchadas, aquellas mayorías postergadas, pueden alcanzar una vida digna y con bienestar para sus familias. Bajo esta perspectiva, se plantearon las diferentes piezas de comunicación publicitaria: paneles unipolares, gigantografías, afiches, volantes, polos, pulseras, llaveros, etc. y los mensajes de los comerciales de TV, radio y redes sociales que buscan generar una conexión directa entre la candidata y las necesidades reales de las mayorías olvidadas.

También se presentó a la candidata con su equipo técnico. A cada regidor se le generaron piezas publicitarias y mensajes dirigidos al segmento que representan: paneles, volantes, llaveros y audiovisuales fueron elaborados.

La campaña se difundió a través de canales de TV de señal abierta y señal de cable que son bastante consumidos en provincia; radios de alcance provincial y radios de mercados; así como redes sociales y plataformas digitales.

\subsection{Público objetivo}

El electorado, definitivamente, es un conjunto heterogéneo de personas con características e intereses determinados, con perfiles e identidades particulares; sin embargo, en medio de esta diversidad de individuos, donde es casi imposible realizar una campaña a la medida de cada elector, todos fueron tomados muy en cuenta.

En la Provincia del Santa, el electorado estuvo conformado por los ciudadanos mayores de 18 años e inscritos en el padrón electoral del RENIEC y que poseen documento de identidad, ascendentes a 350,000 electores aproximadamente y distribuidos en 9 distritos. 
La presente campaña estuvo orientada principalmente y sin carácter exclusivo, al sector sociodemográfico conformado por personas de escasos recursos, bajos ingresos y de menor grado de educación. Normalmente, electores de zonas periféricas, pueblos jóvenes, asentamientos humanos y zonas rurales. Se incidió en el sector femenino y en las personas mayores de 40 años.

\subsection{Objetivos}

2.5.1. Lograr la preferencia del electorado en la provincia del Santa, posicionando a Norma de la farmacia Bazán, como mujer trabajadora y honrada, preocupada por el bienestar de las mayorías que menos tienen.

2.5.2. Posicionar una fórmula electoral sólida: candidata y equipo técnico, con un plan de gobierno visionario, que busca atender efectivamente las necesidades de las grandes mayorías y mejorar su calidad de vida.

2.5.3. Establecer una estructura política sólida, que se identifique y respalde con lealtad a la candidata en la Provincia del Santa.

Por tanto, las actividades de la campaña se orientaron a que los electores de la provincia valoren la honradez y el trabajo de una mujer; se identifiquen con ella con orgullo, pero principalmente valoren su preocupación por el bienestar y mejorar la calidad de vida de los grandes sectores olvidados. El mensaje, eje de la campaña publicitaria, estuvo orientado a comunicar este contenido a la población a través de un lenguaje claro, sencillo y tono positivo.

\subsection{Estrategia de comunicación integrada}

La estrategia de comunicación integrada de la campaña política de Norma de la farmacia Bazán, se traduce en un plan de trabajo que sirvió de ruta para el diseño, implementación y monitoreo de la campaña. 


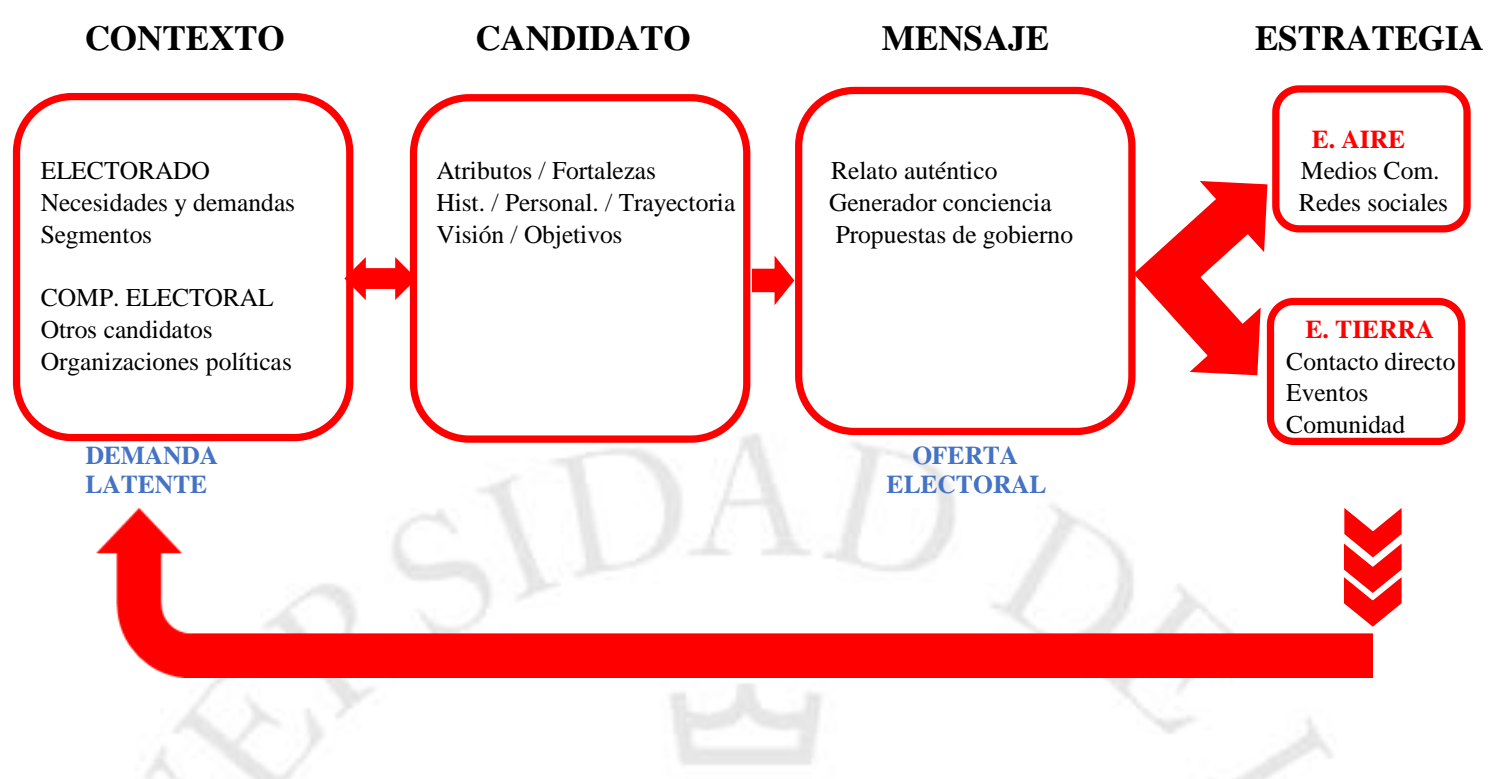

La estrategia de comunicación de la campaña de Norma, se centró en presentar a la candidata como una persona diferente que ingresa en la política, que asegura cambiar, para bien, el caduco sistema gubernamental y corrupto de la Provincia del Santa. Una mujer de lucha, producto de la cultura del esfuerzo, del trabajo honesto y con la energía y la visión necesaria para cambiar, de una vez y para siempre, la actual situación de injusticia predominante, caracterizada por la inequidad y beneficio económico de unos pocos.

Buscando hacer política desde el pueblo mismo, desde las bases; escuchando las necesidades del ciudadano de a pie, de las grandes mayorías sin oportunidades y buscando las soluciones a sus problemas cotidianos, se conceptualizó y elaboró el mensaje central de campaña; contrastado con la propia biografía de la candidata, de su personalidad y trayectoria de vida, marcada por el esfuerzo, el compromiso, la determinación y la superación, proyectando un relato auténtico de una historia de aprendizaje: "Primero los pobres".

Generar conciencia en las grandes mayorías poblacionales postergadas, de que existe una posibilidad de oportunidades, bienestar y calidad de vida constituye la esencia de la estrategia creativa de la campaña; de esta manera, se presentó a la candidata provincial, como la esperanza que muchos electores anhelan hacer suyos, contrario a los intereses de la vieja y corrupta clase política de siempre, una mujer honesta y de trabajo, 
será el icono que representa a los más necesitados y simbolizará la lucha implacable y frontal contra la corrupción.

Por tanto, la estrategia de comunicación de Norma está centrada en el principio de la bisagra, articulada en dos grandes brazos: la campaña de aire y la campaña de tierra. La primera, está implementada a través de los diferentes medios de comunicación, principalmente radio, televisión y redes sociales y la segunda, a través del contacto directo con el pueblo, los electores. La campaña mediática te brinda presencia, visibilidad y llegar con tu mensaje central a grandes masas; mientras que la campaña de tierra, te permite ese contacto directo e irremplazable con el sentir de la gente.

A continuación, se presenta ejemplos de las diferentes herramientas y productos de comunicación elaborados para la presente campaña. Se concentraron los esfuerzos en un pequeño número de temas o ejes de comunicación, con el objetivo de lograr impactar en el electorado y conseguir eficacia en la campaña:

\subsubsection{Publicaciones impresas y digitales}

La creación y desarrollo de contenidos para el electorado provincial, agregaron valor y comunicaron de manera sencilla y directa el concepto central de campaña.

\subsubsection{Volantes}

A. Atributos de candidata - Eje personalizado de campaña 


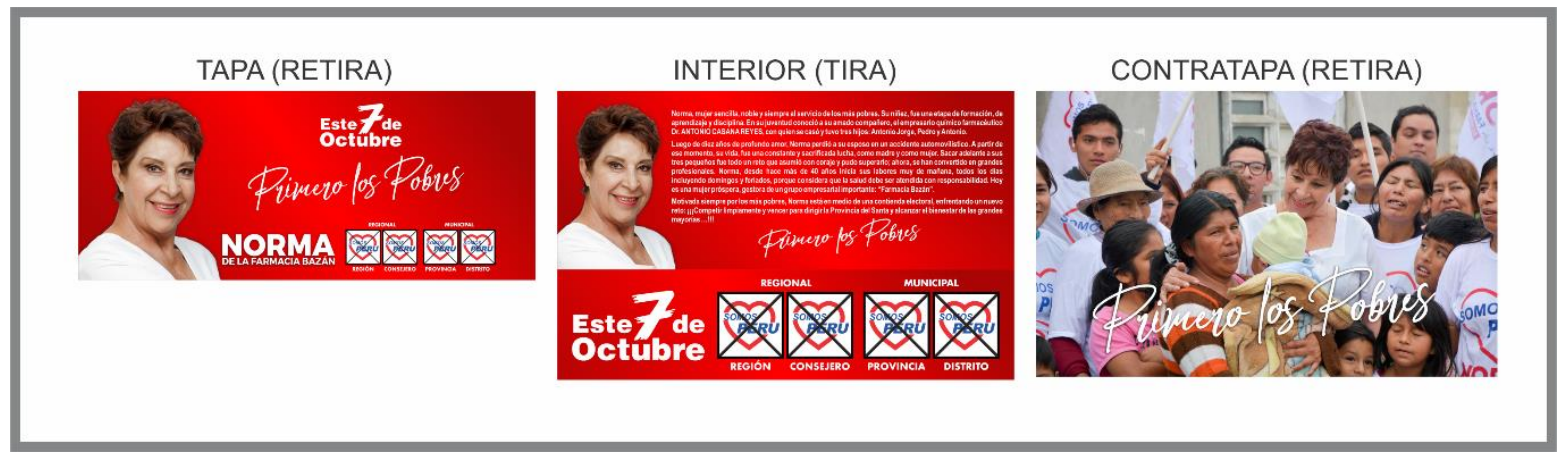

B. Sectores representativos - Eje programático

Ilustración 03: Volante sector salud

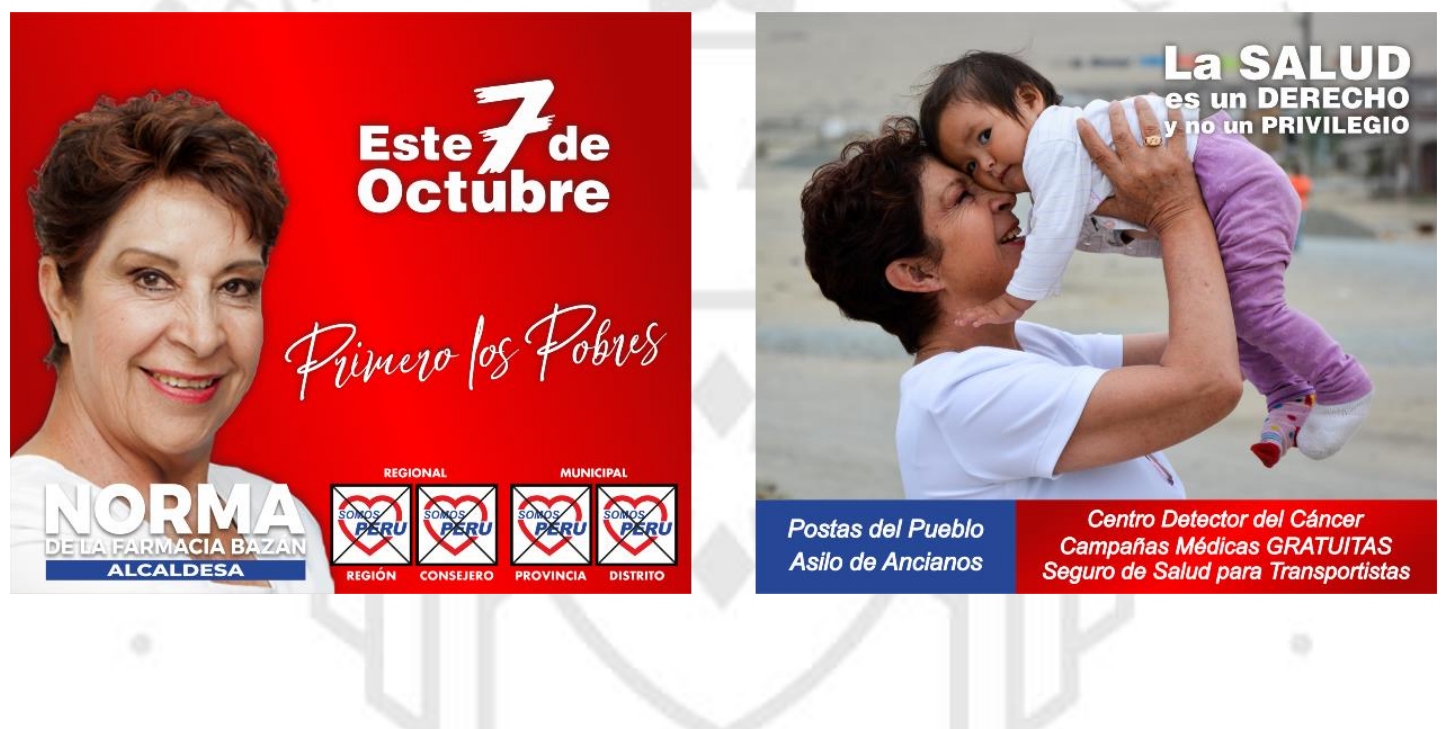

Ilustración 04: Volante sector educación
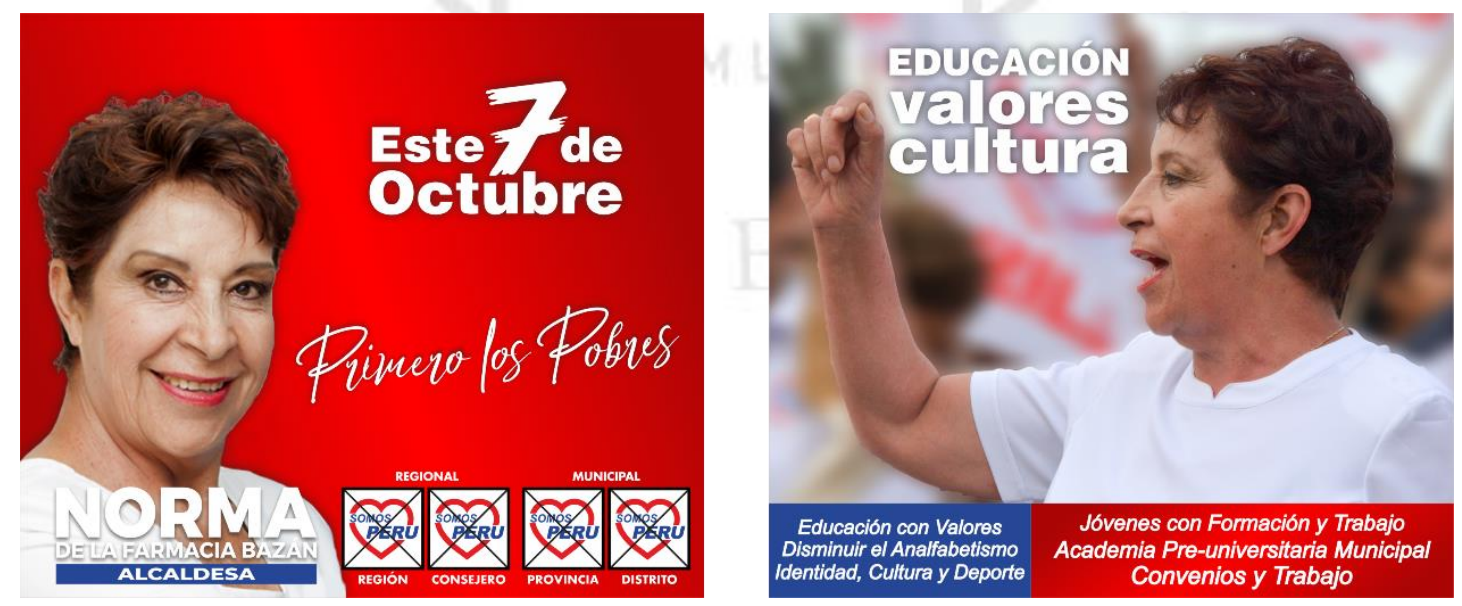

Ilustración 05: Volante sector trabajo 

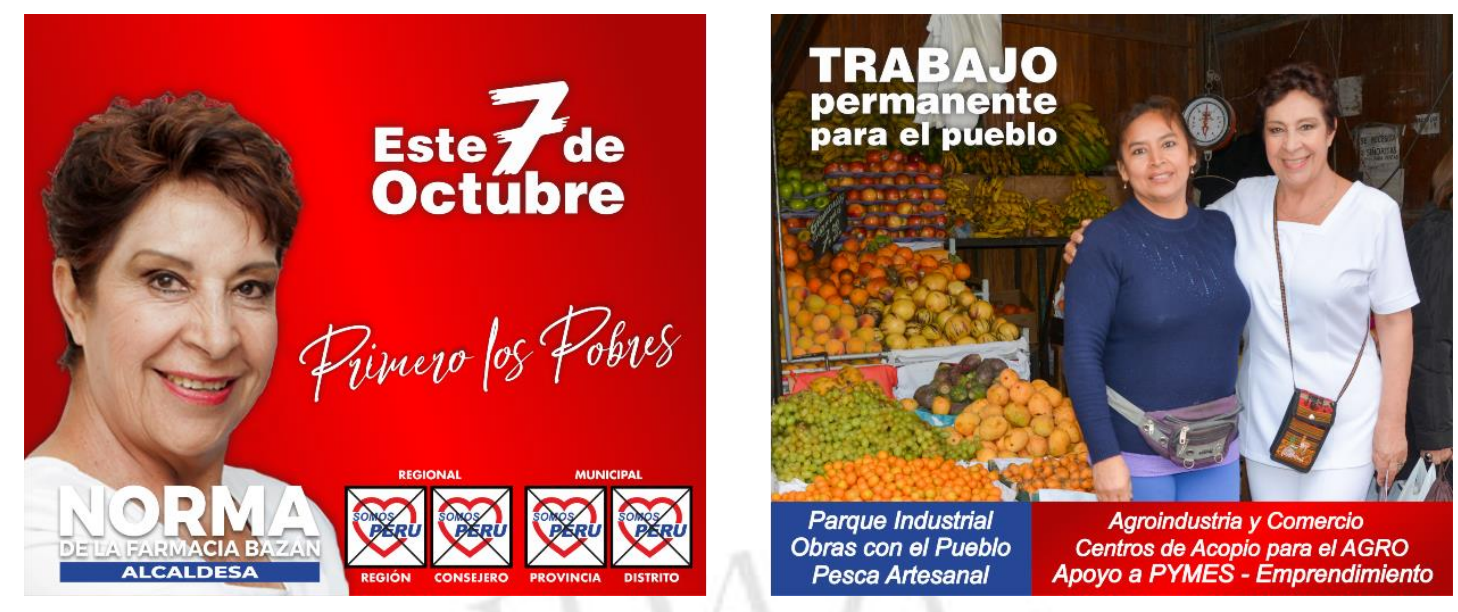

Ilustración 06: Volante sector seguridad
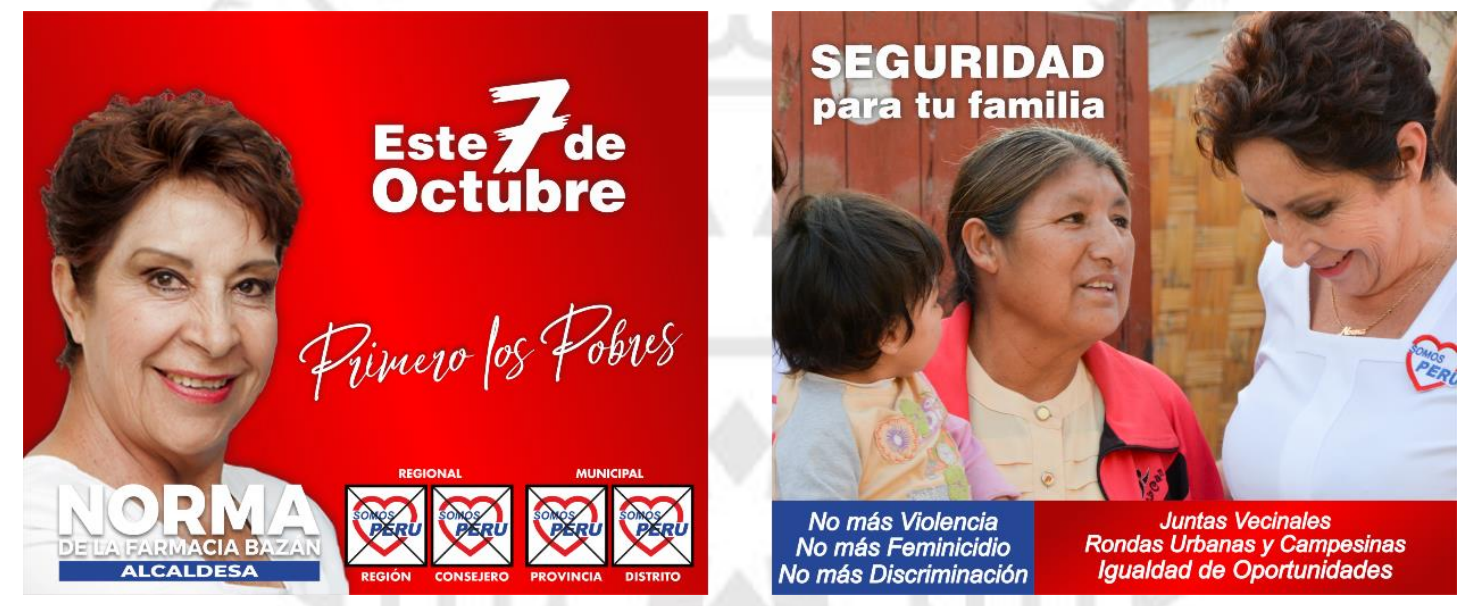

C. Propuestas de plan de gobierno - Eje programático

Ilustración 07: Volante de Propuestas
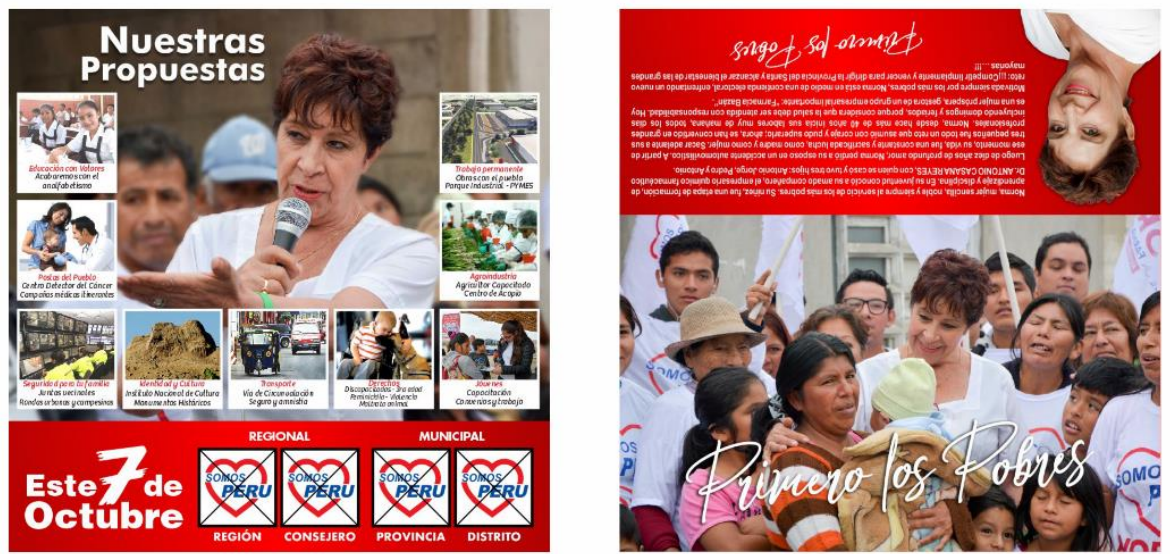
D. Equipo técnico - Eje ideológico y programático

Ilustración 08: Volante candidato a regidor $N^{\circ} 1$

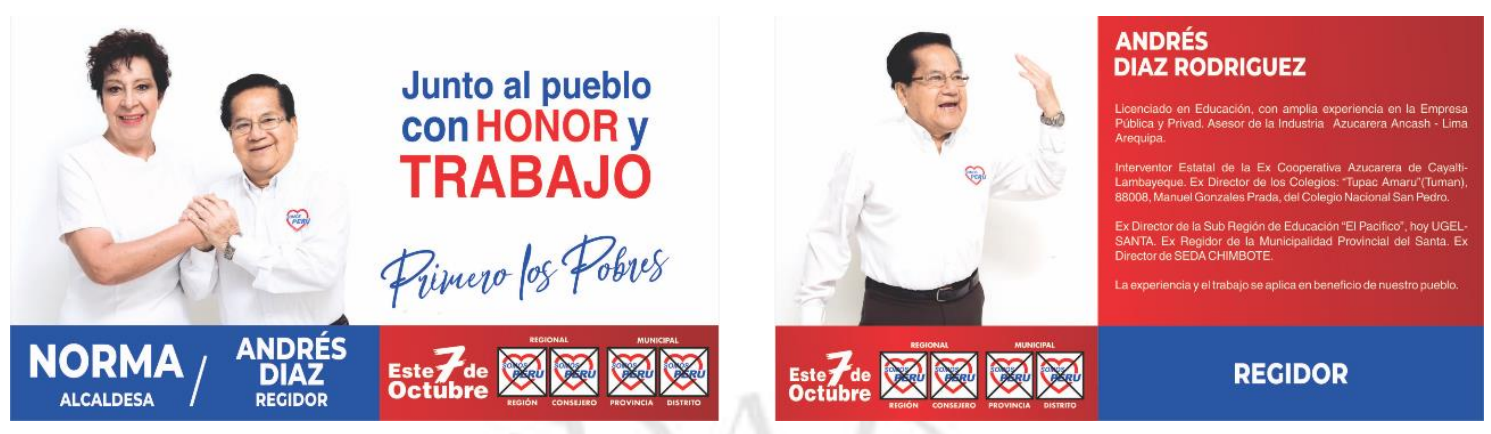

Ilustración 09: Volante candidato a regidor $N^{\circ} 3$

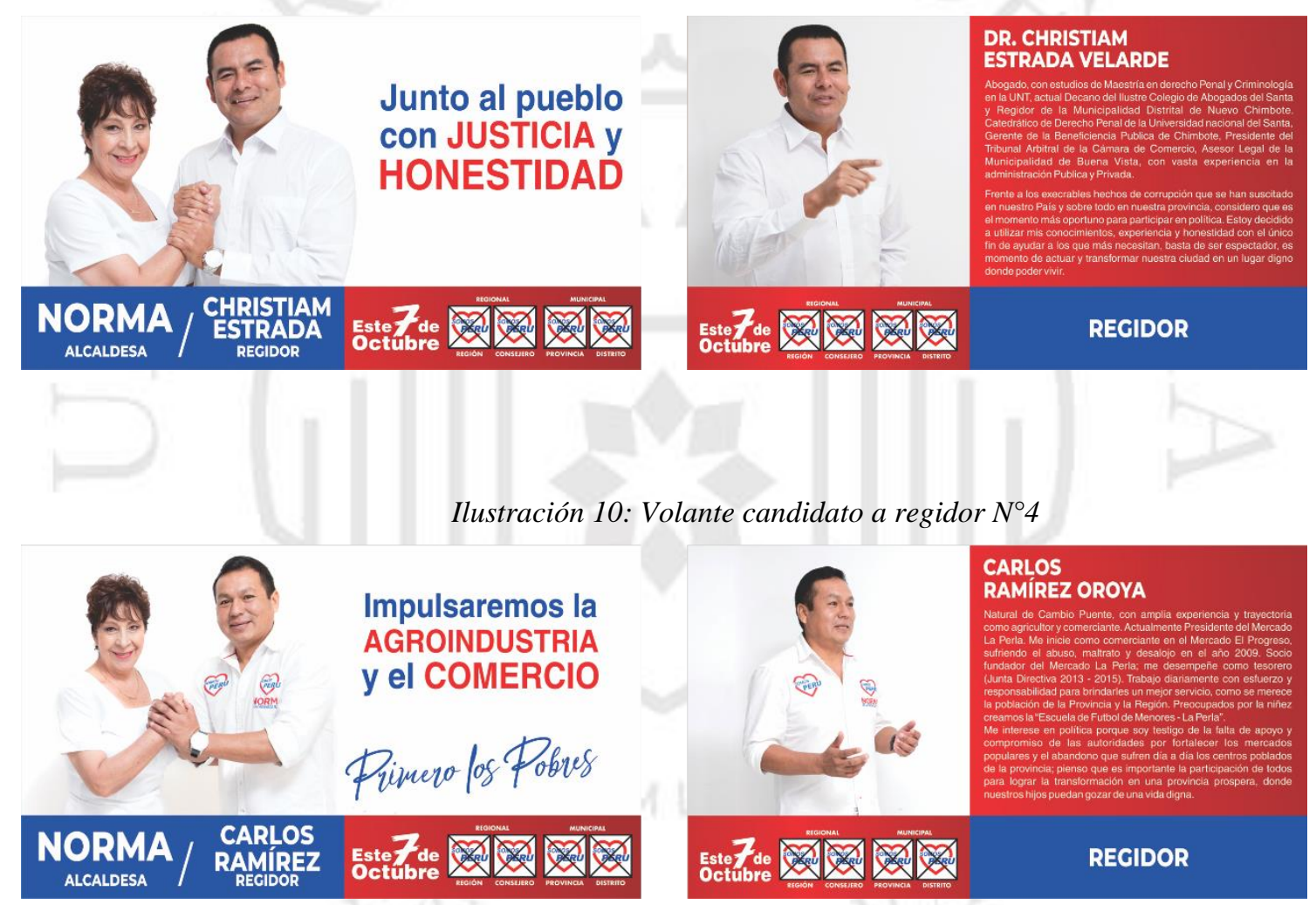

Ilustración 11: Volante candidato a regidor $N^{\circ} 9$
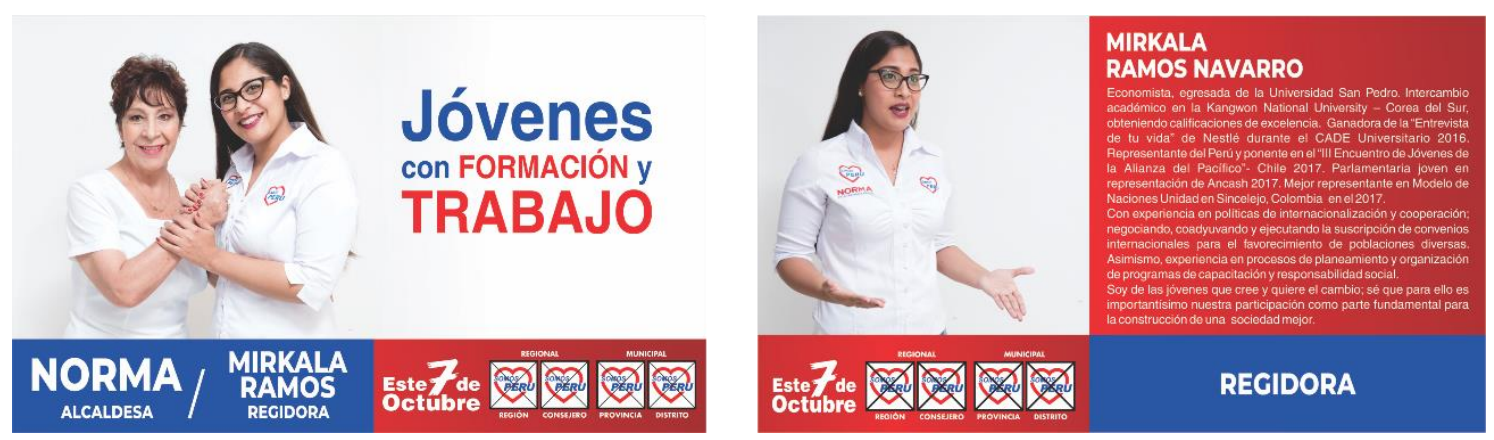
E. Fechas memorables - Eje ideológico

Ilustración 12: Volante celebración de Fiestas Patrias

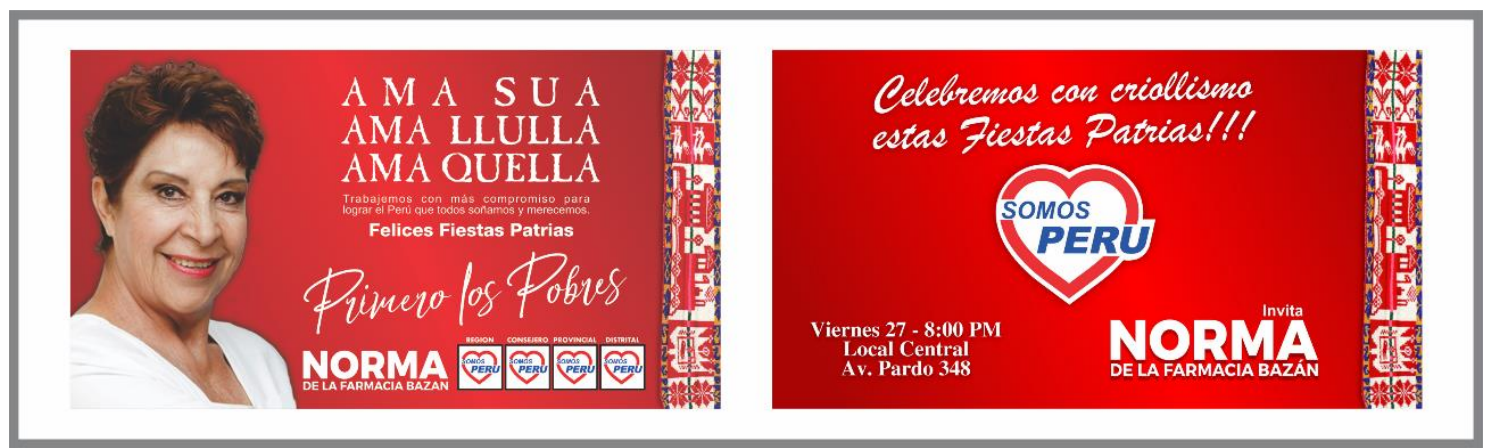

2.6.1.2. Calendarios

Ilustración 13: Calendario de pared

Ilustración 14: Calendario de bolsillo

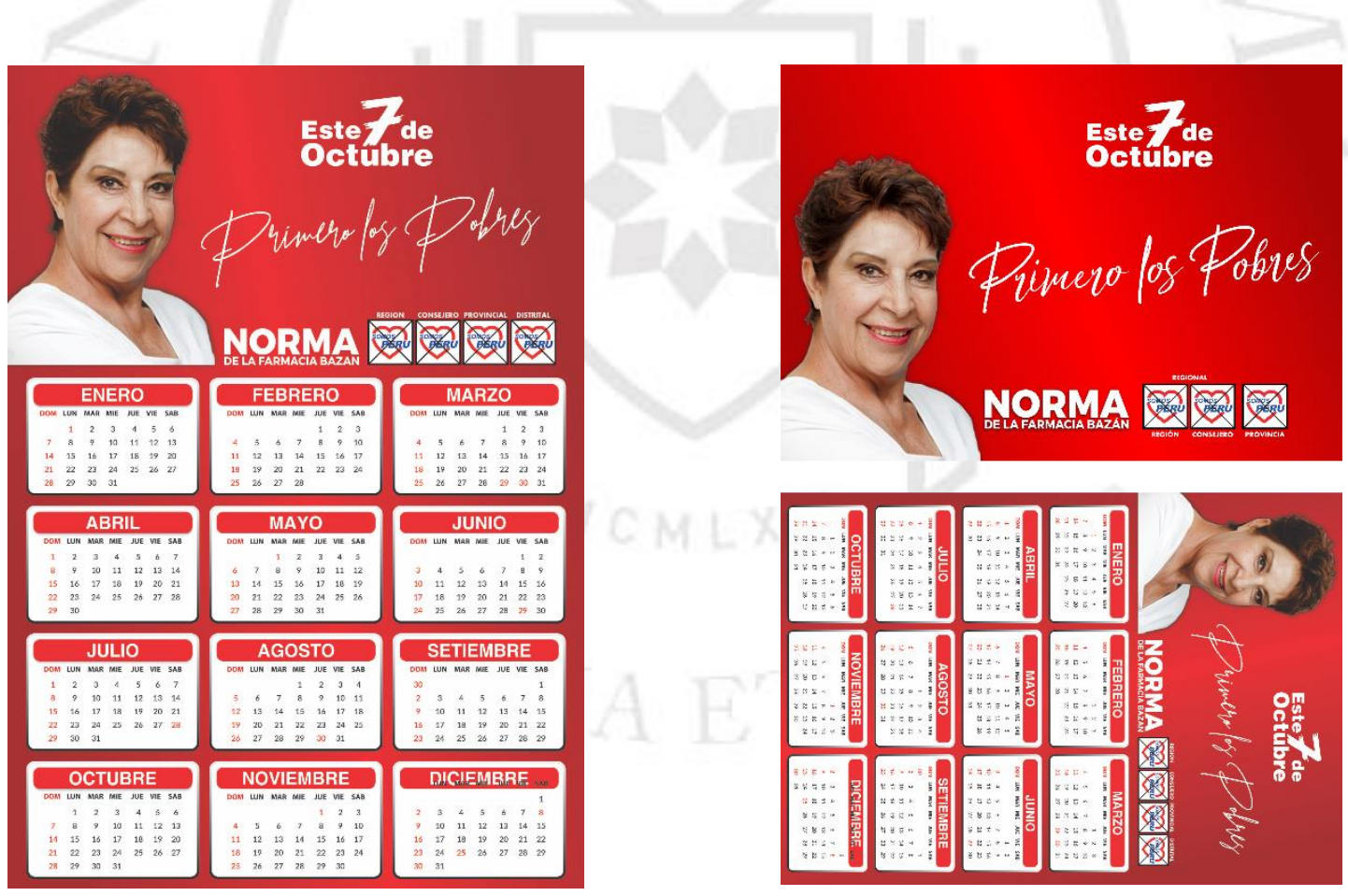


2.6.1.3. Afiches

Ilustración 15: Afiche mensaje central

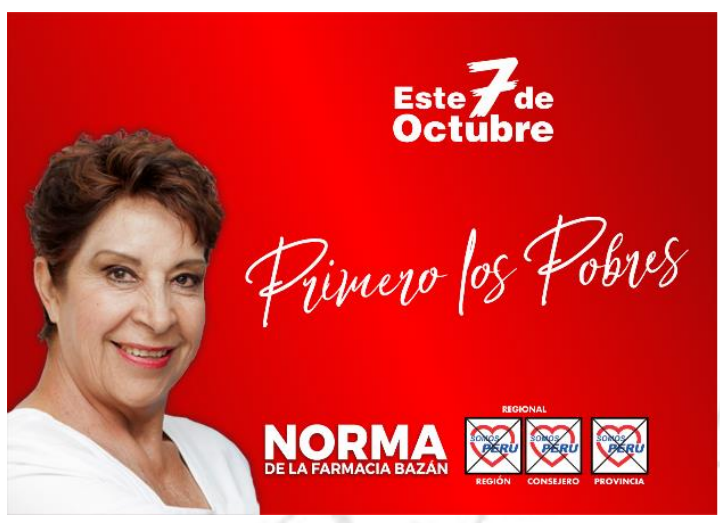

Ilustración 16: Afiche recta final

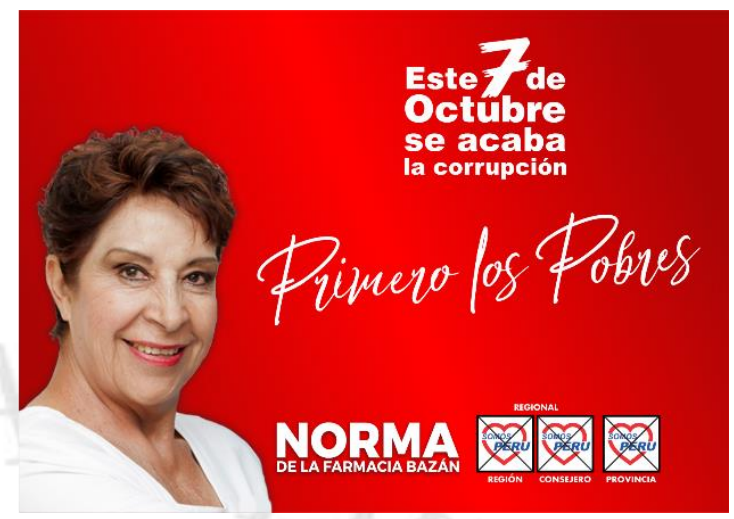

2.6.1.4. Redes sociales

Ilustración 17: Publicaciones - Facebook

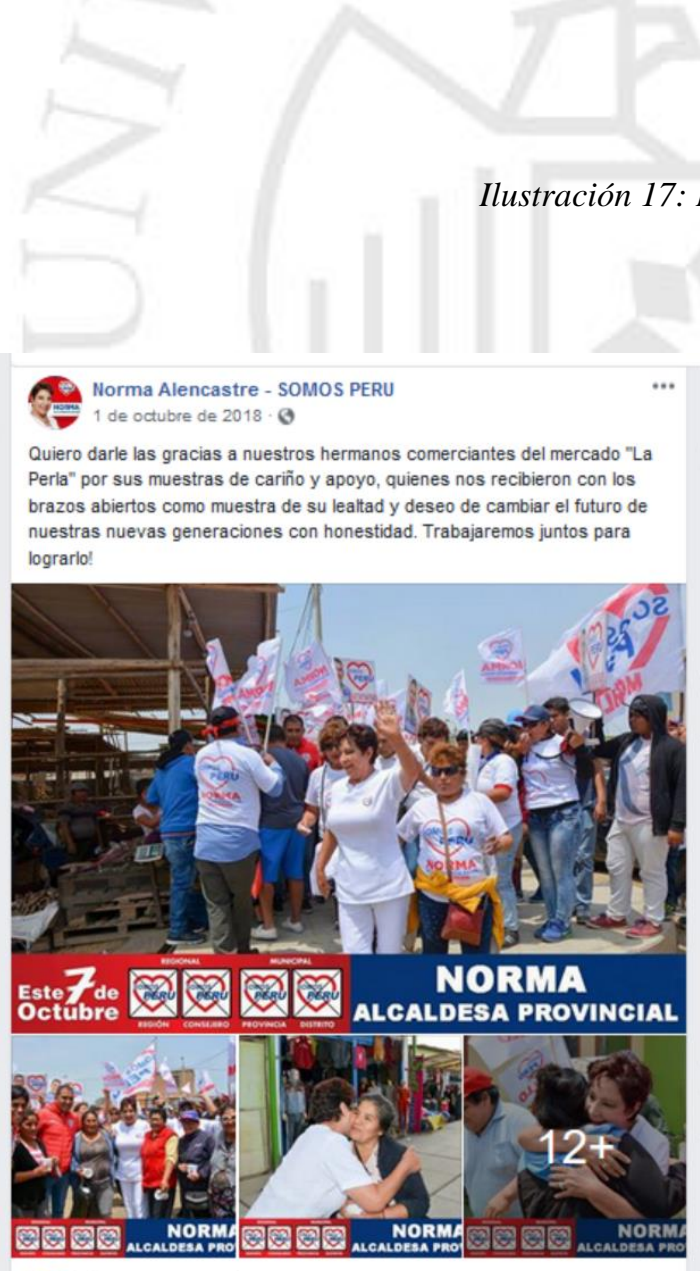

(1) Tú y 67 personas más

16 veces compartida

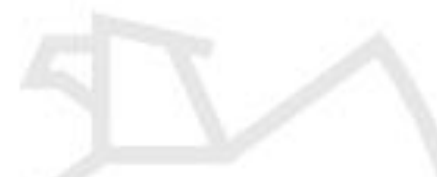

.

6. Norma Alencastre - SOMOS PERU

28 de septiembre de 2018 : 3

Gracias a mi hermanos de Nuevo Chimbote, por el cariño y el respaldo, junto a ustedes lograremos calidad de vida para nuestra gente y nuestras nuevas generaciones.

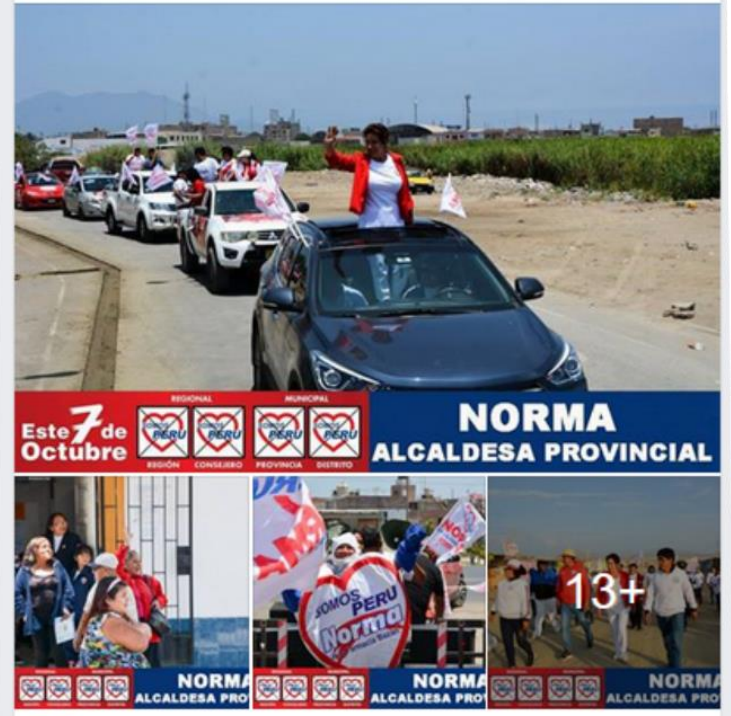

@ 112 
Ilustración 18: Portadas - Facebook
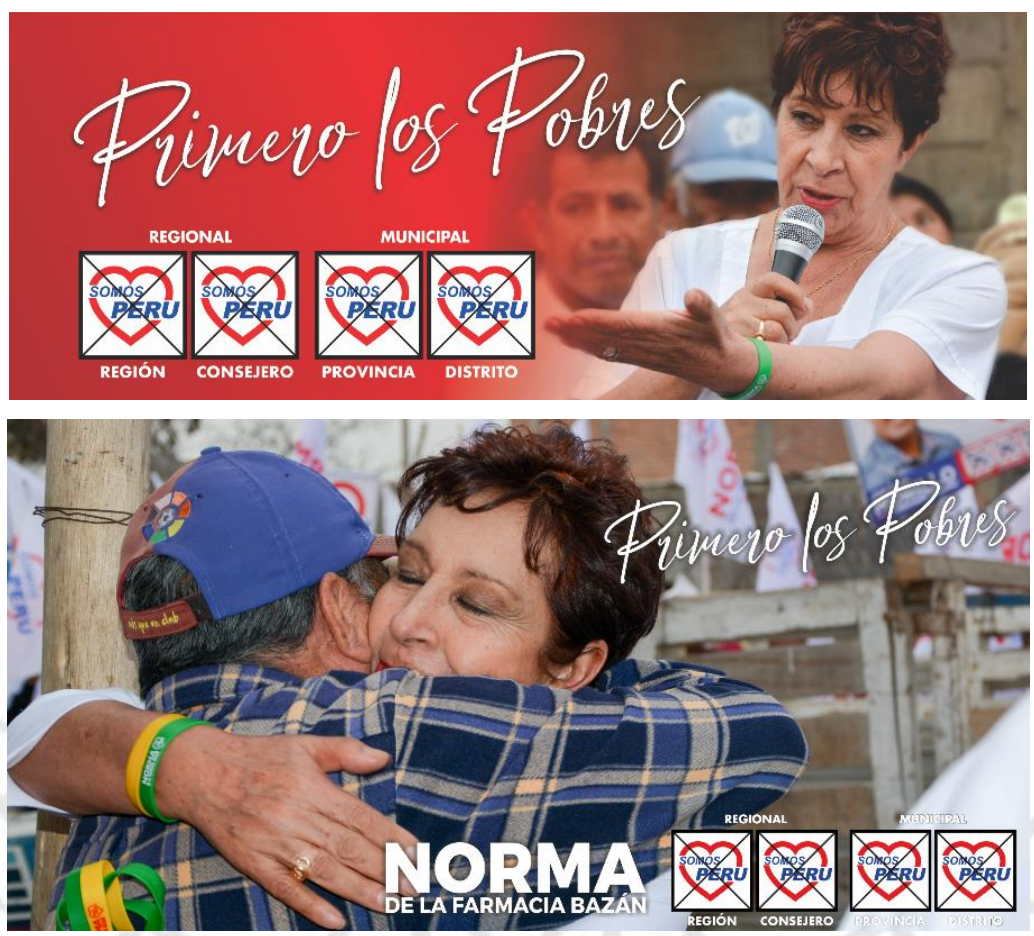

Ilustración 19: Spots, videos, live - Facebook

을 Norma Alencastre - SOMOS PERU

Q 14 de septiembre de $2018 \cdot 0$

"Somos un pueblo fuerte, con gente trabajadora que enfrenta los

problemas y que sigue soñando .... una Provincia con empuje, dispuesta a cambiar su futuro y recuperar nuestra dignidad. Por ello quiero dirigirla y convertirla en el lugar que todos merecemos

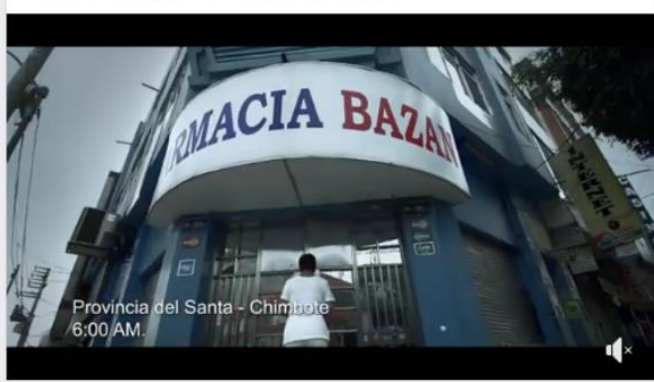

(1) $=373$

82 comentarios 491 veces compartida 15 mil reproducciones

Q2 Norma Alencastre - SOMOS PERU

V. 26 de septiembre de 2018 : ()

Seguimos con las caravanas en diferentes partes de la ciudad

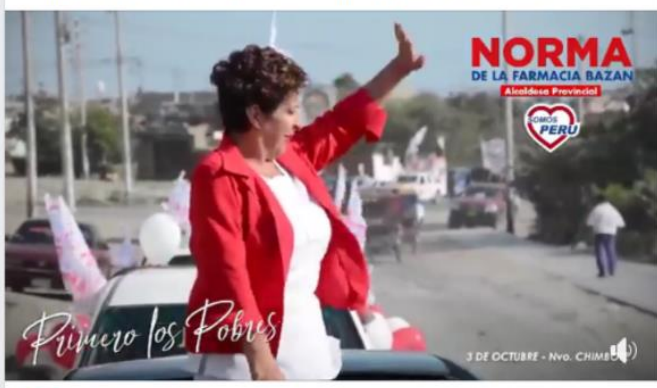

10099
69 Norma Alencastre - SOMOS PERU

25 de septiembre de 2018 - 8

La salud de nuestros hermanos de la provincia es prioridad. Con tu voto lograremos nuestros objetivos

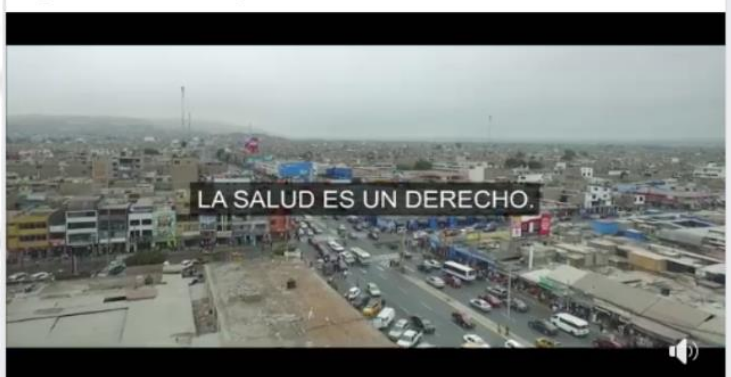

(1) 11113 comentarios 69 veces compartida 2837 reproducciones
그 Me gusta
Comentar
$\Rightarrow$ Compartir
(3)

A Norma Alencastre - SOMOS PERU ha compartido un video ... en directo

4 de octubre de 2018 - \&

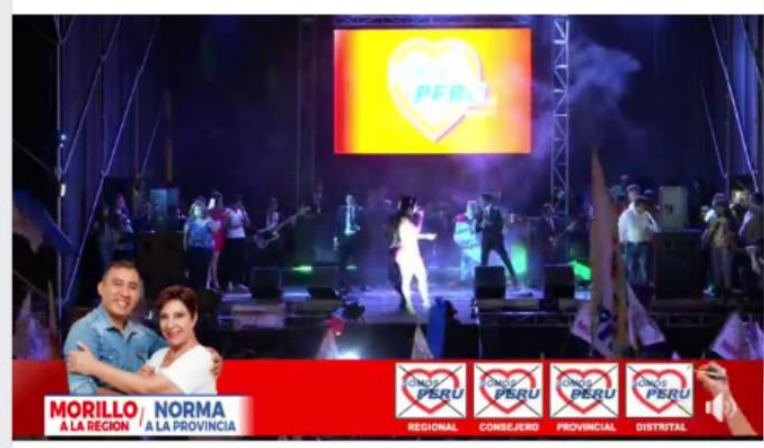

6834 reproducciones 


\subsubsection{Merchandising}

Cada producto publicitario generado, buscó promover en diferentes lugares, situaciones y escenarios una conexión directa entre la candidata y el electorado; "Norma de la farmacia Bazán” está siempre cerca al pueblo: en las calles, en los barrios y pueblos jóvenes, los mercados, los hogares, entre los jóvenes, los transportistas, etc.

Ilustración 20: Polos, vinchas, llaveros
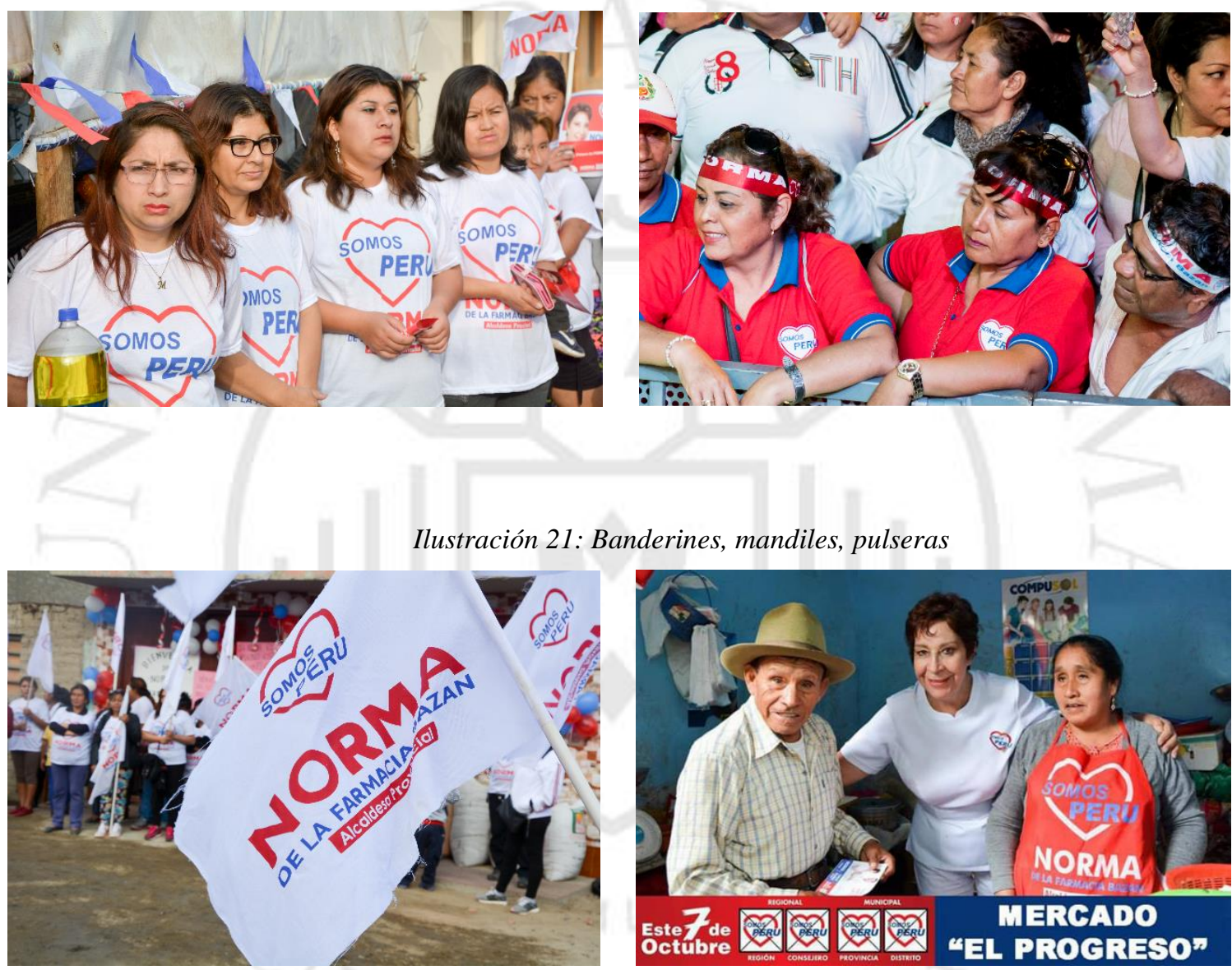

2.6.3. Publicidad exterior

Generar confianza desde la imagen con un mensaje breve que comunique la esencia de la propuesta de campaña fue lo central en la publicidad que competiría frente a otros estímulos visuales en la vía pública. La propuesta de la candidata es lo más importante y fue acompañada por un color rojo impactante, conjugando una pieza publicitaria recordable. 
Ilustración 22: Torre unipolar - Mensaje central

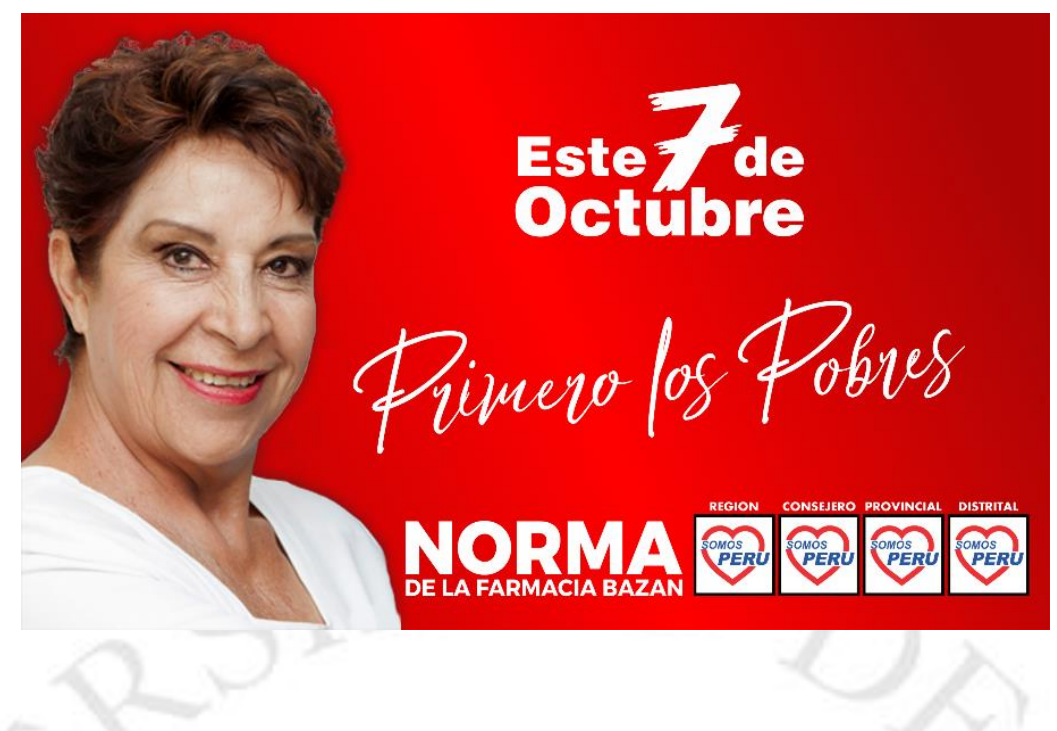

Ilustración 23: Panel - Mensaje segmento agro: valles Santa y Nepeña

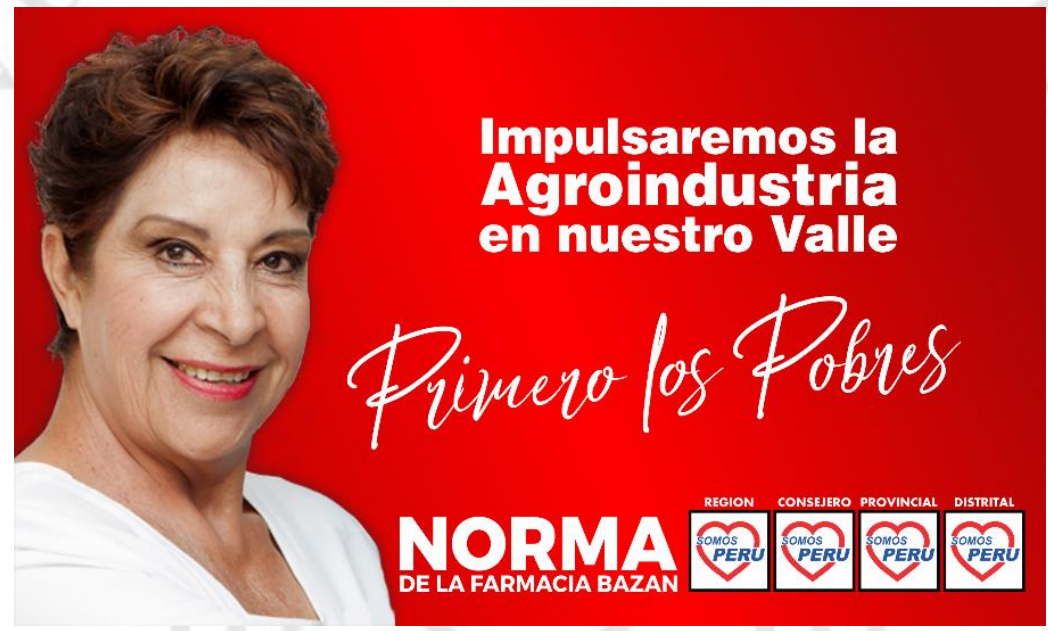

Ilustración 24: Panel - Mensaje recta final

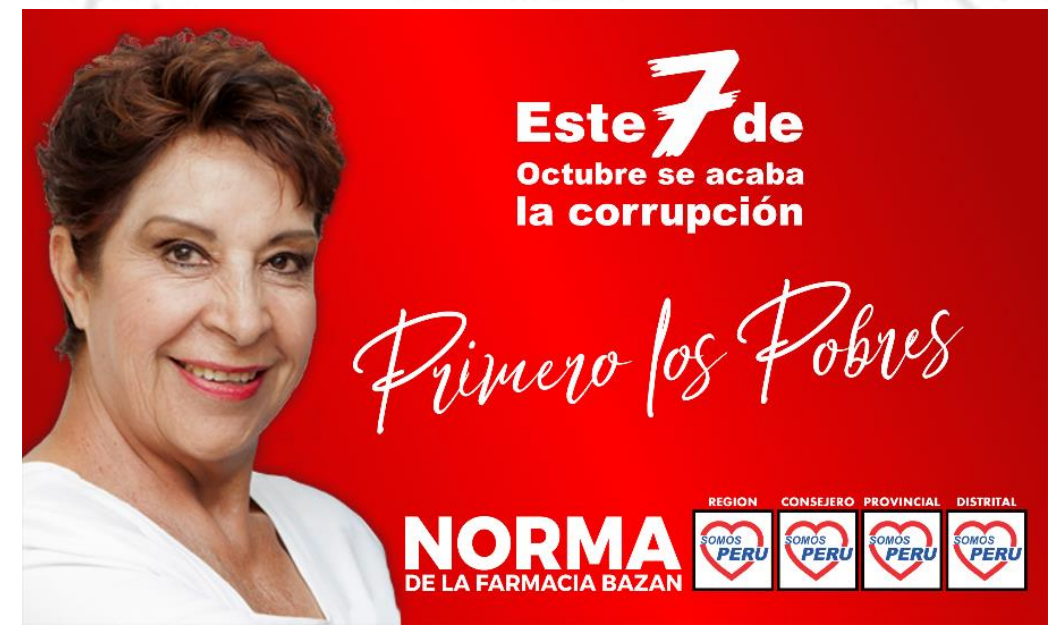


Ilustración 25: Torre unipolar / Panel - equipo candidatos región y provincia

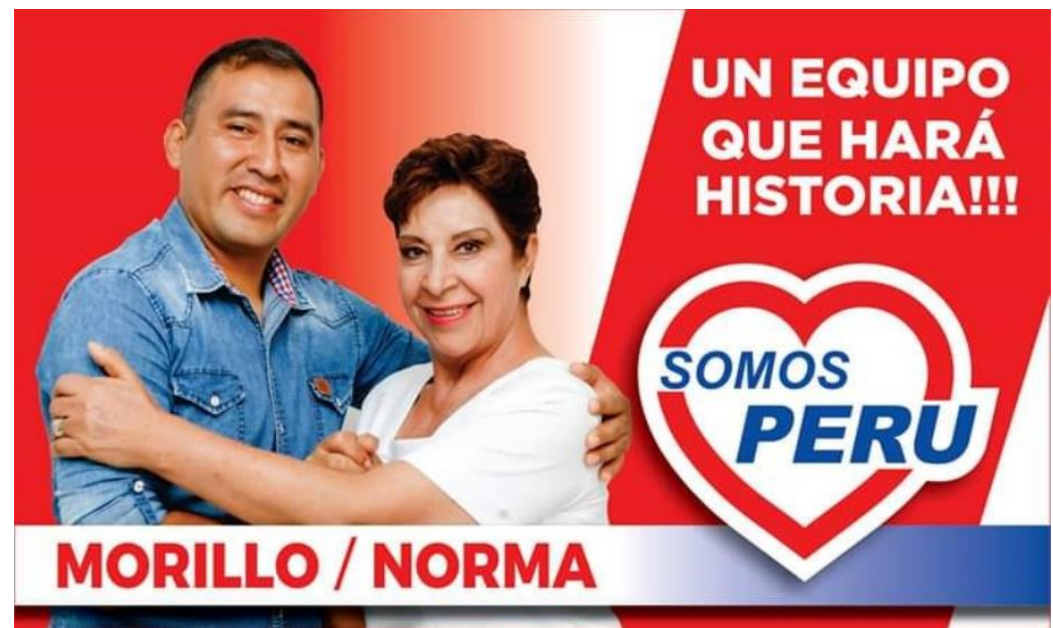

Ilustración 26: Torre unipolar - Panel equipo candidatos región, provincia, distrito Nuevo Chimbote

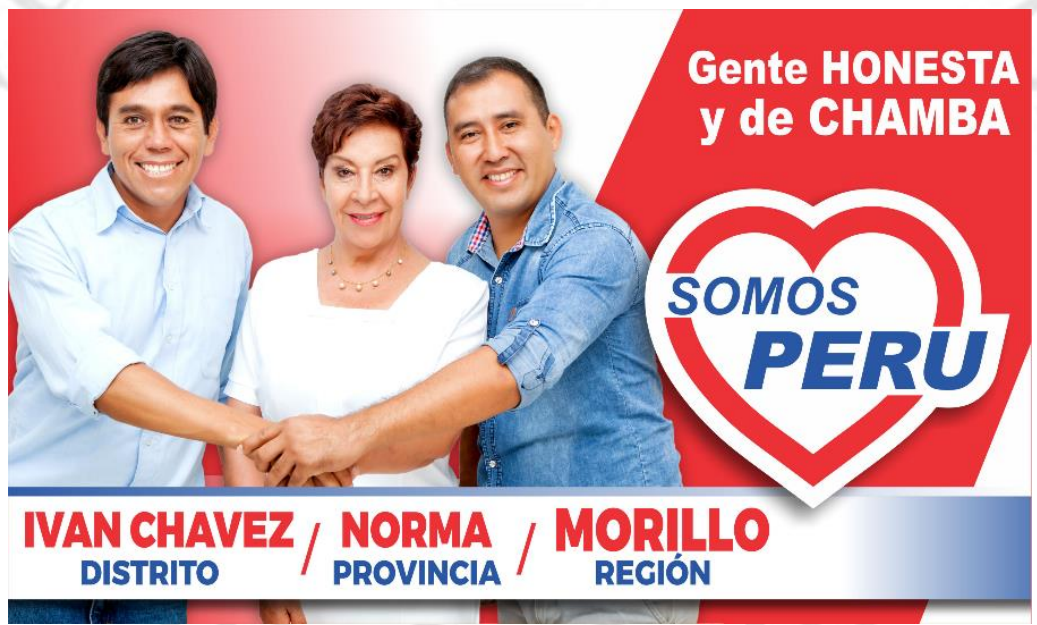

Ilustración 27: Panel - Equipo candidatos región, provincia, distrito Coishco

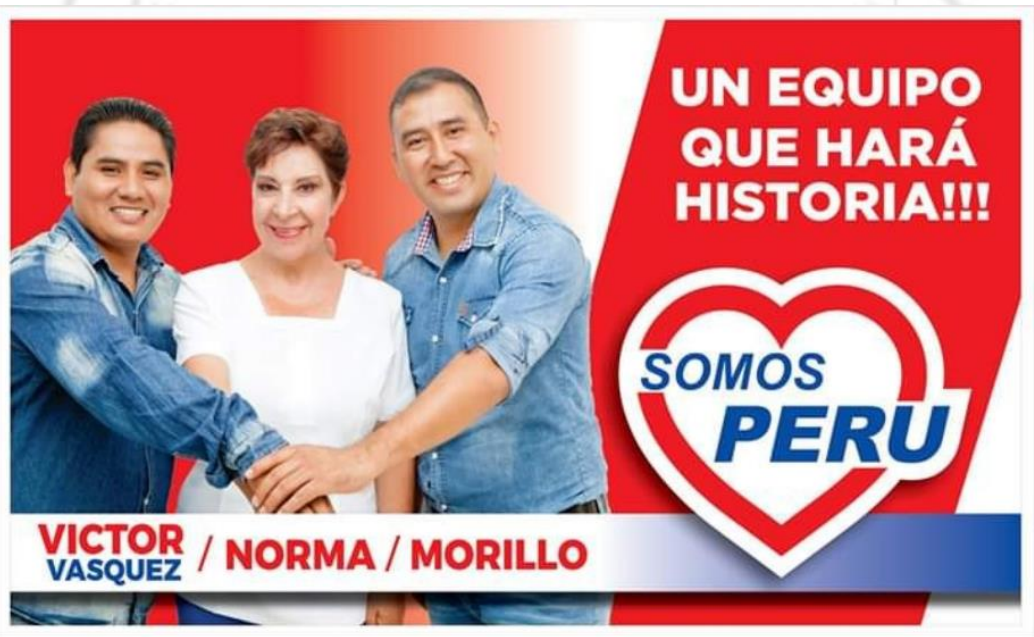


Ilustración 28: Panel - Equipo candidatos región, provincia, distrito Santa

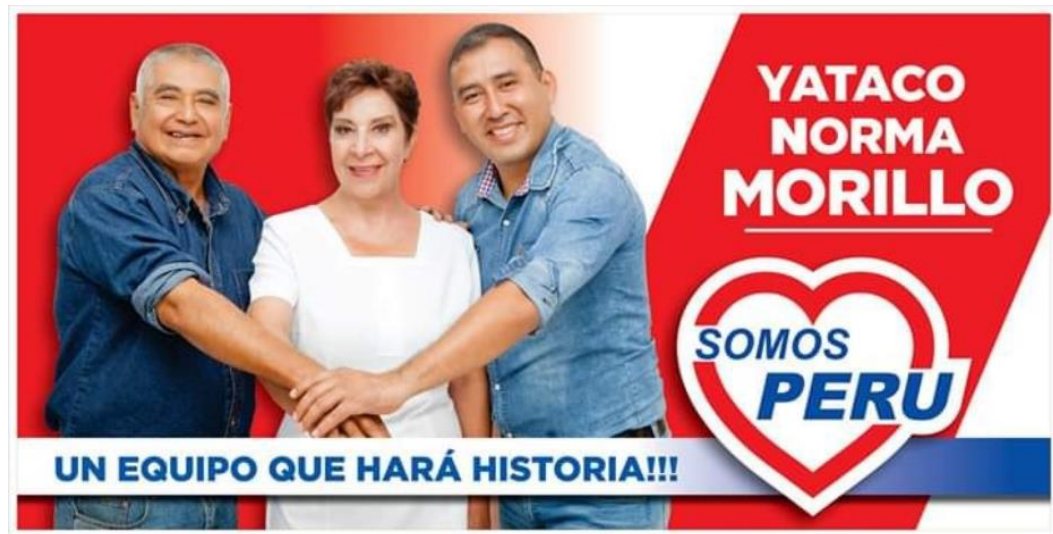

Ilustración 29: Norma móvil, mascota Somos Perú

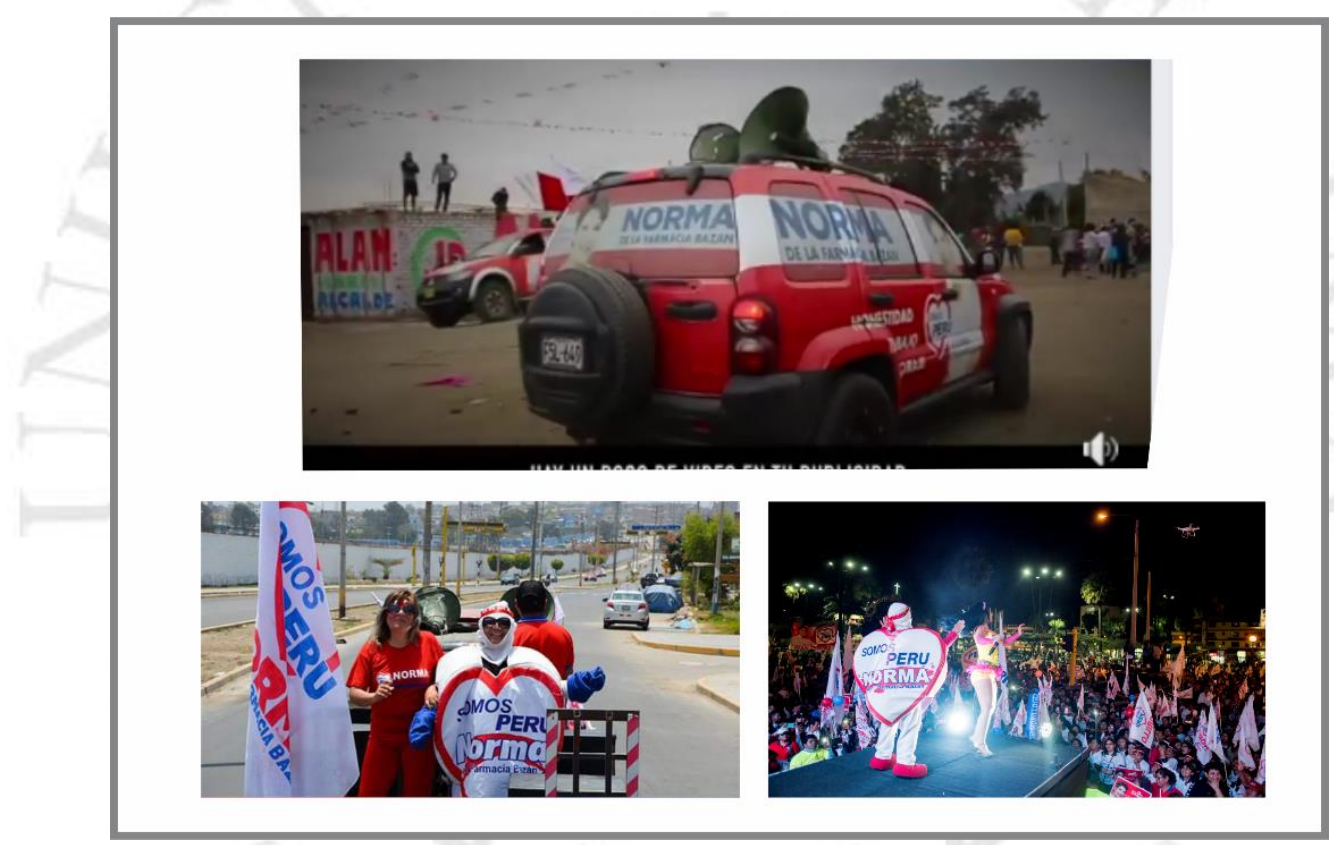

Ilustración 30: Equipo de anfitrionaje
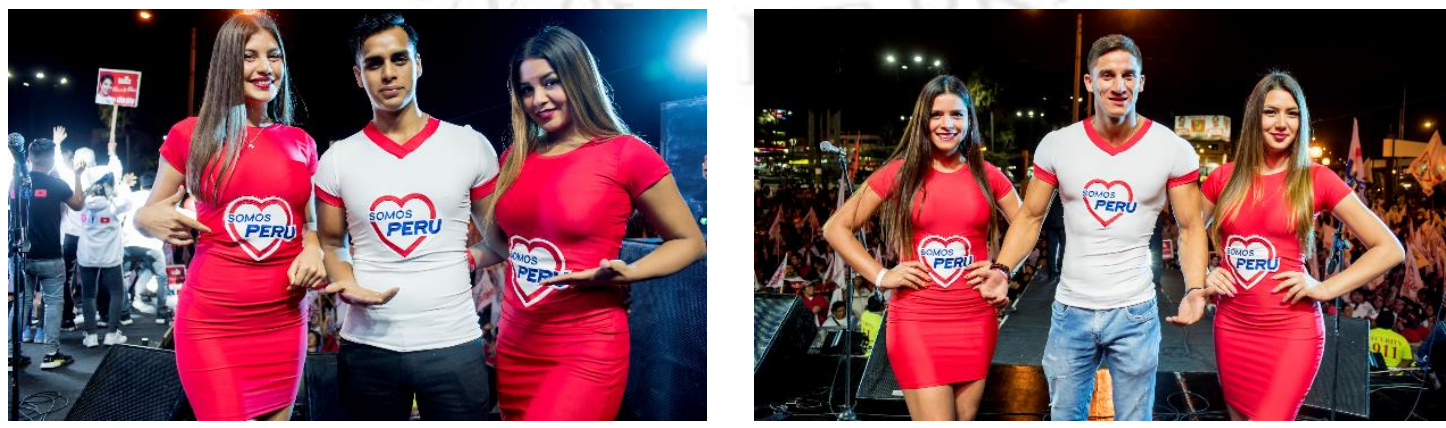


\subsubsection{Audiovisuales}

Adaptaciones musicales de ritmos populares y de fuerte penetración en todos los segmentos de la población electoral, fueron elaborados en tres jingles. Spots de radio protagonizados por jóvenes buscando generar conciencia, así como spots reflexivos sobre la problemática real, se difundieron en radios con cobertura en toda la provincia y en mercados populares.

En la televisión, se trató de comunicar las ideas de la candidata de forma distinta, que permita preservarla y diferenciarla de los competidores, transmitiendo de manera efectiva el mensaje generador de conciencia en las grandes masas electorales de que existe una esperanza con oportunidades y calidad de vida.

Los mítines, presentaciones y entrevistas en diferentes medios masivos, en los que se difundía el plan de gobierno y eran transmitidos en vivo en el Fan Page Oficial de la candidata, fueron reforzados por microprogramas producidos para que sean difundidos en canales de TV, redes sociales y plataformas digitales.

\subsubsection{Jingles}

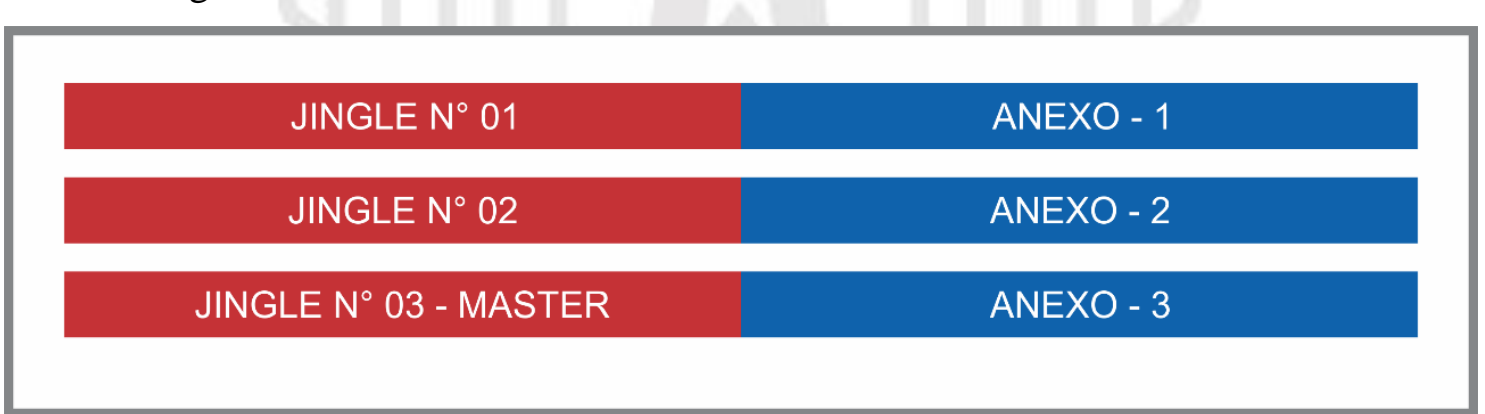

\subsubsection{Radio}

\section{SPOT JÓVENES}

SPOT TESTIMONIO

SPOT NORMA
ANEXO - 4

ANEXO - 5 


\subsubsection{Televisión}

\begin{tabular}{|cc|}
\hline SPOT TÁCTICO - CORRUPCIÓN & ANEXO - 7 \\
\hline SPOT TÁCTICO - SALUD & ANEXO - 8 \\
\hline SPOT TÁCTICO - TRABAJO & ANEXO - 9 \\
\hline SPOT MASTER - NORMA & ANEXO - 10 \\
\hline
\end{tabular}

2.6.4.4. Video

\section{SALUDO NAVIDEÑO}

SALUDO $111^{\circ}$ ANIVERSARIO CHIMBOTE

SALUDO DÍA DEL TRABAJO

SALUDO DÍA DE LA MADRE

SALUDO ANIVERSARIO NCH.

SALUDO $111^{\circ}$ ANIVERSARIO CHIMBOTE

SALUDO SAN PEDRITO

SALUDO FIESTAS PATRIAS

VIDEO MUSICAL "A MI CHIMBOTE"

VIDEO MUSICAL “TE VOTE”

MICROPROGRAMA ANDRÉS DÍAZ

MICROPROGRAMA CHRISTIAM ESTRADA

MICROPROGRAMA JAIME CARRIÓN

MICROPROGRAMA MIRKALA RAMOS

MICROPROGRAMA RODOLFO WATANAVE

MICROPROGRAMA MARJORIE BEJAR
ANEXO - 11

ANEXO - 12

ANEXO - 13

ANEXO - 14

ANEXO - 15

ANEXO - 16

ANEXO - 17

ANEXO - 18

ANEXO - 19

ANEXO - 20

ANEXO - 21

ANEXO - 22

ANEXO - 23

ANEXO - 24

ANEXO - 25

ANEXO - 26 
2.6.5. Eventos y participación en la comunidad

Fueron espacios que se planificaron para generar el acercamiento al pueblo y su problemática de fondo, promoviendo la participación e interacción entre la candidata y los electores, de tal manera que los mensajes y contenidos de comunicación sean consensuados entre sí y en el mejor de los casos interiorizados por los electores.

Ilustración 31: Inauguración de bases políticas
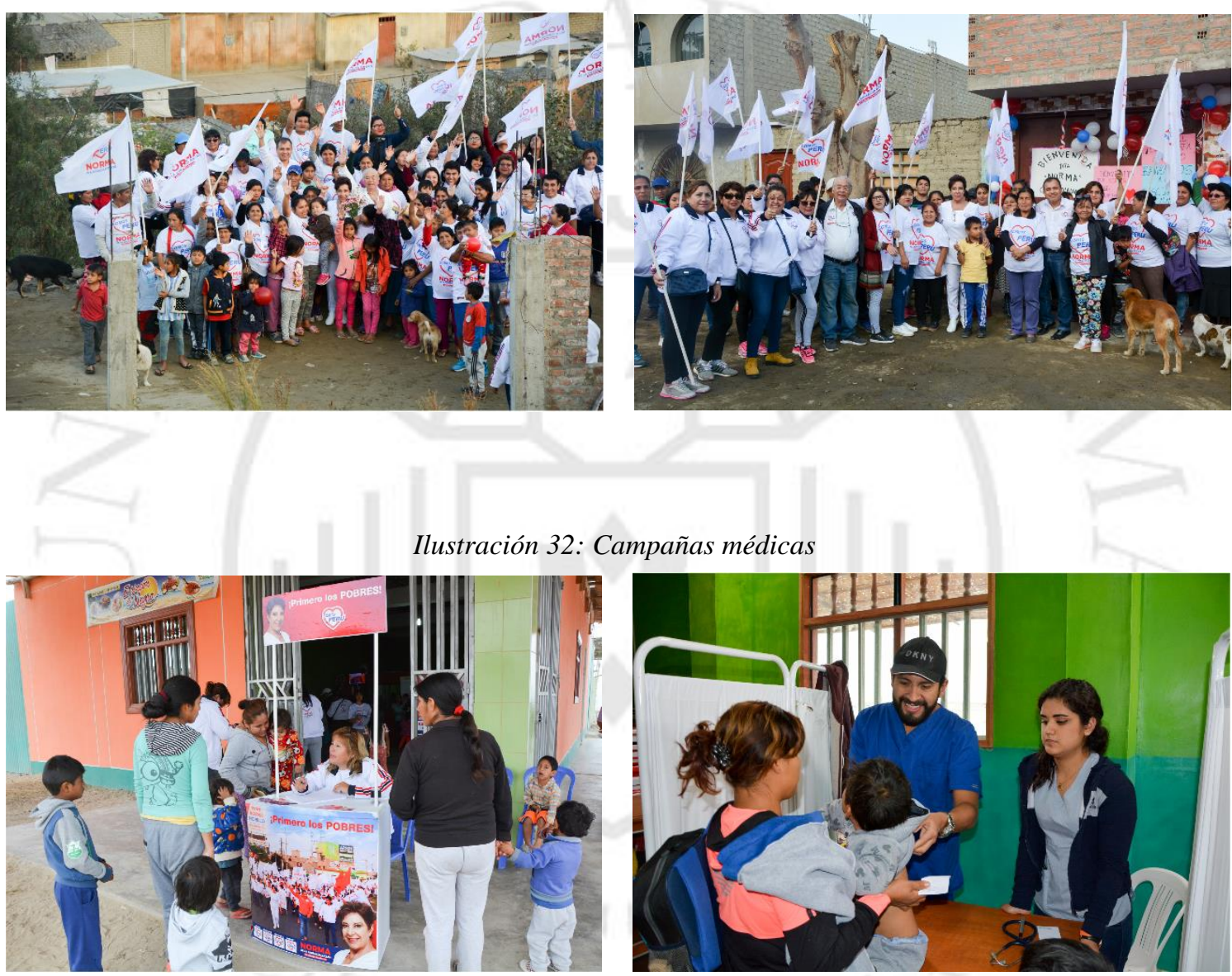

Ilustración 33: Caminatas
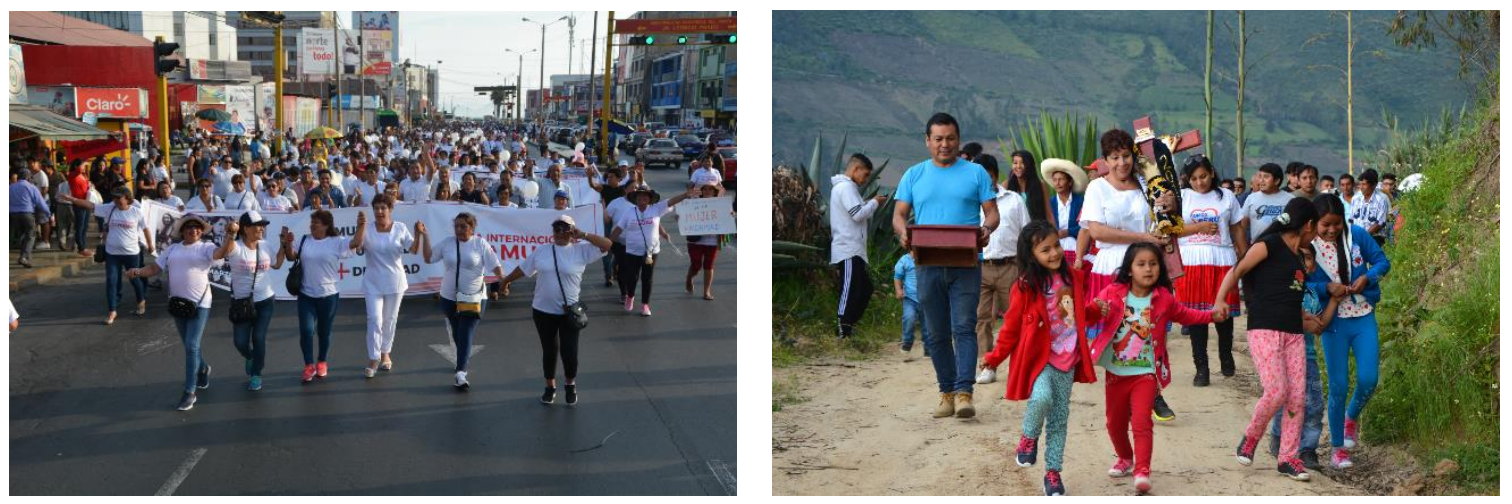
Ilustración 34: Caravanas
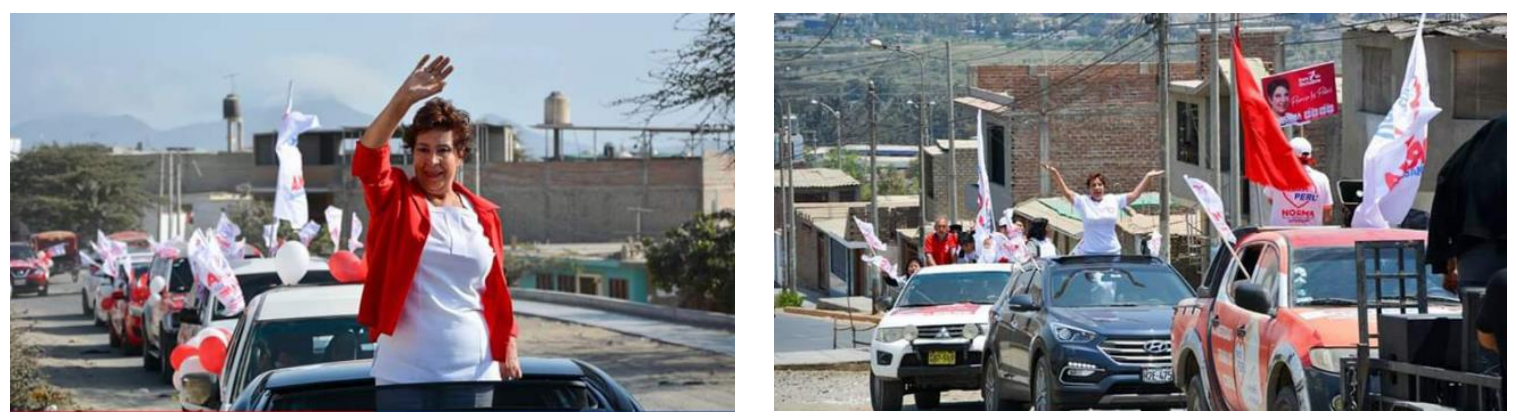

Ilustración 35: Cierre de campaña
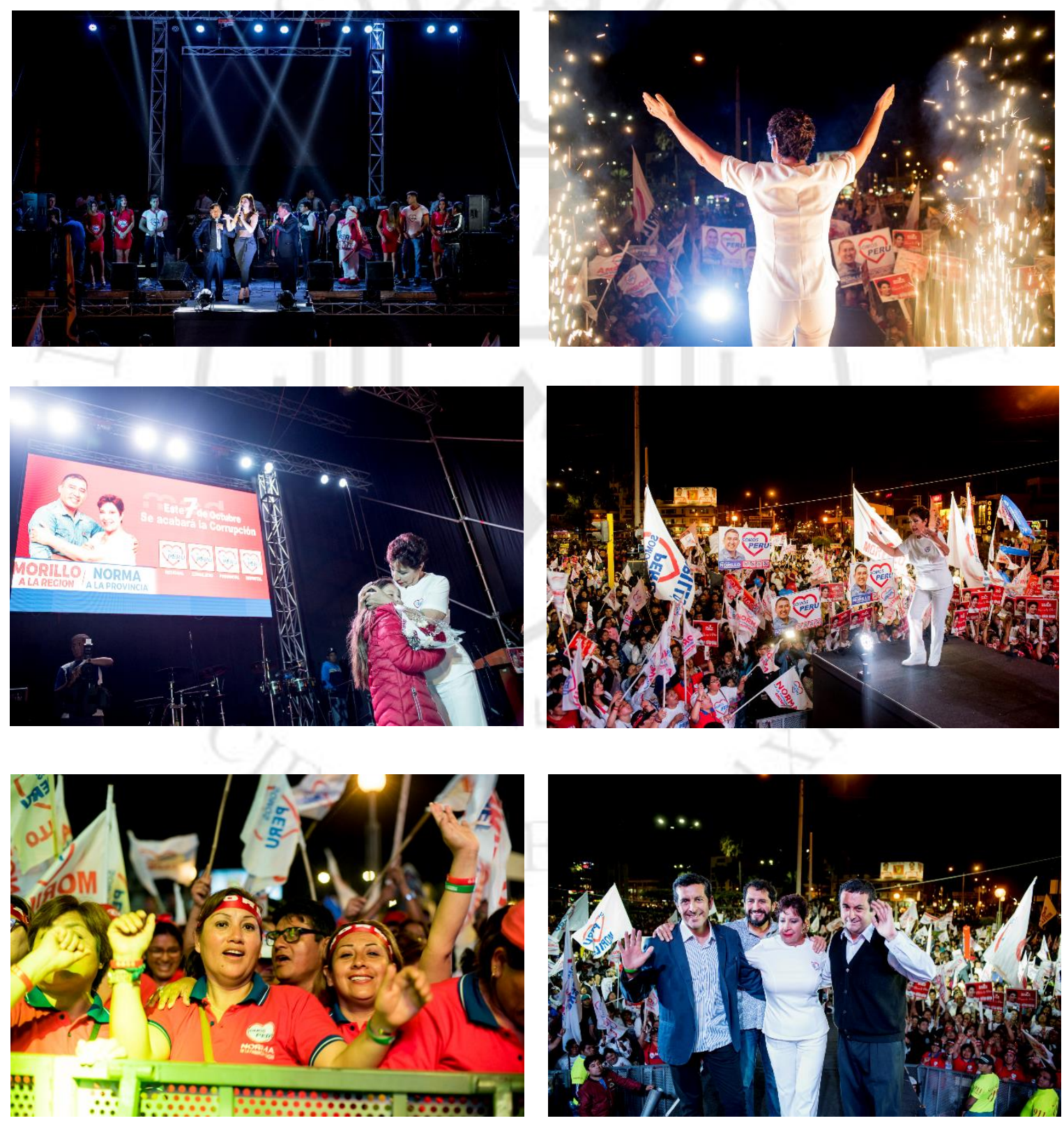


\subsubsection{Cronograma de actividades}

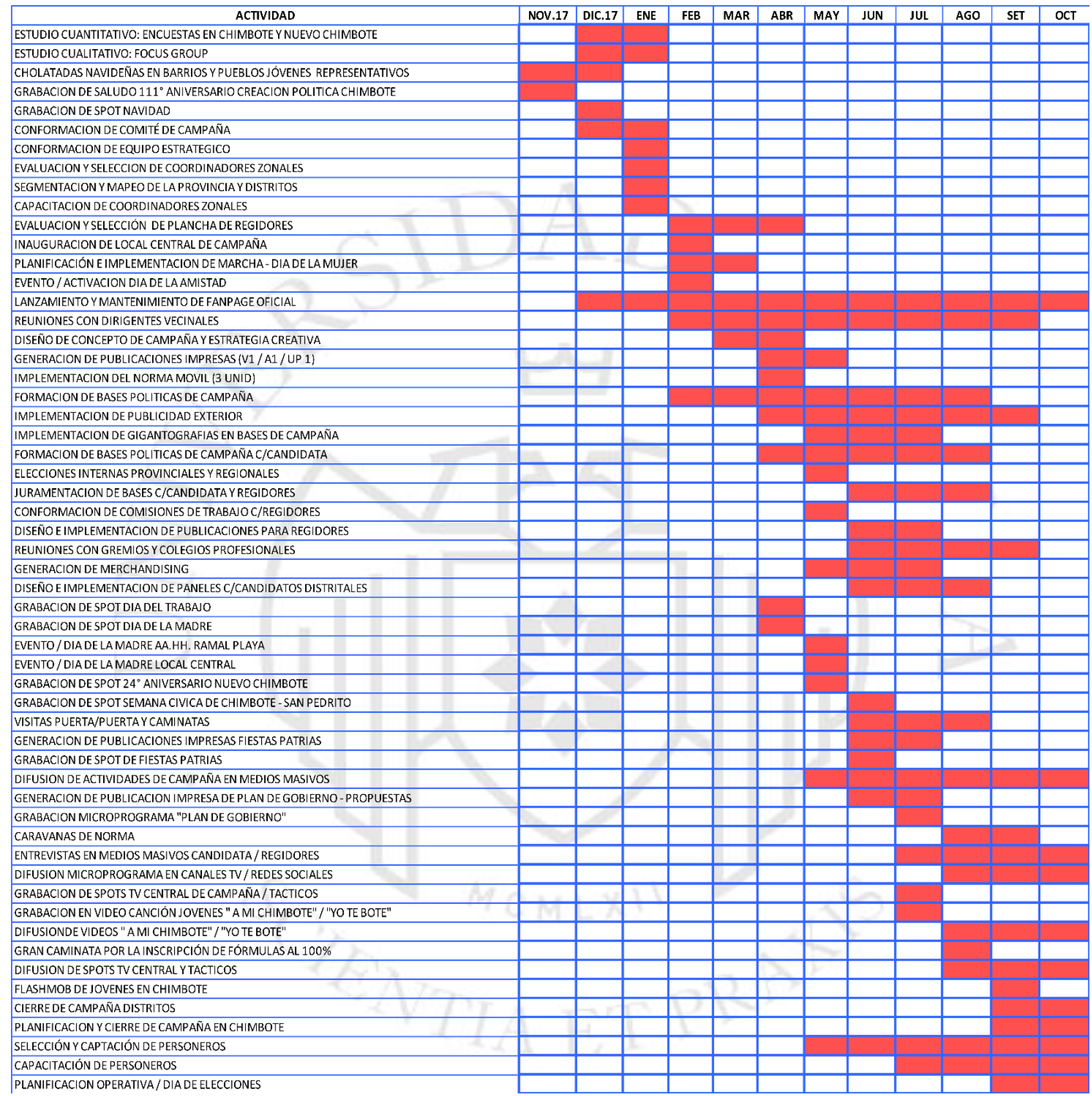




\section{SUSTENTACIÓN}

Una campaña electoral constituye, en esencia, una actividad de comunicación orientada a construir mayorías electorales que le permita al candidato que la lidera, acceder, a una posición de representación pública. En la actualidad, las campañas electorales representan procesos de investigación, de comunicación, de proselitismo, de organización, de movilización, de defensa de cada uno de los votos, que despliegan candidatos, equipos de campaña y simpatizantes, con el objetivo de ganar la elección. En las campañas, las estrategias de comunicación cumplen un papel fundamental y decisivo, a tal punto que pueden determinar el éxito o el fracaso de una contienda electoral, pues lograr una verdadera conexión emocional y un efecto persuasivo en los electores no es una tarea fácil.

Una estrategia de comunicación debe ser formulada con anticipación a su ejecución e implementación, con un objetivo determinado el cual se desea alcanzar, debe estar dirigida hacia un público específico, de tal forma que genere un impacto en el comportamiento o conducta del elector, contrarrestar a los grupos o candidatos opositores $\mathrm{y}$, principalmente, que produzca sentimientos y emociones en la gente para finalmente, lograr el voto esperado.

\subsection{El marketing político y la democracia}

De acuerdo a Núñez (2002):

Existe una percepción errónea y con facilidad suele confundirse el marketing político con el marketing comercial, en el cual el objetivo es adecuar la oferta con la demanda; lo cual equivale a expresar lo que se quiere que se diga y hacer lo que se quiere que se haga. Esto produce desconfianza en el quehacer del marketing político, restándole importancia y significado al punto de vista social de su quehacer.

En política, el objetivo es lograr que el público cambie su percepción respecto a una propuesta, organización política o candidato. Se persigue modificar como los electores enfocan los asuntos que conciernen a la sociedad, un distrito, una provincia 
o una región. El marketing político, no se limita al tema electoral, pues también encontramos el marketing gubernamental y el marketing de oposición, lo que evidencia su implicancia y su relación con la democracia.

De ese modo se "desarrollan acciones y herramientas para mejorar la calidad de la representación política y la transparencia en la administración del Estado. Promueve que los ciudadanos incidan en la definición de políticas públicas y contribuye al fortalecimiento de las instituciones de la democracia. Sus focos de acción son los partidos políticos, la transparencia de las elecciones - incluido el financiamiento de los partidos y las campañas electorales" (p.110).

En el proceso electoral, el marketing político, busca principalmente eliminar todos aquellos obstáculos que puedan surgir y que interfieran la comunicación entre el candidato y los ciudadanos; busca el entorno ideal para que las ideas y propuestas del candidato sean expuestas, las mismas que en su esencia provienen del candidato o del partido político. Por tanto, el papel del marketing político adquiere una gran importancia en la medida que logra despertar el interés de la población en el proceso mismo y en las alternativas y propuestas de los candidatos que participen en la contienda electoral; en otras palabras, permite que se reafirme la confianza en el sistema democrático, fortaleciéndola.

Según Quesada (2005):

Se define como Marketing Político a aquella disciplina que une todas las actividades dentro un solo proceso que vivifica políticamente a un movimiento o partido que aspira a ser Gobierno. Es la forma de construir política para acercar más a los ciudadanos, involucrándolos como partícipes en una gestión, a la vez facilita que la noción de las decisiones diferentes de la política se conozca por los vecinos en forma directa y clara. En período electoral, el Marketing político fortalece la democracia, aunque va más allá de dicha coyuntura.

"Se trata de una especialidad del marketing cuyo objetivo final es vender una ideología, un programa y un candidato. El concepto de marketing aplicado a una 
actividad política es sobre todo un magnífico sistema para influir en la opinión de los votantes, para posicionar al partido o al candidato, respecto a sus competidores" ( $\mathrm{p}$. $10)$.

La visión del Marketing es mucho más amplia, por lo que reducirla a un periodo electoral es una limitante que desaprovecha oportunidades de ser una valiosa herramienta para funcionarios públicos o en ejercicio. El marketing político es portador de una comunicación pensada, en ese sentido, es una señal identitaria de los procesos comunicacionales directos con sus ciudadanos.

Para Olivera (2016):

La utilidad del marketing político se orienta a fondo en el conocimiento de los públicos, se complementa con la realización de estudios de mercadeo, por tanto, emplean técnicas para el recojo, el procesamiento y el análisis de informaciones con el empleo de métodos tanto cualitativos como cuantitativos. Antes todo se basaba en las nociones e impresiones que tenía el promotor, lo cual no era serio ni consistente, una cosa es una simple percepción y otra una medición rigurosa del público, del mercado, de los clientes, de los seguidores.

"La propia tradición política nos recuerda que conocer al electorado y generar empatía en la comunicación son condiciones claves para un buen político. En un inicio, el grupo político seleccionaba entre sus miembros a quien podía ser mejor acogido por el público Hoy, muchos consideran que el producto (candidato) lo es todo para ganar las elecciones. Así, como el fin no es gobernar sino ganar las elecciones, se promoverá un producto que gane pero no se sabe qué ocurrirá después" (p. 4).

En la medida que se complejizan las sociedades, así como los negocios ocurre también lo mismo con la gestión de las herramientas para recopilar datos, por eso se han constituido hoy las direcciones de marketing y con posterioridad las agencias especializadas que describen detalladamente qué y cómo ocurren las cosas en el mundo 
3.2. Estrategia de comunicación en campaña

Para Schröder (2004):

La noción de estrategia resulta proveniente del ámbito militar; se trata de un vocablo derivado del griego. Las estratégicas consideraciones siempre se han hecho necesarias para conducir contingentes humanos grandes, ello demanda de alguna orientación. Su utilización era común cuando se suscitaban las guerras, poco a poco fueron virando con el tiempo hacia los complejos procesos de la industrialización, de ese modo ya no tenía solamente un exclusivo significado militar. Actualmente, se emplea por altos ejecutivos y asesores para la dirección de enormes contingentes de trabajadores en el ámbito económico, surgiendo así las estrategias empresariales para la planificada conducción de individuos en una empresa.

"Que el concepto se derive del griego no sugiere que antes no existieran estrategias. Toda reflexión y planificación orientada hacia un objetivo y ejecutada de manera enfática es una planificación estratégica. Una de las obras fundamentales sobre planificación estratégica, El arte de la guerra de Sun Tzu, que surgió en China hace más de 2000 años, sigue siendo, quizás, el libro más influyente sobre estrategia: es una lectura estándar para los políticos y ejecutivos de Asia” (p. 14).

El concepto fue abarcando poco a poco sectores muy dinámicos y amplios en la sociedad; como es natural también se aproximó al campo político, ocurre que la gestión de los políticos en cuanto a su imagen, su aceptación, sus alianzas, deben calcularse en base a objetivos en función a las grandes masas de la sociedad, incluyendo a los militantes de organizaciones o partidos. Todas las reflexiones y planificaciones se orientan hacia objetivos y se ejecutan de enfático modo. La planificación estratégica surge no solo para direccionar el trabajo en elecciones y luego de estos, sino para evitar desgastes, prevenir errores, etc.

Por su parte Crespo y Moreno (2015):

Cuando se trata de campañas electorales son tres fundamentales factores que deben tenerse en cuenta: La activación, el refuerzo y la conversión. Respecto a la activación 
se tiene como directa referencia al efecto de hacer que quienes permanezcan indecisos terminen sufragando en favor del partido que percibían como muy cercano. En el caso del refuerzo se orienta a que quienes fueron entrevistados decidan su voto por la opción política a la cual manifestaron con anterioridad que si votarían. El tercer factor denominado conversión se refiere a la repercusión de una campaña cuando los votantes terminan decidiéndose por un diferente partido del que antes tenía su preferencia, o cuando en un principio se trataba de un indeciso votante, el cual terminaba decidiendo su voto por algún diferente partido de alguno al que más cercano se sentía.

"El concepto de percepción selectiva incluye los procesos de exposición, comprensión y retención selectivas, que son los mecanismos que, según Lazarsfeld et al. (1944), los individuos ponían en marcha para enfrentarse a la creciente cantidad de propaganda política disponible a medida que avanzaba la campaña. De ahí que la principal función de la propaganda fuera la de reforzar el apoyo a los partidos, ayudándoles a mantener a sus afiliados y simpatizantes" (p. 8).

Cuantitativamente, de acuerdo a sus resultados, el más importante efecto era el de reforzar la intención de sufragio que tenía ya el elector previo a la campaña, en concreto, el equivalente al refuerzo de las latentes inclinaciones políticas de los electores. Fundamentalmente, la campaña reforzaba las inclinaciones propias.

\subsection{Modelo de contingencia estratégica}

Según Calderón (2011):

Lo contingencial implica asumir una perspectiva de lo azaroso o casual, es decir, de aquello que llega en forma intempestiva o que no se esperaba, tratar con posibilidades implica estar atentos y al mismo tiempo pensar como un Gobierno abierto, ya existe a modo de un consenso razonable respecto a la doctrina incipiente de que nos referimos en esencia a una permanente evolución de los sistemas democráticos de valores y convivencia que se basan en el engranaje de mecanismos orientados a la transparencia gubernamental así como de permanentes espacios de 
participación y colaboración de los ciudadanos cuya extensión va más lejos que del ejercicio de derecho a sufragar después de cuatro años.

"Un Gobierno Abierto es aquel que entabla una constante conversación con los ciudadanos con el fin de oír lo que ellos dicen y solicitan, que toma decisiones basadas en sus necesidades y preferencias, que facilita la colaboración de los ciudadanos y funcionarios en el desarrollo de los servicios que presta y que comunica todo lo que decide y hace de forma abierta y transparente" (p. 6).

Se trata de comprender el actual entorno en el que se salta desde un modelo viejo de democracia representativa hacia un modelo más democrático, de tipo abierta y conversacional, en el que se aproveche las posibilidades que son proporcionadas desde las TIC a la ciudadanía por participar en diferentes procesos que involucra la toma de decisiones de tipo gubernamental, inclusive que trasciende el ejercicio mencionado como derecho de participación o de sufragio en tradicionales organizaciones sociales.

\subsection{Los medios en campaña}

Para Castells (2009):

La sociedad actual se caracteriza por ser una en la que se despliegan las redes, su presencia es indiscutible en todo acontecimiento en conformidad a las exigencias comunicacionales contemporáneas, básicamente una en particular es la influencia tecnológica de las redes sociales. Las informaciones son, muchas veces, productos como otros, que se compran y se venden. Los medios son también empresas con intereses grandes en determinado sector de las actividades económicas actuales y del futuro en lo que se refiere a las comunicaciones. Los medios son portadores de mensajes de tipo comercial, implícitos o explícitos, hasta el punto que publicidad e información se confunden.

"La capacidad de las redes para introducir nuevos actores y nuevos contenidos en el proceso de organización social, con relativa independencia de los centros de poder, 
se incrementó a lo largo del tiempo con el cambio tecnológico y más concretamente con la evolución de las tecnologías de la comunicación” (p. 48).

Por mucho tiempo, diversas personas han vivido con perturbaciones por el mito de la libertad de expresión y la libertad de información, como si únicamente los medios de comunicación de masas fueran pilares de la democracia inclusive del sufragio universal. Se ha logrado presentar de la sociedad un paisaje ideal en el que se cree que los medios informan con responsabilidad, con objetividad, con educación y distracción. Toda información es solo un producto más, cuya utilidad implica el ejercicio y fortalecimiento del poder, el político sobre todo 


\section{LOGROS Y RESULTADOS}

En la presente campaña se definieron objetivos claros: el posicionamiento de la candidata, la difusión de un de plan gobierno visionario y la conformación de una de una estructura política sólida en la provincia. Los resultados alcanzados en sus tres niveles permitieron lograr un caudal de votos bastante significativos, aunque insuficientes para obtener la representación municipal, fueron de gran importancia para dejar el camino habilitado a la candidata para desempeñar un papel relevante y una posición a tener en cuenta respecto al desempeño de gobierno en los siguientes 4 años de gestión municipal.

\subsection{A nivel cuantitativo}

El trabajo operativo del equipo de campaña se concentró básicamente en los distritos de mayor población; siendo éstos Chimbote y Nuevo Chimbote en orden de importancia, realizando para ello "bases de apoyo" conformadas cada una de ellas por un Comité de base de 7 integrantes, más simpatizantes respectivos, los cuales eran alrededor de 15 a 20 personas que se adherían a la base de apoyo. Esto no quiere decir que los distritos pertenecientes a los valles hayan sido relegados, muy por el contrario, tuvieron otra forma de tratamiento debido a su particularidad geográfica y distribución poblacional.

Tabla 01: Bases de apoyo aperturadas

\begin{tabular}{|l|r|r|r|r|}
\hline Bases de apoyo & Frecuencia & Porcentaje & \multicolumn{1}{c|}{$\begin{array}{c}\text { Porcentaje } \\
\text { válido }\end{array}$} & $\begin{array}{c}\text { Porcentaje } \\
\text { acumulado }\end{array}$ \\
\hline Chimbote & 451 & 87,4 & 87,4 & 87,4 \\
Nuevo Chimbote & 65 & 12,6 & 12,6 & 100,0 \\
Total & 516 & 100,0 & 100,0 & \\
\hline
\end{tabular}

FUENTE: Comité de Campaña Provincial - Somos Perú 
Gráfico 01: Bases de apoyo aperturadas

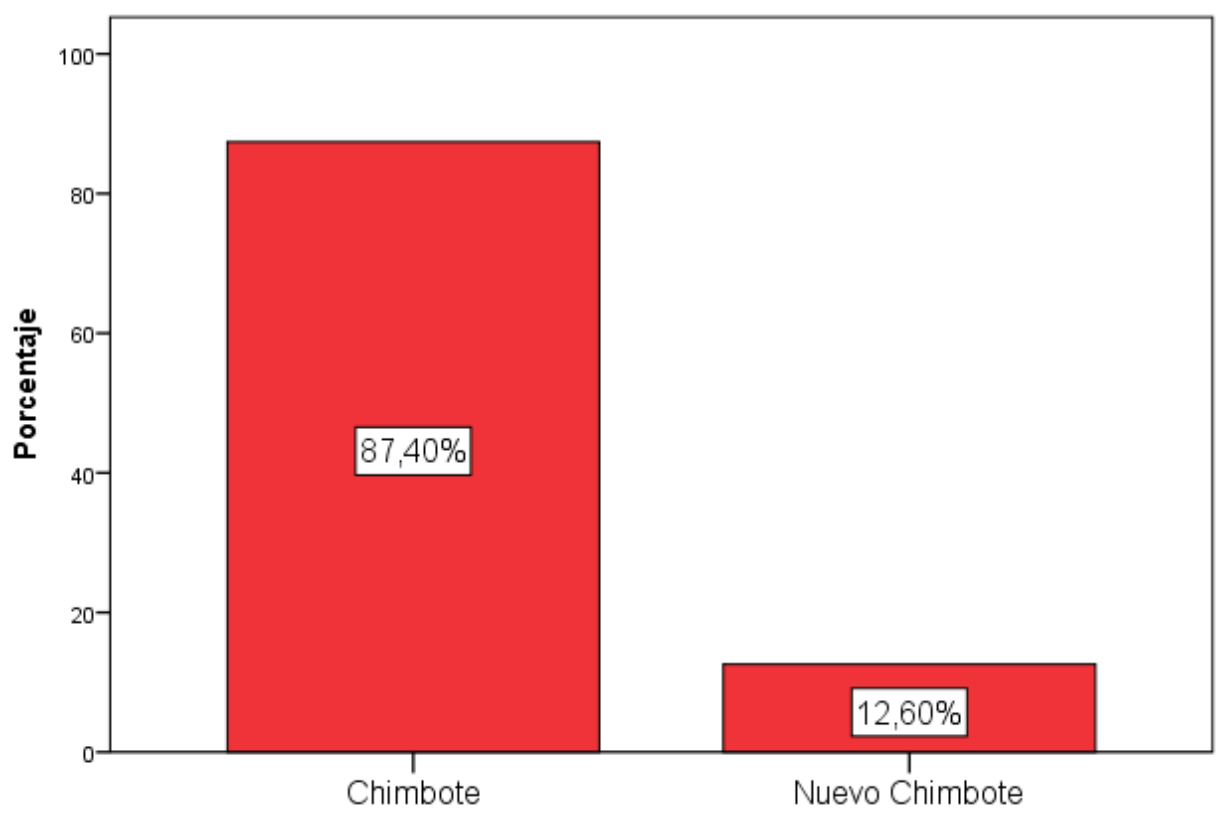

En cada juramentación, se reunía no solamente a los simpatizantes de las bases que juramentaban, sino también a la gente de a pie que se sumaba a escuchar el mensaje de la candidata. Tal vez, no con una audiencia de cientos o miles de personas que normalmente asiste a un mitin, estas juramentaciones diarias eran consideradas como tal, pero en menor magnitud. Aproximadamente 48 mítines en Chimbote, 3 de gran escala (La Primavera, San Pedro, San Juan) 6 en Nuevo Chimbote (San Luis, 217 Hectáreas, Tierra Prometida, Laderas del Sur, 308 hectáreas) y 8 en distritos aledaños; es necesario precisar que, los mítines de cierre de campaña no están contemplados, los cuales fueron: Coishco, Samanco, Nepeña, Moro, Cáceres del Perú, Santa y Chimbote.

Tabla 02: Mítines de campaña realizadas

\begin{tabular}{|l|r|r|r|r|}
\hline Mítines & Frecuencia & Porcentaje & $\begin{array}{c}\text { Porcentaje } \\
\text { válido }\end{array}$ & $\begin{array}{c}\text { Porcentaje } \\
\text { acumulado }\end{array}$ \\
\hline Chimbote & 48 & 77,4 & 77,4 & 77,4 \\
Nuevo Chimbote & 6 & 9,7 & 9,7 & 87,1 \\
Distritos aledaños & 8 & 12,9 & 12,9 & 100,0 \\
Total & 62 & 100,0 & 100,0 & \\
\hline
\end{tabular}

FUENTE: Comité de Campaña Provincial - Somos Perú 


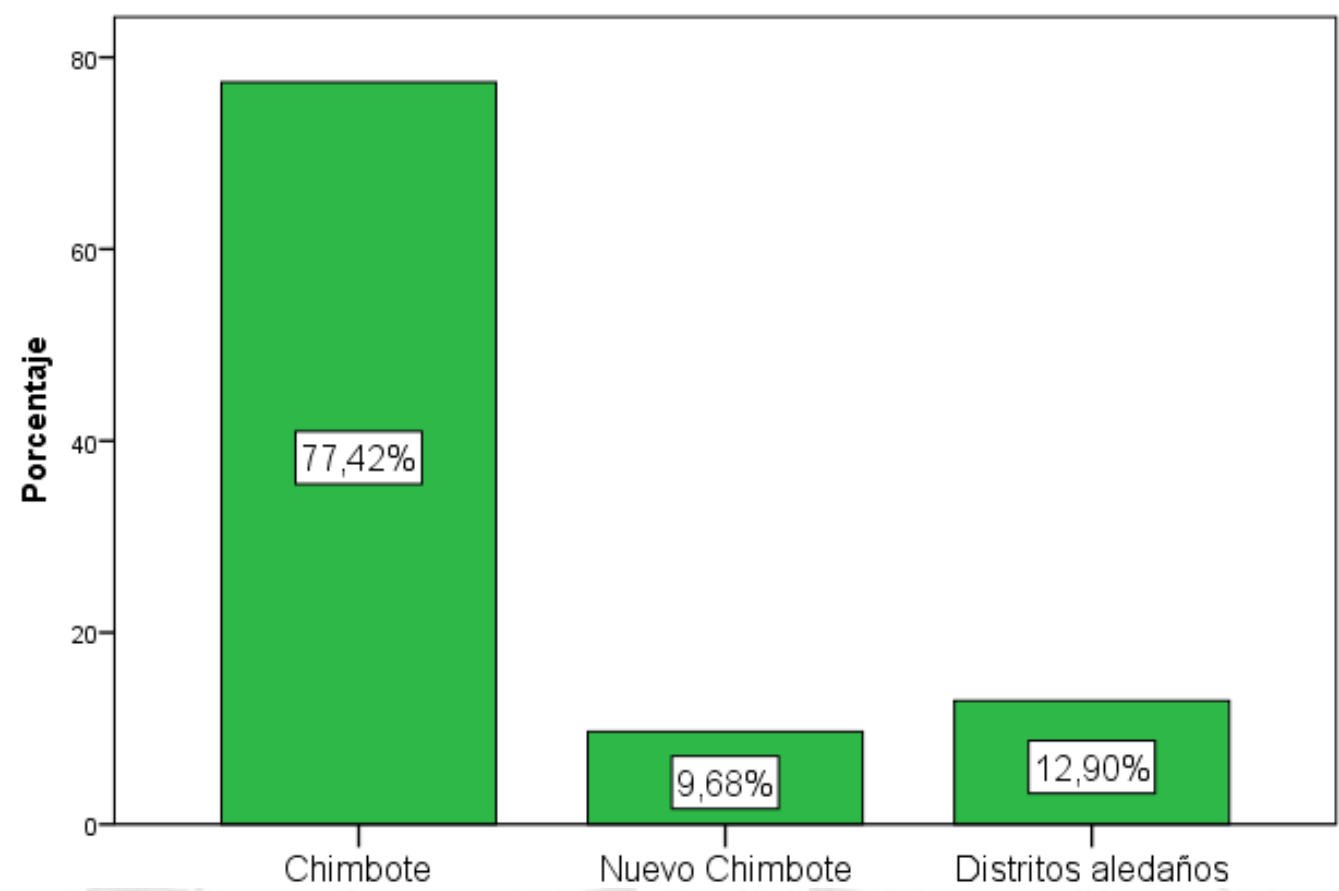

El respaldo de la gente era cada vez mayor, a cada barrio que se visitaba se apreciaba el afecto y la conexión de la candidata con la ciudadanía. Como mencionamos líneas arriba, los mítines de menor escala reunían un promedio de 80 - 90 personas. Los de gran escala, 800 a 1000 personas, mientras que aquellos realizados en los nuevos pueblos del sur, congregaban alrededor de 400 - 500 personas. Cabe añadir que en cuanto a caminatas, hubo 02 en forma masiva. La primera el 8 de marzo, en Chimbote y en conmemoración al día de La Mujer; la segunda, en Nuevo Chimbote, celebrando la publicación de la resolución de inscripción definitiva ante el JNE. Se realizaron 03 visita a la semana por espacio de 3 meses, equivalente a 36 caminatas.

Tabla 03: Concurrencia en mítines

\begin{tabular}{|l|r|r|r|r|}
\hline & Frecuencia & Porcentaje & \multicolumn{1}{c|}{$\begin{array}{c}\text { Porcentaje } \\
\text { válido }\end{array}$} & $\begin{array}{c}\text { Porcentaje } \\
\text { acumulado }\end{array}$ \\
\hline $\begin{array}{l}\text { Mítines de menor } \\
\text { escala }\end{array}$ & 85 & 5,9 & 5,9 & 5,9 \\
Mítines de gran & 900 & 62,7 & 62,7 & 68,6 \\
escala & 450 & 31,4 & 31,4 & 100,0 \\
En pueblos del sur & 1435 & 100,0 & 100,0 & \\
Total & & & \\
\hline
\end{tabular}

FUENTE: Comité de Campaña Provincial - Somos Perú 


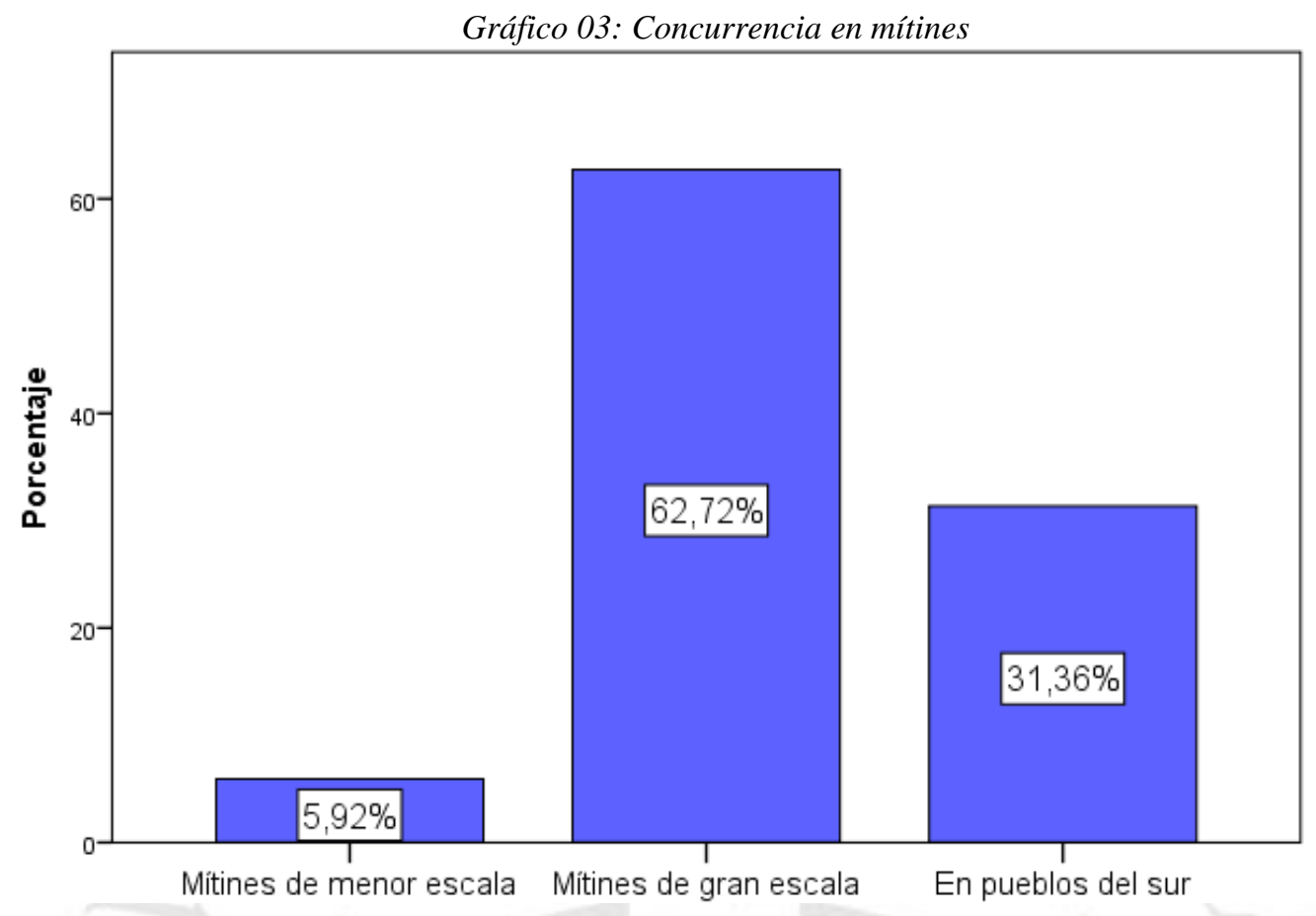

En Chimbote y Nuevo Chimbote se ubicaron 11 paneles publicitarios en vía pública, 30 gigantografías $5 \times 3 \mathrm{~m}$. en avenidas principales, 20 gigantografías $5 \times 3 \mathrm{~m}$. en zonas estratégicas, 500 banners 2 x $1 \mathrm{~m}$. en bases políticas de apoyo y 150 pintas en paredes de avenidas y zonas estratégicas.

Tabla 04: Número de banners colocados en avenidas en Chimbote y Nuevo Chimbote

\begin{tabular}{|c|c|c|c|c|}
\hline Banners & Frecuencia & Porcentaje & $\begin{array}{l}\text { Porcentaje } \\
\text { válido }\end{array}$ & $\begin{array}{l}\text { Porcentaje } \\
\text { acumulado }\end{array}$ \\
\hline Paneles publicitarios & 11 & 1,5 & 1,5 & 1,5 \\
\hline $\begin{array}{l}\text { Gigantografías } 5 \text { × } 3 \mathrm{~m} \text {. en } \\
\text { avenidas }\end{array}$ & 30 & 4,2 & 4,2 & 5,8 \\
\hline $\begin{array}{l}\text { Gigantografías } 5 \text { × } 3 \text { m. en } \\
\text { zonas estratégicas }\end{array}$ & 20 & 2,8 & 2,8 & 8,6 \\
\hline $\begin{array}{l}\text { Banners } 2 \text { x } 1 \mathrm{~m} \text {. en bases } \\
\text { políticas de apoyo }\end{array}$ & 500 & 70,3 & 70,3 & 78,9 \\
\hline $\begin{array}{l}\text { Pintas en paredes de avenidas y } \\
\text { zonas estratégicas }\end{array}$ & 150 & 21,1 & 21,1 & 100,0 \\
\hline
\end{tabular}

FUENTE: Comité de Campaña Provincial - Somos Perú 
Gráfico 04: Número de banners colocados en avenidas en Chimbote y Nuevo Chimbote

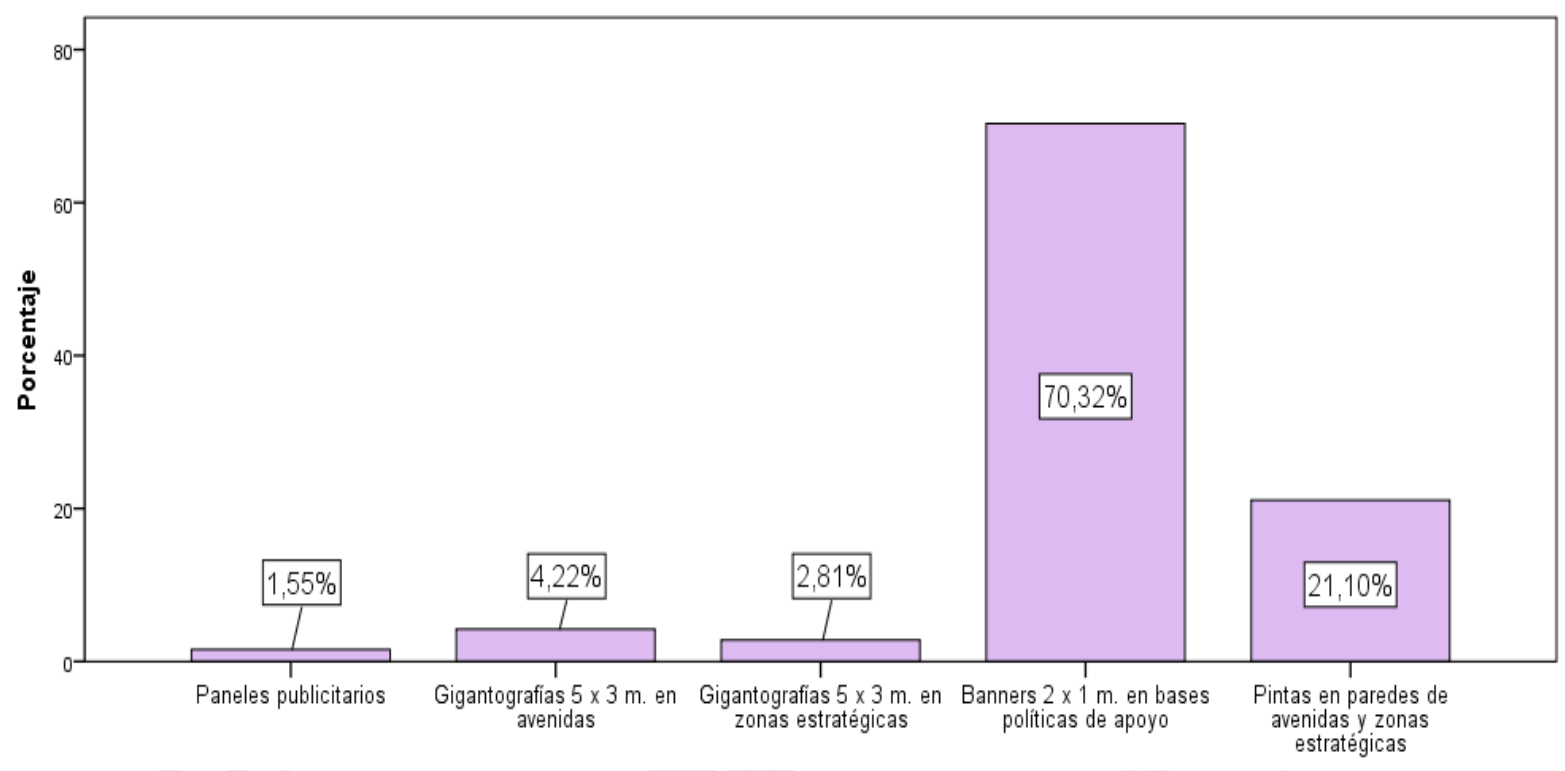

Se distribuyeron 300 millares de volantes con motivos diferentes y 10 millares de afiches.

Tabla 05: Número de afiches y volantes en millares distribuidos

\begin{tabular}{|l|r|r|r|r|}
\hline Material & Frecuencia & Porcentaje & $\begin{array}{c}\text { Porcentaje } \\
\text { válido }\end{array}$ & $\begin{array}{c}\text { Porcentaje } \\
\text { acumulado }\end{array}$ \\
\hline Volantes & 300 & 96,8 & 96,8 & 96,8 \\
Afiches & 10 & 3,2 & 3,2 & 100,0 \\
Total & 310 & 100,0 & 100,0 & \\
\hline
\end{tabular}

FUENTE: Comité de Campaña Provincial - Somos Perú

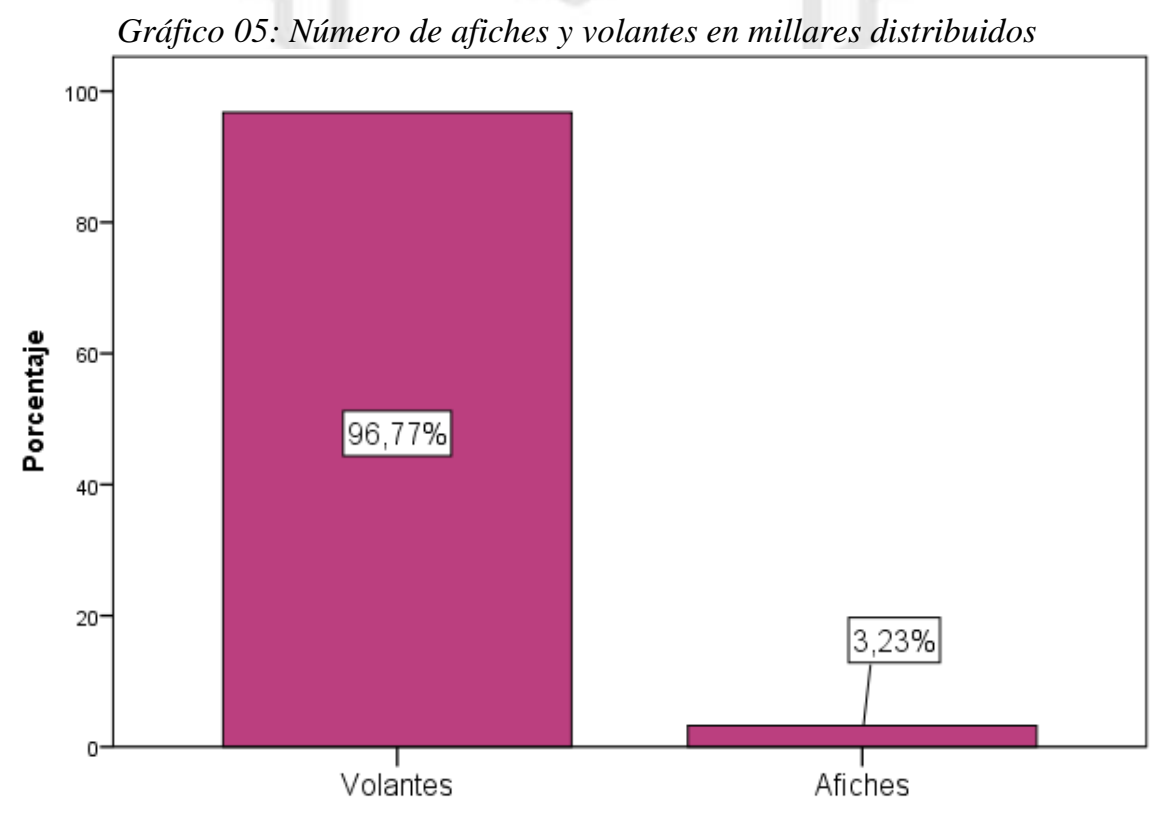


La campaña se planificó orientada a formar una coalición de sectores representativos de la provincia, se designaron responsables para gestionar estas alianzas, además también para coordinar avances distritales.

Tabla 06: Alianzas estratégicas y de apoyo en la localidad

\begin{tabular}{|c|l|l|l|l|}
\hline No & CANDIDATO A REGIDOR & \multicolumn{1}{c|}{ CARGO / ESPECIALIDAD } & \multicolumn{1}{c|}{ COMISIONES } & \multicolumn{1}{c|}{ DISTRITOS } \\
\hline 1 & ANDRES DIAZ & EX DIRECTOR COLEGIO SAN PEDRO & EDUCACION / CULTURA & CHIMBOTE \\
\hline 2 & JAIME CARRION & ALCALDE DE JIMBE & AGRICULTURA / & CACERES DEL PERU \\
\hline 3 & CHRISTIAN ESTRADA & DECANO COLEGIO ABOGADOS DEL SANTA & COLEGIOS PROFESIONALES / TITULAC & MORO / NEPEÑA \\
\hline 4 & CARLOS RAMIREZ & PRESIDENTE MERCADO LA PERLA & COMERCIO & COISHCO \\
\hline 5 & PAULA AMBROSIO & REGIDORA DE NUEVO CHIMBOTE & ASOCIACIONES Y GREMIOS / MUJERES & NUEVO CHIMBOTE \\
\hline 6 & RODOLFO WATANABE & ODONTOLOGO & TRANSPORTE / PERSONEROS & SAMANCO \\
\hline 7 & HERLESS DOMINGUEZ & DOCENTE UNIVERSITARIO & JUVENTUDES & MORO / NEPEÑA \\
\hline 8 & DANIEL MOSCOL ALDANA & DIRECTOR ESCUELA DERECHO ULADECH & EMPRESARIAL / JUVENTUDES & SANTA \\
\hline 9 & MIRKALA RAMOS & ECONOMISTA & JUVENTUDES / MUJERES & NUEVO CHIMBOTE \\
\hline 10 & SELENE HONORIO & FISIOTERAPEUTA & TERCERA EDAD & COISHCO \\
\hline 11 & MARJORIE BREÑA & ESTUDIANTE ULTIMO CICLO MEDICINA & SALUD & NUEVO CHIMBOTE \\
\hline 12 & COMUNERO 1 & AGRICULTOR & AGRICULTURA/SEGURIDAD & MORO \\
\hline 13 & COMUNERO 2 & AGRICULTOR & AGRICULTURA/SEGURIDAD & MORO \\
\hline
\end{tabular}

FUENTE: Comité de Campaña Provincial - Somos Perú

Se logró conseguir el respaldo de:

- Colegio de Abogados del Santa,

- Colegio de enfermeros,

- colegio de odontólogos.

- $\quad$ Mercado La Perla

- $\quad$ Sindicato de obreros de Sider Perú

- $\quad$ Asociación de canillitas de Chimbote

- $\quad$ Asociaciones de mototaxistas 


\subsection{A nivel cualitativo}

4.2.1. Respecto a capacidades desarrolladas en media training de la candidata

La falta de preparación y desconocimiento en gestión pública fue la primera necesidad que se debió atender. La candidata, no era una figura mediática, estuvo más bien poco acostumbrada a brindar entrevistas o declaraciones a los medios, lo que contribuyó a dificultar la generación y articulación de ideas en el discurso.

A mediados de febrero, iniciamos el media training. Los objetivos trazados y logrados fueron:

- Mejorar la vocalización, pronunciación y entonación

- Interpretar el mensaje de los discursos para generar conexión con los ciudadanos

- Generación y articulación de ideas con coherencia y capacidad de respuesta

- Manejo de contenidos en temas de actualidad y problemática local

\subsubsection{Respecto al plan programático}

El plan de gobierno es un documento que fue elaborado luego de haber conocido la problemática y las necesidades reales de la Provincia del Santa. pensando en el servicio al pueblo con honestidad e incluyéndolo en este proceso de gestión edil.

Uno de los principales puntos del plan es la lucha frontal contra la corrupción, para lo cual se realizará una reingeniería en el aparato administrativo, apuntando a una moralización total en el manejo de la cosa pública administrada por el Gobierno Municipal, en todos sus niveles.

Generación de puestos de trabajo permanente, no se necesitan empleos temporales ya que es más de lo mismo, para ello se dará impulso a las PYMES y al emprendimiento, haciendo realidad el Parque Industrial. El apoyo sincero a la gente del agro, pues el desarrollo tiene que ser equitativo y no concentrarse solo en la ciudad. En nuestra provincia tenemos 2 valles importantes, se potenciará la agricultura a través de 2 
Centros de Acopio, para dar un valor agregado a nuestros productos agrícolas y mejorar la economía de la gente del campo.

Considerando que la Salud es un derecho de todos, se crearán las "Postas del Pueblo", dirigiendo atención de calidad a los que más lo necesiten y permanentemente se realizarán campañas médicas en los diferentes distritos. Se promoverá una Educación con Valores, donde se reforzará el papel de la familia y los padres como pilares principales en la formación de los niños; de igual forma se combatirá los altos índices de analfabetismo principalmente en los valles de la provincia.

\subsubsection{Respecto a valores explotados y percibidos en la candidata}

- La vocación de servicio, desprendimiento y preocupación por el bienestar de los que menos tienen, escuchando las necesidades del ciudadano de a pie y buscando las soluciones a sus problemas cotidianos. Se trató de generar conciencia en el electorado de que existe una esperanza para que aquellas personas que nunca fueron escuchadas, aquellas mayorías postergadas ahora tenían la oportunidad de alcanzar una vida digna y con bienestar para sus familias.

- La honestidad y lucha frontal contra la corrupción. Su identificación con los sectores olvidados y no permitir que les sigan robando, fue un flanco bastante explotado en la campaña. "La corrupción equivale a robar a los pobres" pronunciaba en su discurso... "no más diezmos, no más padrinazgos, no más obras con precios inflados ..."

- Trabajo permanente con disciplina, con lo cual se combatirá el desempleo y parte de la crisis económica local; los tranquilizantes con trabajos temporales llegaban a su fin, la provincia y su gente no estaban para mentiras ni recibir propinas.

\subsubsection{Respecto al ánimo que logró despertar la candidata}

El respaldo del pueblo que recibía la candidata era contundente, en los barrios que visitaba, los mercados, en caminatas o caravanas se sentía que la gente de a pie encontraba la esperanza por la que esperó tanto tiempo. La identificaban como la persona que acabaría con los corruptos y respaldaría a la gente más necesitada. 


\section{LECCIONES APRENDIDAS}

Dirigir la Campaña Política de la candidata Norma Alencastre, para la alcaldía de la Provincia del Santa, nos dejó algunas lecciones que pueden ser consideradas para futuras campañas electorales municipales, regionales o congresales, con el fin de mejorar su planificación e implementación. A continuación, se presentan algunos de estos aspectos a considerar:

5.1. Estudio e investigación de la opinión pública. Conocer el pensamiento de la sociedad constituye una herramienta decisiva en una campaña electoral, no sólo te permitirá concentrar el mensaje del candidato en determinados sectores, sino que evitará caer en aquella tendencia de campaña de hablarles a todos sin distinción. El tiempo de la campaña es corto y pareciera que su transcurrir es más veloz cuando la efervescencia de la competencia electoral es mayor; es en este momento, cuando el conocimiento profundo de los ciudadanos se hace más necesario para la toma de decisiones estratégicas con inmediatez. Claro está, que los estudios de opinión, no sólo te permiten investigar el público objetivo, sino también el posicionamiento del candidato y los competidores, definir los temas de campaña más relevantes para los segmentos a los cuales nos dirigimos, o tal vez determinar distintos escenarios de campaña que podrían presentarse. Esta campaña, estudió en dos momentos al electorado, a fines del año 2017 y en septiembre del 2018; sin embargo, consideramos que, con un mejor seguimiento con sondeos periódicos, la evaluación del desempeño de la misma hubiera sido más exacto. A pesar de que siempre los recursos económicos son escasos, es recomendable medir y monitorear al detalle el impacto de la campaña sobre la intención de voto, preferentemente en la recta final de los últimos 30 días, teniendo en cuenta que el voto en regiones como Áncash es muy golondrino y resulta muy cambiante debido a variables diversas.

Por otro lado, se debería evitar que la publicación de resultados de encuestas, pasen a primer plano en el debate electoral, ya que éste debe centrarse en propuestas, programas y candidatos que interesan a la opinión pública. Aunque no hay duda de que éstas influyan de cierta forma en los electores, ya que modifican su comportamiento electoral, con resultados optimistas o pesimistas, es de vital importancia controlar el 
nervio de la campaña, evaluar estrategias y realizar correcciones inmediatas, pues finalmente, es el día de la elección, el único sondeo electoral válido y definitivo.

5.2. La personificación de las campañas políticas. Los candidatos o personas representativas han ganado espacio frente a los partidos políticos que se han ido debilitando a través del tiempo, estos han perdido lealtad e identificación con la ciudadanía.

El candidato, es en la actualidad un factor clave en la determinación del voto, genera su propia marca la que muchas veces genera más identificación que el propio partido. Los atributos y cualidades del candidato, tanto lo qué es o mejor aún, lo que quiere que los ciudadanos perciban qué es, se convierte en lo más importante, la marca política del candidato; es así, que el reto para el período de campaña electoral es cuidar esa marca y no permitir que la competencia pretenda desdibujarla; claro está que la construcción de una marca, va más allá de la época de campaña, aunque se construye y fortalece diariamente, en cada acción, viene de mucho tiempo atrás e incluso persiste una vez que terminan las elecciones. La marca política, es el valor que hace diferente al candidato de los competidores, es el candidato mismo y lo que proyecta en la mente de los electores, se encuentra en un plano estratégico más que en el publicitario, pues no es un logotipo, no es una imagen, no es un slogan o un jingle; su construcción, representa el resultado de la mezcla de las necesidades y expectativas de la gente con la personalidad misma del candidato, con sus características físicas y verbales, cualidades y carisma, manifestadas con naturalidad y autenticidad.

Teniendo en cuenta que, a una campaña no se llega a construir una marca, en la campaña provincial, valoramos el branding de farmacia Bazán, la identidad y la confiabilidad lograda a través del tiempo - más de 40 años - en miles de clientes, es por ello que la marca de la candidata "Norma de la farmacia Bazán" se posicionó positivamente en la población, generando gran expectativa en la contienda electoral.

5.3. Los ciudadanos desean oír una historia, un relato, el cual se convertirá en el eje de la comunicación. Estas equivalen a narraciones que cuentan historias: la del candidato, la del partido, la del gobierno saliente y de la sociedad. Cada trama es contada desde una óptica y perspectiva propia, involucrando a ciertos actores políticos, sociales, 
económicos, entre otros. La finalidad consiste en que cada relato sea adoptado como suyo por las masas electorales, la mayoría de votantes, y que de esta manera se comprenda la realidad. Detrás de cada marca política, existe un relato coherente, que genera escenarios de competencia entre los candidatos, privilegiando la confrontación y el antagonismo entre ellos. A manera de ejemplo, podemos traer a nuestras memorias al candidato McCain, quien defendía la república y representaba el arquetipo de "guerrero", "héroe de guerra"; por otro lado, el candidato Obama, encarnaba el sueño americano, bajo el arquetipo de "inocente".

La honestidad y la lucha frontal contra la corrupción fue el flanco explotado por la candidata provincial, bajo el arquetipo de "mujer solidaria y luchadora" la prioridad fueron los más necesitados; éste fue el eje del relato. El mensaje central se elaboró y conceptualizó contrastando con la propia biografía de la candidata, de su personalidad y trayectoria de vida, marcada por el esfuerzo, el compromiso, la determinación y la superación, proyectando un relato auténtico de una historia de aprendizaje: "Primero los pobres", que hacía suyo el problema de las grandes mayorías, que buscaba lograr que la gente lo perciba como parte de su propia historia, narrado de manera simple, fácil de comprender y poder transmitir a otros.

5.4. El acto público, se ha convertido en una estrategia eficaz. Su valor comunicacional, representa la interacción simbólica entre el candidato y sus seguidores, es una acción comunicativa que reúne principalmente elementos de persuasión, emotivos, rituales y míticos de la política, dentro de una manifestación pública que supera lo tradicional. Cada vez más, los equipos de campaña hacen un esfuerzo por presentar mítines y concentraciones multitudinarias; caminatas, recorridos y caravanas masivas; campeonatos, inauguraciones y juramentaciones con gran planificación, porque están convencidos que estos actos públicos son irremplazables, son generadores de legitimidad y respaldo popular. Cada acto público, es una muestra de peregrinaje permanente hacia el pueblo, es un encuentro con las necesidades reales de la gente, es una manifestación de predicamento constante, persistente y tenaz para proponer, convencer y ganar voluntades. La campaña de la candidata para la provincia del Santa, en su estrategia de tierra ejecutó más de 60 de mítines en diferentes distritos, barrios y pueblos jóvenes, buscando conectar con el sentir de la gente a través del contacto directo con el pueblo y los electores. 
5.5. La emotividad como impulsora del voto. Las emociones y sentimientos de los ciudadanos hacia los candidatos, muchas veces pueden determinar las preferencias electorales. Los sentimientos constituyen el componente objetivo de las emociones, en otras palabras, son una especie de etiqueta que se ponen de manifiesto ante determinadas situaciones como una reacción y las conocemos como alegría, cariño, gratitud, esperanza o tristeza, ira, hostilidad, miedo, entre otras. Muchas veces, las emociones son mas fuertes que las ideas y cuando existe un choque entre "razón y emoción" ésta última suele prevalecer. Es de vital importancia conocer estos aspectos, pues es bastante conocido que un gran porcentaje de los votos en una elección se encuentran en los niveles inferiores de la pirámide de necesidades de Maslow, donde encontramos principalmente las necesidades básicas de la población, de una mayoría que espera que los problemas reales de la sociedad sean escuchados, puestos en agenda por las autoridades y finalmente atendidos y resueltos. Es en este contexto, que la estrategia planteada por el candidato, articulada por el mensaje central de campaña y el relato narrado en el discurso, generará gran motivación en el electorado, es decir, se convertirá en una fuerza impulsora o motivadora hacia determinado comportamiento, hacia el voto. Sin embargo, existen candidatos que se centran en propuestas específicas del plan de gobierno o en asuntos que consideran relevantes, pensando que los electores deciden el voto desapasionadamente; al final, estos candidatos tienen problemas de no incidir propiamente en la agenda electoral.

Aquí, algunos ejemplos de políticos que hicieron uso de la emotividad en sus campañas electorales:
Rafael Correa
"Con amor infinito"
Cristina Fernández de K. : "La fuerza del amor"
Ollanta Humala
"Amor por el Perú"
Fernando Lugo
"Porque él quiere a los humildes y ama al Paraguay"

En el caso de la campaña de la candidata a la provincia del Santa:

Norma Alencastre : : "Primero los pobres" 
5.6. En una campaña electoral, los pactos y alianzas políticas son necesarias, aunque muchas veces un tanto inestables y trabajosas, ya que requieren de acciones cotidianas para garantizar apoyos que pueden variar inesperadamente, cuando se recurre a ellas principalmente en tiempos de elecciones, la finalidad es alcanzar la meta establecida.

Los líderes de diferentes sectores trabajan diariamente desde su propio sector o comunidad llevando el mensaje del candidato. Sin embargo, hay que ser bastante cuidadosos en política, pues a diferencia de las matemáticas, algunas sumas en lugar de sumar restan. No olvidemos que los sistemas políticos operan a través de un conglomerado de actores diversos, donde cada uno posee voz e intereses propios.

Las políticas de alianzas, deben ser congruente con los objetivos políticos y nuestro mercado electoral. Una elección se gana con la suma de diferentes sectores de la sociedad que se adhieren a una propuesta o a un candidato. Por lo tanto, es importante saber a qué sectores es necesario atraer para lograr el triunfo.

5.7. Las nuevas tecnologías han ingresado y avanzan a pasos agigantados en la política. En la actualidad, debido al impacto de las mismas, principalmente de las redes sociales, la comunicación cambia a gran velocidad; por lo tanto, también la comunicación política está recibiendo una gran influencia de ella, generando un cambio sustantivo en la práctica de la política. No obstante, es necesario indicar que las nuevas tecnologías no deben excluir a los medios tradicionales, muy por el contrario, deben ser convergentes y complementarios.

Teniendo en cuenta lo anterior, para el candidato, es fundamental la construcción de un liderazgo que sea visible, sin él sería muy difícil posicionarse exitosamente en el terreno de la política, tampoco construir un relato auténtico y persuasivo en las diferentes plataformas mediáticas para transmitirlos con eficacia hacia la audiencia electoral; pues a partir de las nuevas tecnologías de la comunicación, específicamente de las redes sociales, se ha generado una opinión pública alterna o paralela a la tradicional, esta vez más orientada a la acción ciudadana. Se busca crear una comunidad interactiva y participativa, haciendo parte de la campaña no solo a militantes y simpatizantes del partido o candidato, sino a grupos más amplios que se suman a brindar apoyo, a quienes se les comparte información a través de las redes sociales antes que a los medios 
tradicionales para que organicen eventos y actividades propias de carácter político. En la campaña provincial, como parte de la estrategia de aire, fueron tomadas en cuenta las diferentes plataformas mediáticas, tanto tradicionales como también redes sociales, ésta última con miles de seguidores, donde se difundieron todas las actividades llevadas a cabo según cronograma.

5.8. La gestión de temas y contenidos durante la campaña electoral. Así como existe una disputa entre candidatos y partidos en este periodo de elecciones, también existe una disputa para ubicar en agenda los temas que traerán mas beneficios a una agrupación política. Independientemente de la coyuntura o sucesos que acontecen diariamente, los candidatos van desarrollando temas o propuestas contemplados en su plan de gobierno que previamente han sido elaborados. Es necesario, tener muy en cuenta el impacto que cada tema generará en la opinión pública y que éste impacto siempre será limitado temporalmente, de allí la importancia de las decisiones del timming o manejo de los tiempos para los temas de campaña. Es de gran ayuda el manejo de un cronograma de actividades, donde se establezca un calendario de apariciones de acuerdo a los ejes temáticos y propuestas de campaña, estableciendo una lista de prioridades.

Siempre existe un tema que marca la agenda en el día y que normalmente suele dominar a la opinión pública, aunque pueden existir algunos otros temas relevantes que se ubican entre los preferidos en el público. Esta agenda es dinámica, rota semana a semana, hay que tener en cuenta las épocas y períodos del año, así como también las famosas "cortinas de humo" y "rumores" que no son otra cosa más que temas distractivos que buscan desviar la atención de la audiencia por razones puntuales de quienes la fabrican. Sin embargo, no se debe permitir que los temas marcados por los otros candidatos, desvíen nuestra concentración y el seguimiento de la estrategia; es decir, es importante no dejarse llevar por críticas de adversarios, ni tampoco ingresar al esquema de acción - reacción. Es necesario sentar posición ante acontecimientos políticos o climas de opinión, siempre y cuando se tenga en claro la razón y el porqué de cada acción. 


\section{REFERENCIAS}

Asociación Civil Transparencia (2006) Comunicación política en campañas electorales. Módulo avanzado de formación política. Lima. Ágora, p. 42.

Calderón, C. (2011) ¿Qué es el gobierno abierto? Madrid. Colección: Cuadernos de comunicación Evoca, p. 46.

Castells, M. (2009) Comunicación y poder. España. Alianza editorial, p. 667.

Crespo, I. y Moreno, C. (2015) Los efectos de la comunicación política en el comportamiento electoral. España. Derecho Electoral, p. 35.

Eskibel, D. (2016). Recuperado de: Guía Rápida para Planificar la Estrategia de tu Campaña Electoral. Maquiavelo \& Freud. Recuperado de: https://maquiaveloyfreud.com/guia-rapida-para-planificar-la-estrategia-de-campana/

JEE (2018) Resolución N073-2018-JEE-SNTA/JNE. Chimbote.

JEE (2018) Resolución Nº1015-2018-JEE-SNTA/JNE. Chimbote.

LEY DE ORGANIZACIONES POLÍTICAS N²8094. Lima. El Peruano.

Núñez, C. (2002) El Marketing político en el nuevo milenio. Argentina. Universidad de Buenos Aires.

ODCA (2006). Manual de campaña electoral. Argentina. CENTRO DEMOCRACIA Y COMUNIDAD, p. 108.

ODCA (2006). Manual de campaña electoral: marketing y comunicación política. Argentina. Konrad-Adenauer-Stiftung, p. 144. 
Olivera, L. (2016) El marketing en la política. Lima. Pontificia Universidad Católica del Perú, p. 50.

Quesada, J. (2005). Marketing político. España. Partido Popular, p. 44.

Schröder, P. (2004). Estrategias políticas. Alemania. Fundación Friedrich Naumann, p. 320. 


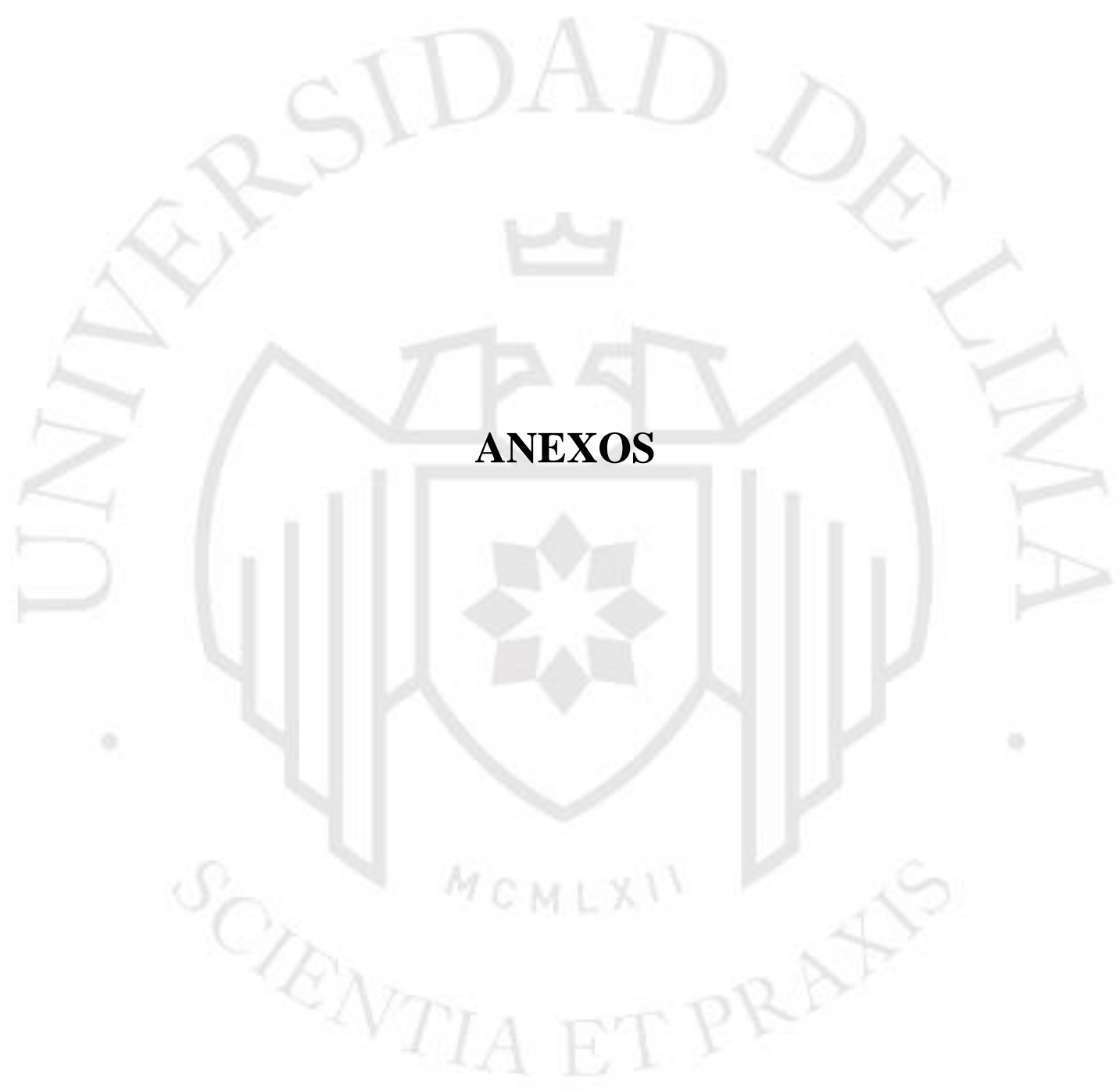




\section{ANEXO 1: Cronograma de actividades navideñas}

\begin{tabular}{|l|l|l|l|l|l|c|}
\hline DOM. 26 NOV. & \multicolumn{1}{|c|}{ LUN. 27 NOV. } & \multicolumn{1}{|c|}{ MAR. 28 NOV. } & \multicolumn{1}{|c|}{ MIE. 29 NOV. } & JUE. 30 NOV. & VIE. 01 DIC. & SAB. 02 DIC. \\
\hline Pedregal - 4pm & La Unión - 5pm & Porvenir - 4pm & La Victoria - 4pm & El Castillo - 2pm & Vinzos - 4pm & San José - 3pm \\
\hline N. Vinzos - 5pm & C. Vallejo - 6pm & Pensacola - 5pm & Dos de Mayo - 5pm & & & \\
\hline & & El Carmen - 6.00pm & San Francisco - 6pm & & & \\
\hline & & & & & & \\
\hline
\end{tabular}

\begin{tabular}{|c|l|l|l|l|l|l|}
\hline DOM. 03 DIC. & \multicolumn{1}{|c|}{ LUN. 04 DIC. } & \multicolumn{1}{|c|}{ MAR. 05 DIC. } & \multicolumn{1}{|c|}{ MIE. 06 DIC. } & \multicolumn{1}{c|}{ JUE. 07 DIC. } & \multicolumn{1}{c|}{ VIE. 08 DIC. } & \multicolumn{1}{c|}{ SAB. 09 DIC. } \\
\hline Cascajal - 5pm & Miraflores - - 4pm & Florida A. - 4pm & P. Libre - 4pm & El Acero - 4pm & S. Pedro - 2pm & Trapecio - 3pm \\
\hline & Miramar A. - 5pm & Florida B. - 5pm & Magdalena - 5pm & $\begin{array}{l}\text { La Balanza - } \\
\text { 5pm }\end{array}$ & V. Mar - 3pm & Libertad - 4pm \\
\hline & Miramar B - 6pm & Reubicación - 6pm & & R. Castilla - 6pm & La Huaca - 4pm & Sr. Milagros 5pm \\
\hline & & & & & Jardines - 5pm & \\
\hline
\end{tabular}

\begin{tabular}{|c|l|l|l|l|}
\hline DOM. 10 DIC. & \multicolumn{1}{|c|}{ LUN. 11 DIC. } & \multicolumn{1}{|c|}{ MAR. 12 DIC. } & \multicolumn{1}{c|}{ MIE. 13 DIC. } & JUE. 14 DIC. \\
\hline Licenciado-3pm & Coishco - 4pm & San Juan - 2pm & V. España - 4pm & Fraternidad-3pm \\
\hline Laderas S. - 4pm & & Las Dunas - 3pm & 3 Estrellas - 5pm & 25 Mayo - 4pm \\
\hline & & El Milagro - 4pm & & 7 Febrero - 5pm \\
\hline & & N. Eden - 5pm & & \\
\hline & & Paisajes - 6pm & & \\
\hline
\end{tabular}


ANEXO 2: Mapeo / zonificación de Chimbote y valle Santa

\begin{tabular}{|c|c|c|c|c|c|c|}
\hline & ZONA I & ZONA II & ZONA III & ZONA IV & ZONA V & ZONA VI \\
\hline & PUEBLOS & PUEBLOS & PUEBLOS & PUEBLOS & PUEBLOS & PUEBLOS \\
\hline 1 & V. LOS JARDINES & LA UNION & ESPERANZA B. & EL PROGRESO & 21 ABRIL - A & DOS DE MAYO \\
\hline 2 & AMP. V. JARDINES & AMP. LA UNION & PENSACOLA & BOLIVAR A. & 21 ABRIL - B & MAGDAL. N. \\
\hline 3 & OCTAVIO ARROYO & PRIMAVERA B. & SANTA CRUZ & BOLIVAR B. & 12 DE OCTUB. & LA VICTORIA \\
\hline 4 & SAN PEDRO & PRIMAVERA A. & 16 DE DICIEMBRE & LA BALANZA & SAN ISIDRO & A. ORREGO \\
\hline 5 & NUEVA GENERAC. & CESAR VALLEJO & VILLA MADRID & M. AREVALO & S. FRANCISCO & \\
\hline 6 & AMP. N. GENERAC. & & EL CARMEN & VICTOR RAUL & & \\
\hline 7 & SANCHEZ MILLA & & EL PORVENIR & B. FISCAL № 05 & & \\
\hline 8 & MANUEL G. PRADA & & B. HORIZONTE & R. CASTILLA & & \\
\hline 9 & DOS DE JUNIO & & RICARDO PALMA & A. DE MAYOLO & & \\
\hline 10 & ESPERANZA ALTA & & AMP. V. MADRID & EL ACERO & & \\
\hline 11 & L. DEL NORTE & & 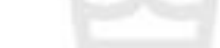 & NUEVA CALETA & & \\
\hline 12 & EL PARAISO & & & & & \\
\hline 13 & EL BALCON & & & & & \\
\hline
\end{tabular}

\begin{tabular}{|c|c|c|c|c|c|c|}
\hline & ZONA VII & ZONA VIII & ZONA IX & ZONA X & ZONA XI & ZONA XII \\
\hline & PUEBLOS & PUEBLOS & PUEBLOS & PUEBLOS & PUEBLOS & VALLE SANTA \\
\hline 1 & PUEBLO LIBRE & SAN MIGUEL & EL MILAGRO & MIRAFLORES A. & LA LIBERTAD & CASCAJAL \\
\hline 2 & MIRAMAR ALTO & FRATERNIDAD & NUEVO EDEN & FLORIDA BAJA & S. MILAGROS & VINZOS \\
\hline 3 & MIRAMAR BAJO & $\begin{array}{l}\text { CORAZ. DE } \\
\text { JESUS }\end{array}$ & TRES ESTRELLAS & FLORIDA ALTA & TRAPECIO I & N. VINZOS \\
\hline 4 & CIUDAD DE DIOS & SANTA IRENE & VILLA EL SOL & A. MIRAFLORES & TRAPECIO II & EL PEDREGAL \\
\hline 5 & MIRAFLORES BAJO & V. LAS FLORES & VILLA ESPAÑA & REUBICACION & TRAPECIO III & EL 24 \\
\hline 6 & ALTO PERU & RAMAL PLAYA & SAN JUAN & MIRAF. ALTO III & RAUL CLARK & RINCONADA \\
\hline 7 & $\theta$ & A. RAM. PLAYA & LAS DUNAS & & 15 DE ABRIL & EL CASTILLO \\
\hline 8 & & CIUDAD DE PAZ & LOS PAISAJES & & 6 DE ABRIL & COISHCO \\
\hline 9 & & 7 DE FEBRERO & & & 27 DE OCTUB. & \\
\hline 10 & & 25 DE MAYO & & & & \\
\hline 11 & & М. СНIMBOTE & & & & \\
\hline 12 & & 10 DE SEPT. & & & & \\
\hline
\end{tabular}


ANEXO 3: Mapeo / zonificación de Nuevo Chimbote

\begin{tabular}{|c|c|c|c|c|c|c|}
\hline & ZONA I & ZONA II & ZONA III & ZONA IV & ZONA V & ZONA VI \\
\hline & PUEBLOS & PUEBLOS & PUEBLOS & PUEBLOS & PUEBLOS & PUEBLOS \\
\hline 1 & $1^{\circ}$ DE MAYO & AAHH LOMAS & $\begin{array}{l}\text { S.U BUENOS } \\
\text { AIRES }\end{array}$ & URB. UNICRETO & BELLAMAR I & TAWANTIN. \\
\hline 2 & VILLA MARIA & HUP SATELITE & BUENOS AIRES I & BANCHERO & BELLAMAR II & HOUSTON \\
\hline 3 & SIETE DE JULIO & AMPL. SATELITE & BUENOS AIRES II & SAN RAFAEL & GARATEA I & BELLA VISTA \\
\hline 4 & VILLA HERMOSA & PROG. PILOTO I & MIGUEL GRAU & S.CRSITINA & GARATEA II & V. VICTORIA \\
\hline 5 & HUP V. MARIA 1 & DAVID DASSO A & LOS JARDINES & EL DORADO & F.CASAS & PACHACUTEC \\
\hline 6 & HUP V. MARIA A & DAVID DASSO B & LOS CIPRESES & CANALONES & CALIFORNIA & S. ROSA SUR \\
\hline 7 & URB. LAS BRISAS & AAHH 15 JUNIO & EL BOSQUE & CASUARINAS & SAN DIEGO & LOMAS SUR \\
\hline 8 & TRES DE OCTUBRE & AAHH 14 FEB. & SANTA ROSA & BRUCES & LAS FLORES & \\
\hline 9 & HUP G. PERSICO & VILLA MARCELA & LOS PORTALES & & & \\
\hline 10 & & A.V. MARCELA & EL PACIFICO & & & \\
\hline
\end{tabular}

\begin{tabular}{|c|c|c|c|c|c|}
\hline & ZONA VII & ZONA VIII & ZONA IX & ZONA X & ZONA XI \\
\hline & PUEBLOS & PUEBLOS & PUEBLOS & PUEBLOS & PUEBLOS \\
\hline 1 & DON VICTOR & JASMINEZ & LOS CEDROS & U.P.I.S. BELEN & T.PROMETIDA \\
\hline 2 & PRADERAS SUR & QUINTANAS & SAN FELIPE & BELEN & V. AL MAR \\
\hline 3 & CONQUISTADORES & AMERICAS & V.MAGISTERIAL & VILLA MARIA & JERUSALEN \\
\hline 4 & VICTORIA DEL SUR & INDEPENDENCIA & TERESA CALCUTA & $1^{\circ} \mathrm{DE}$ AGOSTO & VILLA SOL \\
\hline 5 & NUEVO HORIZONTE & 19 DE MARZO & VISTA ALEGRE & V.SAN LUIS I & LA LIBERTAD \\
\hline 6 & NUEVA ESPERANZA & LICENCIADOS & LA MOLINA & V.SAN LUIS II & STA ROSA II \\
\hline 7 & BEGONIAS & DELICIAS I & LOS ANGELES & VILLA DEL MAR & GARDENIAS \\
\hline 8 & A. BEGONIAS & DELICIAS II & V. LAS PALMAS & TOLEDO & \\
\hline 9 & CONSTRUCTORES & & VILLA DEL SUR & LOS JARDINES & \\
\hline 10 & & & LOS DELFINES & N.CANAN-308H & \\
\hline 11 & & & & L. DEL MAR & \\
\hline
\end{tabular}


ANEXO 4: Modelo de cronograma operativo semanal

\begin{tabular}{|c|c|c|c|c|c|c|c|}
\hline & LUN $13 / 8$ & MAR $14 / 8$ & MIER $15 / 8$ & JUE $16 / 8$ & VIER $17 / 8$ & SAB $18 / 8$ & DOM $19 / 8$ \\
\hline ACTIVIDAD & REU. COORD. & & $\begin{array}{l}\text { BASES } \\
\text { VIVAS }\end{array}$ & BASES VIVAS & BASES VIVAS & BASES VIVAS & MERCADO \\
\hline HORA & $10 \mathrm{PM}$ & & 9AM-1PM & 9AM-1PM & 9AM-4PM & 9AM-1PM & 9AM \\
\hline LUGAR & OFICINA & & $\mathrm{Z1}$ & $\mathrm{Z2}$ & $\mathrm{Z1} \mathrm{NVO} \mathrm{CH}$ & Z6 & MIRAMAR \\
\hline ACTIVIDAD & & & $\begin{array}{l}\text { BASES } \\
\text { VIVAS }\end{array}$ & BASES VIVAS & MERCADO & CAMINATA+INAU & CAMINATA+MITI \\
\hline HORA & & & 2PM-4PM & 2PM-4PM & $11 \mathrm{AM}$ & $4 \mathrm{PM}$ & $4 \mathrm{PM}$ \\
\hline LUGAR & & & $\mathrm{Z1}$ & $\mathrm{Z3}$ & VILLA MARIA & SAN JACINTO & COISHCO \\
\hline ACTIVIDAD & & CAMINATA & CAMINATA & CAMINATA & CAMINATA & & \\
\hline HORA & & 4PM & 4PM & 4PM & 4PM & & \\
\hline LUGAR & & $\begin{array}{c}\text { CERRO } \\
\text { PARTIDO } \\
\end{array}$ & SAN PEDRO & VIA MADRID & CERRO PARTIDO & & \\
\hline ACTIVIDAD & CAP.PERSON. & $\begin{array}{c}\text { REU } \\
\text { SIMPAT. }\end{array}$ & $\begin{array}{l}\text { BASES } \\
\text { VIVAS }\end{array}$ & BASES VIVAS & BASES VIVAS & & \\
\hline HORA & 7PM & $8 \mathrm{PM}$ & 9PM & 9PM & 9PM & & \\
\hline LUGAR & OFICINA & L.CENTRAL & 2DE MAYO & SAN MIGUEL & LA VICTORIA & & \\
\hline
\end{tabular}

\begin{tabular}{|c|c|c|c|c|c|c|c|}
\hline & LUN 20/8 & MAR 21/8 & MIER 22/8 & JUE $23 / 8$ & VIER $24 / 8$ & SAB $25 / 8$ & DOM 26/8 \\
\hline ACTIVIDAD & BASES VIVAS & MERCADO & $\begin{array}{l}\text { BASES } \\
\text { VIVAS }\end{array}$ & BASES VIVAS & MERCADO & BASES VIVAS & $\begin{array}{l}\text { CAMPAÑA } \\
\text { MEDICA }\end{array}$ \\
\hline HORA & 9AM-1PM & 10:30AM & 9AM-1PM & 9AM-1PM & 9AM & 9AM-1PM & 9AM \\
\hline LUGAR & $\mathrm{Z9} \mathrm{CH}$ & $\begin{array}{c}\text { VILLA } \\
\text { MARIA }\end{array}$ & $\mathrm{Z3CH}$ & $\mathrm{Z4}$ & $21 \mathrm{DE}$ ABRIL & Z6 & $217 \mathrm{HC}$ \\
\hline ACTIVIDAD & BASES VIVAS & $\begin{array}{l}\text { BASES } \\
\text { VIVAS }\end{array}$ & $\begin{array}{l}\text { BASES } \\
\text { VIVAS }\end{array}$ & BASES VIVAS & BASES VIVAS & & INAUGURACIÓN \\
\hline HORA & 2PM-5PM & 12PM- $2 \mathrm{PM}$ & 2PM-4PM & 2PM-5PM & 9AM- 4PM & & 03:00 p.m. \\
\hline LUGAR & $\mathrm{Z9} \mathrm{CH}$ & $\mathrm{Z} 2 \mathrm{CH}$ & $\mathrm{Z} 3 \mathrm{CH}$ & $\mathrm{Z4}$ & $\mathrm{Z5}$ & & B. ATAHUALPA \\
\hline ACTIVIDAD & & & CAMINATA & & INAUGURACIÓN & INAUGURACIÓN & \\
\hline HORA & & & $5 \mathrm{PM}$ & & 4-5PM & 4-5PM & \\
\hline LUGAR & & & $\begin{array}{c}\text { VILLA } \\
\text { MADRID } \\
\end{array}$ & & B.BELLAMAR & B. RINCONADA & \\
\hline ACTIVIDAD & BASES VIVAS & $\begin{array}{c}\text { REU } \\
\text { SIMPAT. }\end{array}$ & $\begin{array}{l}\text { BASES } \\
\text { VIVAS }\end{array}$ & BASES VIVAS & BASES VIVAS & BASES VIVAS & BASES VIVAS \\
\hline HORA & 9PM & $8 \mathrm{PM}$ & 9PM & 9PM & 9PM & 9PM & 9PM \\
\hline LUGAR & $\begin{array}{c}\text { MAGDALENA } \\
\mathrm{N}\end{array}$ & L.CENTRAL & $\begin{array}{l}21 \mathrm{DE} \\
\mathrm{ABRIL}\end{array}$ & $\begin{array}{c}\text { SAN } \\
\text { FRANCISCO }\end{array}$ & EL CARMEN & 10DESETIEMB. & RAMAL PLAYA \\
\hline
\end{tabular}

